\author{
Universidade de São Paulo \\ Instituto de Astronomia, Geofísica e Ciências Atmosféricas \\ Departamento de Ciências Atmosféricas
}

EduARdo Wilde BÁrbaro

\begin{abstract}
Investigação da camada limite planetária noturna na região metropolitana de São Paulo utilizando o modelo LES
\end{abstract}

São Paulo

2010 
EduARdo Wilde BÁrbaro

\section{Investigação da camada limite planetária noturna na região metropolitana de São Paulo utilizando o modelo LES}

Dissertação de mestrado apresentada ao departamento de ciências atmosféricas para obtenção do título de Mestre em ciências.

Área de concentração: Meteorologia.

Orientador: Professor Doutor Amauri Pereira de Oliveira.

São Paulo

2010 
À MINHA TIA YVONNE. 


\section{Agradecimentos}

Primeiramente ao meu orientador Amauri Pereira de Oliveira pela excelente orientação e por ter acreditado, muitas vezes mais do que eu, na realização deste trabalho. Agradeço também à professora Jacyra Soares pela amizade, ideias e discussões que foram fundamentais na construção deste trabalho.

À Fundação de Amparo à Pesquisa do Estado de São Paulo (FAPESP - processo 2008/07532 - 0) e ao Conselho Nacional de Desenvolvimento Científico e Tecnológico (CNPq - processo $476807 / 2007-7$ ).

Aos professores Edson Pereira Marques-Filho (UFRJ), Umberto Rizza (CNR-ISAC) e ao MSc Franciano Puhales (UFSM) pela valiosa ajuda durante a execução do trabalho e ao professor Eduardo Landulfo pelos dados de LIDAR.

Aos colegas do DCA. Agradeço ao Fábio pela grande amizade desde o tempo da graduação.

A todo pessoal do Lab Micro. Em especial à Georgia e ao Maurício.

Ao pessoal da seção de informática, principalmente ao analista de sistemas Sebastião Antônio pela ajuda com a instalação do LES e do MPI.

Às secretárias do DCA Ana, Bete e Sônia pela ajuda e à equipe da gráfica pelo excelente trabalho de impressão.

Finalmente gostaria de agradecer toda a minha família pelo apoio e por compreender meus momentos de afastamento. À Bia pelo amor incondicional e por estar sempre ao meu lado. Agradeço também à familia dela pelo ótimo convívio. 
"Vasculhe cada exemplar da pseudociência e você encontrará um cobertorzinho de estimação, um dedo para chupar, uma saia para segurar."

IsAaC AsImov 


\section{Resumo}

O presente trabalho tem como objetivo investigar a evolução temporal e espacial da camada limite planetária (CLP) na cidade de São Paulo durante o período noturno, utilizando o modelo LES. Foram simulados os campos tridimensionais das três componentes da velocidade do vento, temperatura potencial e concentração de monóxido de carbono (CO). Três propriedades da CLP noturna em São Paulo foram analisadas: a) Altura da CLP estável (CLE); b) Jatos de baixos níveis (JBN); c) Dispersão turbulenta de CO. Foi analisado também o ciclo diurno dos fluxos turbulentos de calor sensível e de CO na superfície. Inicialmente foi desenvolvido um procedimento de validação para avaliar o desempenho do modelo LES na simulação das propriedades da CLP convectiva, neutra e estável, utilizando como referência os resultados de simulações consagrados na literatura. A validação foi realizada comparando os perfis verticais médios de velocidade horizontal, temperatura potencial, variância das componentes da velocidade e as componentes da equação do balanço de energia cinética turbulenta (ECT). Os resultados dessa comparação indicam que o modelo LES atual é capaz de reproduzir todas as características dos processos turbulentos destes escoamentos. Foram realizados quatro experimentos numéricos com o intuito de investigar a evolução diurna da CLP para a situação de inverno em São Paulo, usando como condições de contorno, valores horários médios mensais de temperatura potencial e concentração de monóxido de carbono observados em superfície durante o mês de junho em São Paulo. Esses experimentos utilizaram também como condição de contorno a situação média nos dias de céu claro (sem nuvem) no mês de junho em São Paulo. O impacto da intensidade do vento também foi analisado especificando-se como forçante externa o vento geostrófico igual a $5 \mathrm{~ms}^{-1}$ e $10 \mathrm{~ms}^{-1}$ de oeste. Os dados utilizados neste trabalho foram medidos na plataforma micrometeorológica do IAG-USP (temperatura do ar e fluxo turbulento de calor sensível) e na estação Lapa da CETESB (concentração de monóxido de carbono e velocidade do vento). Os resultados destas 4 simulações indicam que a altura da CLE foi simulada pelo modelo LES de forma consistente com as forçantes e condições de contorno usadas, indicando que durante o mês de junho em São Paulo a altura da CLE varia entre $100 m$ e $275 m$ (médias) e $62 m$ e $203 m$ (dias de céu claro). Verificou-se também que a turbulência da CLE é mantida pela produção mecânica de ECT e dissipada majoritariamente pela destruição térmica. A dissipação molecular tem um papel secundário e o transporte turbulento não afeta as propriedades 
da CLE. Os resultados indicam que as formulações empíricas utilizadas neste trabalho são capazes de reproduzir de forma equivalente a ordem de magnitude da altura da CLE simulada para São Paulo. O melhor resultado foi obtido com $h=700 u_{*}$ e $h=0,5 \sqrt{\frac{u_{*} L}{|f|}}$. As simulações do JBN indicaram que para São Paulo o mecanismo de ajuste inercial gera máximos da ordem de $7,1 \mathrm{~ms}^{-1}$ em torno de $210 \mathrm{~m}$ as 05:30HL (forçante de $5 \mathrm{~ms}^{-1}$ ) e de $14,5 \mathrm{~ms}^{-1}$ em torno de $420 \mathrm{~m}$ e as 05:30HL (forçante de $10 \mathrm{~ms}^{-1}$ ). Foi observada uma intensificação da turbulência acima do topo da camada estável. A evolução espacial e temporal da concentração de CO simulado pelo modelo LES apresenta um padrão de dispersão turbulento compatível com o esperado para o inverno em São Paulo. Finalmente, o modelo LES é capaz de reproduzir as principais características da evolução diurna do fluxo de calor sensível e de monóxido de carbono da superfície observados no mês de junho na cidade de São Paulo. 


\begin{abstract}
The main objective of this work is to investigate the temporal and spatial evolutions of the planetary boundary layer (PBL) in the city of São Paulo during the nighttime period, using a large-eddy simulation (LES) model. It was simulated the 3-dimensional fields of the three components of the wind speed, potential temperature and carbon monoxide concentration. Three properties of nocturnal PBL were investigated: a) PBL depth; b) Low level jet (LLJ) and c) Turbulent dispersion of CO. The diurnal evolution of the turbulent fluxes of sensible heat and CO was also analyzed. Initially, a validation procedure was carried considering the performance of LES model in to simulate the behavior of the PBL for convective, neutral and stable conditions using as reference simulation results available in the literature. The validation was performed by comparing the mean vertical profiles of horizontal wind, potential temperature, variance of wind speed components and the turbulent kinetic energy (TKE) equation components. They indicated that the actual version of LES model is capable to simulate the entire cycle of the PBL diurnal evolution over a homogeneous and flat surface. Once validated, the LES model was applied to simulate the PBL for a complete diurnal cycle over a flat and homogeneous surface with aerodynamic roughness length representative of a typical urban area of São Paulo. Four simulations were designed to investigate the nighttime PBL evolution for winter conditions in São Paulo, using as input, monthly average hourly values of potential temperature and monoxide carbon observed at the surface during June in São Paulo. The mean condition for clear sky days observed in June in São Paulo was also considered as input in these simulations. The impact of wind intensity was also analyzed by considering as the external forcing in these simulations a constant background geostrophic wind of 5 and $10 \mathrm{~ms}^{-1}$ from West. The dataset used in this work was observed in the micrometeorological platform of IAG (air temperature and sensible heat flux) and at the surface station of environmental agency of the state of São Paulo (CETESB) locate at Lapa (CO and wind speed). The results indicate that the height of stable PBL was simulated consistently with the boundary conditions and external forcing, indicating that during June the in São Paulo the PBL height may vary from 100m (mean condition) and 62m (clear days condition) at the beginning of the night to $275 \mathrm{~m}$ (mean condition) and $203 \mathrm{~m}$ (clear sky conditions) at the end of nighttime. It was verified that the turbulence in the Stable PBL is maintained by the mechanical production of TKE and dissipated, mainly, by the
\end{abstract}


negative thermal production. Molecular dissipation has a secondary role and turbulent transport of TKE does not affect the stable PBL. All the empirical formulations used here reproduced the order of magnitude of the stable PBL height. The best performance was obtained by $h=700 u_{*}$ and $h=0.5 \sqrt{\frac{u_{*} L}{|f|}}$. The simulated nocturnal LLJ indicated that for São Paulo the inertial oscillation yields a maximum intensity is $7.1 \mathrm{~ms}^{-1}$ at $210 \mathrm{~m}$ and 05:30LT (forcing of $5 \mathrm{~ms}^{-1}$ ) and $14.5 \mathrm{~ms}^{-1}$ at $420 \mathrm{~m}$ at 05:30LT (forcing of $10 \mathrm{~ms}^{-1}$ ). In both cases the LLJ intensified the turbulence at the top of the stable PBL. The simulated spatial and temporal evolution of the carbon monoxide concentration shows a pattern of turbulent dispersion consistent with the expected one for winter time in the city of São Paulo. Finally, LES model is able to reproduce the main features of the diurnal evolution of turbulent sensible heat and carbon monoxide fluxes at the surface for São Paulo during the winter. 


\section{Índice}

Lista de Figuras $\quad$ xi

Lista de Tabelas $\quad$ xiv

1 Introdução 1

1.1 A camada limite planetária . . . . . . . . . . . . . . . . 1

1.2 Geração e manutenção da turbulência . . . . . . . . . . . . . . . . . . . 2

1.3 A camada limite estável . . . . . . . . . . . . . . . . . 5 5

1.4 Modelagem numérica da CLP e o modelo LES . . . . . . . . . . . . . 8

1.5 Motivação: São Paulo e problemas ambientais . . . . . . . . . . . . . . . . 12

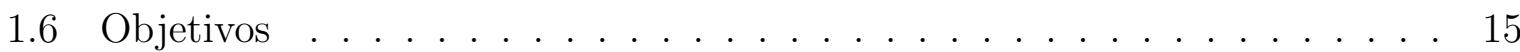

2 Descrição e validação do modelo LES $\quad 17$

2.1 Descrição do modelo LES . . . . . . . . . . . . . . . . . . . . . 17

2.1.1 Descrição da escala resolvida . . . . . . . . . . . . . . . . . . . 19

2.1.2 Descrição da escala de subgrade . . . . . . . . . . . . . . . . 20

2.2 Validação do modelo LES atual . . . . . . . . . . . . . . . . . . . . 22

2.2.1 Caso I: convectivo . . . . . . . . . . . . . . . . . . . . . . . 24

2.2.2 Caso II: CLP na transição convectivo-estável . . . . . . . . . . . . . 27

2.2.3 Caso III: CLP estável . . . . . . . . . . . . . . . . . . . . . . . 30

$\begin{array}{lll}3 & \text { Resultados } & 34\end{array}$

3.1 Descrição dos experimentos numéricos . . . . . . . . . . . . . . . . . 34

3.1.1 Conjunto de dados utilizado . . . . . . . . . . . . . . . . . . 34

3.1 .2 Caracterização dos experimentos numéricos . . . . . . . . . . . 38

3.2 Fluxos turbulentos em superfície . . . . . . . . . . . . . . . . . . 44 
3.3 Evolução diurna da CLP . . . . . . . . . . . . . . . . . . . . . . . 47

3.4 Balanço de ECT na CLP . . . . . . . . . . . . . . . . . . . . . 50

3.5 Evolução temporal dos perfis verticais na CLE . . . . . . . . . . . . 55

3.5.1 Importância do JBN na evolução da CLE . . . . . . . . . . . . . . . 55

3.5.2 Perfis de temperatura potencial e concentração de CO . . . . . . . . 59

3.5.3 Estimativa de altura da CLE . . . . . . . . . . . . . . . . . 60

4 Conclusão $\quad 63$

$\begin{array}{lc}\text { Conclusão } & 63\end{array}$

$\begin{array}{ll}\text { Referências Bibliográficas } & 67\end{array}$ 


\section{Lista de Figuras}

1.1 Esquema do espectro de energia $S(k)$ na $C L P$; as três regiões representam (A) produção, (B) subintervalo inercial e $(C)$ dissipação. $k$ representa o número de onda, $\lambda_{m}$ o comprimento de onda associado ao turbilhão mais energético e $\eta$ a microescala de Kolmogorov. Adaptado de Marques-Filho

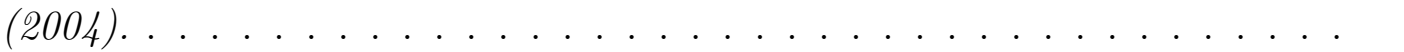

1.2 Posição geográfica do (a) estado de São Paulo, (b) cidade de São Paulo e (c) RMSP e localização do IAG-USP . . . . . . . . . . . . . . . . 13

2.1 Perfis verticais das componentes zonal e meridional do vento médio. . . . . 25

2.2 Perfis verticais das variâncias de velocidade normalizadas pela escala característica de velocidade, $w_{*}$. . . . . . . . . . . . . . . . . . 26

2.3 Perfil vertical do balanço de energia cinética turbulenta. . . . . . . . . . . . 26

2.4 Perfil vertical da velocidade. . . . . . . . . . . . . . . . . . . . 28

2.5 Variação temporal da intensidade máxima do JBN durante o período estável da simulação. A linha pontilhada representa a curva teórica proposta por Blackadar (1957). . . . . . . . . . . . . . . . . . . 29

2.6 Variação temporal da altura máxima do JBN durante o período estável da simulação. . . . . . . . . . . . . . . . . . . . . . . . . . . . 29

2.7 Balanço de energia cinética turbulenta para o final da simulação. . . . . . . 30

2.8 Perfil vertical de temperatura potencial. . . . . . . . . . . . . . . . . . . 31

2.9 Perfil vertical de velocidade do vento. . . . . . . . . . . . . . . . . . 32

2.10 Variação temporal da altura da CLP . . . . . . . . . . . . . . . . . 32

2.11 Evolução temporal do fluxo devido à produção térmica em superfície. . . . . 32

2.12 Evolução temporal do fluxo de momento em superfície. . . . . . . . . . . 33

3.1 Médias mensais para temperatura do ar e umidade relativa observadas na plataforma micrometeorológica do IAG-USP. . . . . . . . . . . . . . . . . .

3.2 Médias mensais para CO e vento observados na estação Lapa da CETESB entre 1996 e 2005. . . . . . . . . . . . . . . . . . 36 
3.3 Evoluções horárias para o mês de junho da temperatura do ar e CO para o caso médio e somente dias de céu claro. . . . . . . . . . . . . . . . . . . 37

3.4 Perfis iniciais dos campos de temperatura, CO e vento para os experimentos

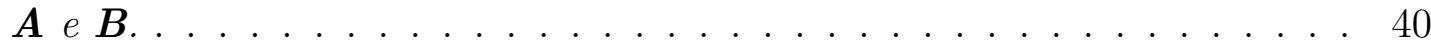

3.5 Variação do passo de tempo observado para os experimentos $\boldsymbol{A}$ e $\boldsymbol{B}$. . . . 40

3.6 Evoluções temporais da temperatura e da concentração de CO usadas como condições de fronteira no modelo LES. As linhas indicam os valores interpolados utilizados a cada passo de tempo. Os pontos são os valores medidos. 41

3.7 Perfis iniciais dos campos de temperatura, $C O$ e vento para experimentos

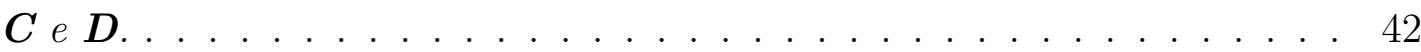

3.8 Variação do passo de tempo observado para os experimentos $C$ e D. . . . . 42

3.9 Evoluções temporais da temperatura e da concentração de CO usadas como condições de fronteira no modelo LES. As linhas indicam os valores interpolados utilizados a cada passo de tempo. Os pontos são os valores medidos para os dias claros. . . . . . . . . . . . . . . . . . . . . . . . 43

3.10 Evolução temporal da velocidade do vento para todos os experimentos. . . . 43

3.11 Evoluções temporais da velocidade do vento para o caso médio (a) e somente céu claro (b). . . . . . . . . . . . . . . . . . . . . . 44

3.12 Evolução temporal do fluxo de calor sensível em superfície. . . . . . . . . . 45

3.13 Evolução temporal do fluxo de monóxido de carbono em superfície. . . . . . 46

3.14 Evolução diurna da altura da CLP. . . . . . . . . . . . . . . . . . . . . 47

3.15 Evolução temporal da CLP estimada pelo LIDAR. Imagem cedida pelo Dr. Eduardo Landulfo, (comunicação pessoal). . . . . . . . . . . . . . . . . . . 48

3.16 Evolução diurna da temperatura potencial para o experimento B. . . . . . . 49

3.17 Evolução temporal do comprimento de Obukhov. . . . . . . . . . . . . . . 49

3.18 Evolução temporal da ECT média na CLP. . . . . . . . . . . . . . . . . . . 51

3.19 Produção térmica - Escalas resolvida e subgrade. Simulação convectiva de Moeng e Sullivan (1994) . . . . . . . . . . . . . . . . . 51

3.20 Distribuição vertical das componentes do balanço de ECT para CLP convectiva (13:30HL)- céu claro . . . . . . . . . . . . . . 52

3.21 Distribuição vertical das componentes do balanço de ECT para CLP neutra - céu claro . . . . . . . . . . . . . . . . . . . . . 53

3.22 Distribuição vertical das componentes do balanço de ECT para CLP moderadamente estável - caso médio. . . . . . . . . . . . . . . . . . . 53 
3.23 Distribuição vertical das componentes do balanço de ECT para CLP forte-

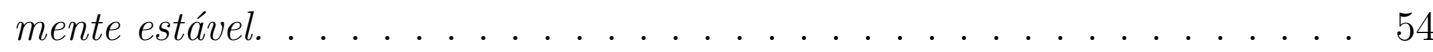

3.24 Variação temporal do perfil vertical de velocidade para os experimentos com forçante geostrófica fraca. . . . . . . . . . . . . . . . . . . 56

3.25 Variação temporal do perfil vertical de velocidade para os experimentos com forçante geostrófica forte. . . . . . . . . . . . . . . . . . . 56

3.26 Altura e velocidade do máximo do JBN. . . . . . . . . . . . . . . . . . 57

3.27 Perfis verticais da velocidade do vento zonal. . . . . . . . . . . . . . . . . 57

3.28 Perfil vertical dos momentos estatísticos de segunda ordem para velocidade. 58

3.29 Perfil vertical do número de Richardson. . . . . . . . . . . . . . . . . . . . 58

3.30 Variação temporal do perfil vertical de temperatura potencial para os experimentos do caso médio. . . . . . . . . . . . . . . . . . . . . . . . . . 59

3.31 Variação temporal do perfil vertical de concentração de CO para os experimentos do caso médio. . . . . . . . . . . . . . . . . . . . . . . . . 60

3.32 Performance das formulações empíricas comparadas ao resultado do modelo LES. . . . . . . . . . . . . . . . . . . 62 


\section{Lista de Tabelas}

2.1 Estatísticas implementadas no modelo LES. . . . . . . . . . . . . . . . . . 23

2.2 Comparação das propriedades do escoamento para o caso convectivo . . . . 24

3.1 Caracterização dos quatro experimentos numéricos . . . . . . . . . . . 38

3.2 Condições iniciais utilizadas para os experimentos numéricos . . . . . . . . 39 
CAPÍtulo 1

\section{Introdução}

\subsection{A camada limite planetária}

A evolução temporal e espacial da camada limite planetária (CLP) sobre regiões urbanas é uma componente fundamental para modelos numéricos de escala regional, continental ou global. Mais ainda, o conhecimento das propriedades da CLP está ligado a uma melhor compreensão de fenômenos como dispersão de poluentes ou formação de orvalho e neblina. Previsão de tempo, interação superfície-atmosfera e relação das nuvens com aerossóis têm na compreensão da fenomenologia da CLP um fator importante,(Schumman e Moeng, 1991; Raga et al., 1999; Jiménez e Cuxart, 2005; Patton et al., 2005; So et al., 2005; Marques-Filho et al., 2006; Masson et al., 2008; Guo et al., 2010). Além disso, informações da escala micrometeorológica, e.g. altura da CLP ou intensidade dos fluxos turbulentos em superfície, são condições de contorno importantes em modelagem numérica, (Garrat, 1993).

Existem diversas definições para CLP. A mais conhecida, dada por Stull (1988), define CLP como a porção da atmosfera diretamente influenciada pela presença da superfície, i.e. afetada pelos fluxos turbulentos de momento (quantidade de movimento), calor e massa, respondendo às forçantes superficiais numa escala temporal da ordem de horas. Em geral a CLP estende-se entre 100-3000m (Garrat, 1994; Arya, 2001). Acima da CLP, o gradiente de pressão e a força de Coriolis estão aproximadamente em balanço. Esta região é conhecida como atmosfera livre.

Os escoamentos turbulentos são tridimensionais, caracterizados por flutuações de vorticidade e descritos por equações não-lineares (Frisch, 1995). Além disso, sem o fornecimento contínuo de energia, escoamentos turbulentos tendem a voltar ao estado laminar. A não-linearidade associada à falta de informação sobre as condições iniciais e de fron- 
teira bem como o fato de haver interconexão entre estas características tornam a solução analítica da turbulência impossível (Garrat, 1994).

Assim, a grande dificuldade em quantificar os processos turbulentos que ocorrem na CLP consiste no fato de que as propriedades do fluido, e.g. densidade, velocidade e pressão, não podem ser preditas diretamente, visto que os valores instantâneos destas quantidades são altamente variáveis. Entretanto, as observações indicam que as propriedades estatísticas como médias espaciais e temporais, funções correlação e funções densidade probabilidade apresentam um comportamento regular. Esse fato permite descrever os escoamentos turbulentos estatisticamente, considerando as variáveis dinâmicas e termodinâmicas como aleatórias (Garrat, 1994; Frisch, 1995).

\subsection{Geração e manutenção da turbulência}

Como em escoamentos turbulentos velocidade e temperatura variam irregularmente no tempo e espaço, é comum em micrometeorologia decompor tais variáveis como a soma entre sua média de Reynolds e respectiva flutuação:

- $\tilde{u}=\bar{u}+u^{\prime \prime}$ (componente zonal do vento)

- $\tilde{v}=\bar{v}+v^{\prime \prime}$ (componente meridional do vento)

- $\tilde{w}=\bar{w}+w^{\prime \prime}$ (componente vertical do vento)

- $\tilde{\theta}=\bar{\theta}+\theta^{\prime \prime}$ (temperatura potencial)

Onde $\left(^{\sim}\right)$ representa valores instantâneos, $\left(^{-}\right)$valores médios e $(")$ flutuações.

Segundo Frisch (1995) o primeiro esforço teórico importante com o intuito de compreender as características universais da turbulência foi de Kolmogorov, em 1941, com a teoria do equilíbrio universal. A teoria diz que para números de Reynolds grandes, o espectro de energia cinética turbulenta (ECT) apresenta três regiões bem definidas; (A) produção, (B) subintervalo inercial e (C) dissipação. No subintervalo inercial, supondo que haja equilíbrio, não deve haver produção nem destruição de ECT, mas sim transferência das escalas maiores para as menores, (Moreira et al., 2005). Este processo de 
transferência espectral de energia cinética turbulenta (ECT) é denominado cascata de energia, como observa-se no esquema do espectro de energia da figura 1.1.

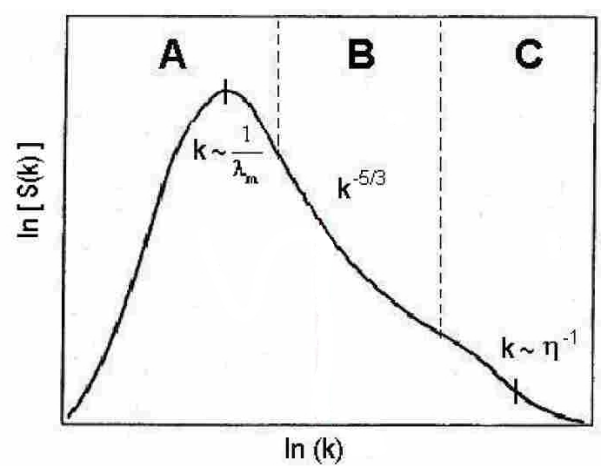

Figura 1.1: Esquema do espectro de energia $S(k)$ na $C L P$; as três regiões representam (A) produção, (B) subintervalo inercial e $(C)$ dissipação. $k$ representa o número de onda, $\lambda_{m}$ o comprimento de onda associado ao turbilhão mais energético e $\eta$ a microescala de Kolmogorov. Adaptado de Marques-Filho (2004).

Não é fácil identificar, muito menos definir turbulência ou tampouco seus efeitos. Os dois mecanismos mais evidentes de geração de turbulência são a produção térmica (PT) e a produção mecânica (PM). A equação de ECT, 1.1, mostra estes dois mecanismos, além da dissipação (D) e o transporte de energia (T) de(para) outros locais do fluido. A dissipação, que ocorre somente na região $(\mathrm{C})$ do espectro, é a responsável pela destruição dos turbilhões de pequena escala. Os pequenos turbilhões são dissipados pela viscosidade molecular tal que a menor escala de comprimento possível em um escoamento turbulento é dada pela microescala de Kolmogorov, $\eta=\sqrt[4]{\frac{\nu^{3}}{\epsilon}}$, onde $\nu=15 \times 10^{-6} m^{2} s^{-1}$ é a viscosidade cinemática do ar.

$$
\frac{\partial \bar{e}}{\partial t}=\underbrace{-\overline{u^{\prime \prime} w^{\prime \prime}} \frac{\partial \bar{u}}{\partial z}-\overline{v^{\prime \prime} w^{\prime \prime}} \frac{\partial \bar{v}}{\partial z}}_{P M}+\underbrace{\frac{g}{\theta_{0}} \overline{\theta^{\prime \prime} w^{\prime \prime}}}_{P T}-\underbrace{\frac{\partial}{\partial z}\left(\overline{e w^{\prime \prime}}+\frac{\overline{p^{\prime \prime} w^{\prime \prime}}}{\rho_{0}}\right)}_{T}-\underbrace{\epsilon}_{D}
$$

Onde:

$e=\frac{1}{2}\left(u^{\prime \prime 2}+v^{\prime \prime 2}+w^{\prime \prime 2}\right)$ é a ECT específica;

$\overline{u^{\prime \prime} w^{\prime \prime}}$ é o fluxo vertical turbulento da componente zonal do vento;

$\overline{v^{\prime \prime} w^{\prime \prime}}$ é o fluxo vertical turbulento da componente meridional do vento; 
$\overline{\theta^{\prime \prime} w^{\prime \prime}}$ é o fluxo vertical turbulento de calor sensível;

$\overline{e w^{\prime \prime}}$ é o fluxo vertical turbulento de ECT;

$\overline{p^{\prime \prime} w^{\prime \prime}}$ é o fluxo vertical turbulento da flutuação de pressão;

$\epsilon$ é o taxa de dissipação molecular de ECT;

$g / \theta_{0}$ é o parâmetro de empuxo.

Segundo diversos autores, e.g. Stull (1988) e Arya (2001), a CLP pode ser classificada em:

- convectiva $\left(\frac{\partial \bar{\theta}}{\partial z}<0\right)$

- neutra $\left(\frac{\partial \bar{\theta}}{\partial z}=0\right)$

- estável $\left(\frac{\partial \bar{\theta}}{\partial z}>0\right)$

Esta classificação tradicional é baseada na estabilidade estática da atmosfera, porém reflete também os mecanismos dominantes de geração/destruição de ECT, dados pela equação 1.1. A CLP é convectiva quando a superfície está mais aquecida do que a atmosfera resultando em produção térmica de ECT, $P T>0$. Na CLP neutra não ocorre produção/destruição térmica de ECT, i.e. $P T=0$. Neste caso, a fonte geradora de turbulência é a produção mecânica e a destruição de ECT dá-se exclusivamente pelo termo de dissipação molecular. A CLP é estável quando a superfície está mais fria do que o ar adjacente. Sob o regime estável, $P T<0$, a turbulência é somente gerada pela produção mecânica e destruída pelos termos térmico e dissipativo. O transporte, devido às flutuações de velocidade e pressão, não é importante na camada limite estável visto que o tamanho dos tubilhões mais energéticos é pequeno. Para o caso convectivo, o transporte é importante e atua no sentido de transferir ECT da superfície para o topo da atmosfera. Os turbilhões mais energéticos $\lambda_{m}$ são da mesma ordem de grandeza que a extensão vertical da CLP. 


\subsection{A camada limite estável}

Segundo Basu e Porté-Angel (2006) e van Dop e Axelsen (2007), a competição entre a produção mecânica e a destruição térmica é a responsável pela diminuição da intensidade da turbulência na camada limite estável (CLE). Essa diminuição está diretamente ligada ao tamanho dos vórtices turbulentos ser muito menor do que na CLP convectiva (Beare et al., 2006; Mahrt e Vickers, 2006; Acevedo e Mahrt, 2010). Entretanto, segundo Howell e Sun (1999), experimentos de laboratório, observações e modelagem numérica indicam que, mesmo sob condições de forte estabilidade estática, alguma turbulência e mistura vertical ainda persistem no sistema.

Um dos parâmetros mais importantes na descrição do desenvolvimento e da estrutura vertical da CLE é a altura da camada limite (Holtslag e Nieuwstadt, 1986; Vickers e Mahrt, 2004). Sua determinação é extremamente importante em diversas áreas, e.g. estudos da qualidade do ar, além disso, diversos modelos utilizam uma prescrição direta ou parametrização da altura da CLE (Pichugina e Banta, 2010). Diversas definições para altura da CLE são possíveis (Vickers e Mahrt, 2004; Steeneveld et al., 2007; Pichugina e Banta, 2010). As mais conhecidas surgiram nas décadas de 70-80 e são dadas por:

- Posição do máximo inferior da velocidade do vento - Melgarejo e Deardorff (1974);

- Posição do máximo do fluxo turbulento de calor sensível (destruição térmica) Caughey et al. (1979);

- Topo da inversão de temperatura da primeira descontinuidade no perfil de temperatura potencial - Yamada (1979);

- Fração da atmosfera na qual a turbulência existe - Lenschow et al. (1988);

Além da dificuldade de estimativa na altura da CLE, durante a noite a turbulência é gradualmente suprimida podendo apresentar um comportamento altamente intermitente. Diversos autores dedicaram-se à tarefa de estimar a altura da CLE. As formulações são divididas basicamente em dois grupos, número de Richardson e parâmetros de superfície (para revisões recentes ver Zilitinkevich e Baklanov (2002), Vickers e Mahrt (2004), Steeneveld et al. (2007), Pichugina e Banta (2010)). Neste trabalho serão analisadas as 
fórmulas baseadas nos parâmetros de superfície. Basicamente, estas formulações utilizam os seguintes parâmetros para estimar a altura da CLE:

- velocidade característica $u_{*}$;

- Produção térmica em superfície $\left(P T=\frac{g}{\theta_{0}} \overline{\theta^{\prime \prime} w^{\prime \prime}}{ }_{0}\right)$

- Parâmetro de Coriolis $(f)$;

- Estabilidade do fluxo acima da camada turbulenta, (dada pela frequência de BruntVäisällä) $\left(N=\sqrt{\frac{g}{\theta_{0}} \frac{\partial \bar{\theta}}{\partial z}}\right)$

O perfil vertical do vento também apresenta um papel importante na descrição da turbulência na CLE. Segundo Blackadar (1957), mesmo em condições de vento fraco observase um máximo no perfil do vento próximo à superfície. Este máximo, conhecido como jato de baixos níveis (JBN), ocorre tipicamente entre 100-500 metros (Baas et al., 2009). O JBN pode intensificar a turbulência na região do seu máximo ou ainda próximo à superfície, visto que o cisalhamento vertical é intensificado (Mahrt et al., 1998). O JBN inicia sua formação após o final do período convectivo próximo ao topo da camada de inversão.

Existem vários mecanismos que podem gerar JBN na CLE (Karam, 2002). Os JBNs associados ao ajuste inercial são os mais frequentes e serão investigados neste trabalho. Entretanto, os JBNs podem estar associados a efeitos topográficos (mecânicos e térmicos) e efeitos associados à ocupação heterogênea do solo (baroclinicidade).

Os JBNs associados à oscilação inercial atingem seu máximo antes do final do período estável nas latitudes onde o comprimento da noite é menor do que a metade do período inercial $P=\frac{2 \pi}{|f|}=\frac{\frac{1}{2} d i a}{|\sin \phi|}$, onde $\phi$ é a latitude (Holton, 2004). Sua formação deve-se ao desacoplamento do fluxo turbulento da superfície que é seguido por uma aceleração do vento na CLP e ao subsequente desenvolvimento de oscilações inerciais (Blackadar, 1957; Karipot et al., 2008).

Diversos autores já estudaram o JBN e suas implicações; para revisões recentes ver Song et al. (2005); Cuxart e Jiménez (2007); Karipot et al. (2008); Baas et al. (2009). Banta et al. (2002) definem o JBN como um dos processos mais importantes e mais comumente encontrados na CLE durante condições não-perturbadas e terrenos não-montanhosos. 
Baas et al. (2009) definem o JBN como um mecanismo importante para estudos em aviação, energia eólica e transporte de poluentes ou outros constituintes atmosféricos, e.g. ozônio. Segundo Mahrt et al. (1998) o JBN é um fator importante na estrutura vertical da CLE, entretanto ele dificulta a predição acurada de suas propriedades.

Segundo Karam (2002), o JBN foi observado em diversas regiões do Brasil, e.g. Amazônia (Oliveira e Fitzjarrald, 1994) e Iperó (Oliveira, 2003). Na cidade de São Paulo existem evidências da presença do JBN (Nair et al., 2004). Entretanto, apesar da importância, suas propriedades não tem sido suficientemente investigadas na região, pois do ponto de vista observacional não existem sondagens com resolução vertical e frequência para descrever suas propriedades. Outro problema que tem dificultado a investigação do JBN em São Paulo é que os modelos de meso-escala não apresentam resolução vertical suficiente para a investigação deste fenômeno.

Os primeiros estudos teóricos e observacionais sobre a CLE datam do final da década de 70. Segundo van Dop e Axelsen (2007), o estudo teórico da CLE ou ainda experimentos de campo são de realização mais complexas do que os estudos para a CLP convectiva. Os resultados de uma série de experimentos realizados de 1977 a 1979 com o intuito de estudar as características da CLE foram publicados somente em 1984, (Nieuwstadt, 1984). Esses dados são ainda hoje uma das bases mais importantes para o estudo da CLE.

Durante a década de 90 alguns experimentos de campo foram conduzidos, o AtmosphereSurface Turbulent Exchange Research (ASTER) em 1995 (Howell e Sun, 1999) e o Cooperative Atmosphere-Surface Exchange Study (CASES-99) em 1999 (Poulos et al., 2002).

O ASTER foi realizado no estado do Kansas, localizado no centro dos EUA. Seis torres micrometeorológicas de 10 metros cada foram montadas pelo National Center for Atmosphere Research (NCAR). Sensores de umidade e temperatura (frequência $1 \mathrm{~Hz}$ ), anemômetros (frequência $5 \mathrm{~Hz}$ ), anemômetros sônicos, higrômetros-UV e termômetros (frequência $10-20 \mathrm{~Hz}$ ) foram instalados. Os dados foram coletados entre 20:00 e 03:20 (hora local) para cada noite do experimento (Howell e Sun, 1999).

As principais conclusões referem-se a análise de 9 noites com observações completas. Uma forte divergência do fluxo de calor sensível, mesmo sob condições de fraca estabilidade foi identificada. O estudo reporta ainda que o fluxo de calor sensível é mais intenso no início da noite, visto que a queda na temperatura do ar é mais acentuada. Os processos 
não-turbulentos como taxa de resfriamento, são importantes também e não podem ser negligenciados.

Segundo Poulos et al. (2002), o experimento CASES-99 foi realizado com quatro objetivos principais:

- Prover a comunidade com dados de qualidade dos fenômenos na CLE avaliando as contribuições nos fluxos intermitentes de calor sensível, momento e umidade.

- Medir fluxos de calor sensível, momento e suas divergências; avaliar a validade das teorias de similaridade para condições de estabilidade fraca e forte;

- Definir a importância da heterogeneidade da superfície sob condições de vento fraco analisando o papel dos transportes horizontal e vertical resultantes da heterogeneidade;

- Comparar os resultados observados com modelos numéricos além de estudar os períodos de transição convectivo-estável-convectivo.

As conclusões do experimento CASES-99 indicam que a utilização de instrumentação de sensoriamento remoto, aviões e sensores de alta frequência em superfície e em elevação são ferramentas fundamentais para a boa caracterização dos fenômenos na CLE. Entretanto, os principais desafios são relativos a representar adequadamente a influência dos fenômenos de microescala em modelos numéricos, que tipicamente utilizam espaçamento de grade maiores.

Não existe registro na literatura sobre experimentos dedicados ao estudo da CLE realizados no Brasil. No caso específico da cidade de São Paulo, muito pouco é conhecido sobre suas propriedades.

\subsection{Modelagem numérica da CLP e o modelo LES}

A complexidade e dificuldade de parametrização dos processos envolvidos na evolução da atmosfera, principalmente os associados à descrição da turbulência na CLP, muitas vezes requer o uso de modelos numéricos, visto que modelos empíricos ou experimentos de campo são algumas vezes alternativas inviáveis (Garrat, 1994; Jiménez e Cuxart, 
2005). Segundo Moeng (1984), para se desenvolver um modelo empírico seria necessária uma quantidade muito grande de dados sobre diferentes condições de larga escala. Estes dados, por sua vez, são de difícil obtenção, e.g. dados oceânicos (Moeng et al., 2009). Nas análises observacionais, existem ainda fatores como custo operacional e limitação na representatividade espacial. Segundo Masson et al. (2008), poucas campanhas observacionais têm disponibilidade de medição de parâmetros físicos e químicos em regiões urbanas, e esses processos são fundamentais no entendimento do clima urbano e seus impactos.

Existem basicamente três tipos de modelos numéricos para o estudo da turbulência:

- RANS - Reynolds-Averaged Navier-Stokes

- DNS - Direct Numerical Simulation

- LES - Large Eddy Simulation

As equações nos modelos RANS são médias de Reynolds das equações do movimento. Este tipo de modelagem é utilizada para obtenção de soluções simplificadas de processos turbulentos, principalmente em regiões com topografia acentuada ou heterogeneidades, (Sørensen et al., 2007). Estas equações podem ser utilizadas como aproximações baseadas no conhecimento de propriedades da turbulência com o objetivo de fornecer soluções médias aproximadas das equações do movimento, (Baggett, 1998).

Na simulação numérica direta, ou DNS em inglês, as equações do movimento são resolvidas numericamente sem nenhum tipo de simplificação (direta). Isto significa que todas as escalas espaciais da turbulência são resolvidas, desde as escalas dissipativas (microescala de Kolmogorov), até as maiores escalas associadas com movimentos dos turbilhões mais energéticos $\left(\lambda_{m}\right)$, (Orellano e Wengle, 2000; Glowinski et al., 2001). Apesar de eficiente para números de Reynols pequenos, o processo torna-se ineficiente quando o fluido é geofísico devido ao número de Reynolds, ou quando o domínio torna-se grande (Moeng, 1984; Mansour e Wray, 1994).

O LES é uma técnica muito utilizada para simulação de escoamentos turbulentos. Uma das implicações da teoria da similaridade de Kolmogorov é o fato dos turbilhões maiores serem dependentes da geometria, enquanto os de escala menor apresentam características mais universais, (Frisch, 1995). Essa é a vantagem do modelo LES, visto que ele resolve 
diretamente a turbulência de grande escala e indiretamente a de escala menor (Moeng, 1984; Moeng e Wyngaard, 1988; Sullivan et al., 1994). Isso torna a simulação da turbulência em fluidos geofísicos factível, visto que o problema de fechamento fica confinado a parte do espectro de turbulência localizada entre o subintervalo inercial e a região de dissipação molecular (Moeng, 1984; Moeng e Wyngaard, 1988; Arya, 2001). Para as escalas menores o LES utiliza um modelo de subgrade (SGS), (Smagorinsky, 1963; Deardoff, 1972; Moeng, 1984; Moeng e Wyngaard, 1988; Mason, 1994; Sullivan et al., 1994; Iizuka e Kondo, 2004). Do ponto de vista numérico, esse tipo de modelo alia precisão na descrição da turbulência de grande escala e eficiência na modelagem dos turbilhões de menor escala.

O modelo LES parte das seguintes hipóteses:

- Grandes turbilhões têm muita energia e são explicitamente calculados;

- Pequenos turbilhões têm pouca energia e são parametrizados por um modelo SGS.

Segundo Wyngaard e Peltier (1996) existem diferenças entre os termos modelagem e simulação. A palavra modelagem representa os processos turbulentos através de aproximações nas equações. Já palavra simulação, indica a resolução das equações na sua forma exata. Assim pode-se afirmar que os modelos numéricos do tipo LES simulam os grandes turbilhões e modelam os menores, i.e. a escala não resolvida.

Os modelos tipo LES e RANS, são duas técnicas hoje muito empregadas em dinâmica de fluidos geofísicos, muitas vezes até em conjunto, e.g. modelos de meso-escala (Oberkampf e Truncano, 2002; Baik et al., 2003). Ambos os modelos são muito utilizados também na área de Engenharia (Baggett, 1998; Wang e Pitsch, 2007).

Como os recursos computacionais existentes atualmente, os modelos tipo LES atingiram uma resolução espacial da ordem de poucos metros e número de pontos de grade da ordem de $10^{6}$, (Andrén, 1995; Lesieur e Métais, 1996; Su et al., 1998; Jiménez e Cuxart, 2005).

Como todo o modelo numérico, o LES apresenta algumas limitações, principalmente na representação da camada limite superficial (CLS) onde observam-se restrições impostas pela grade numérica. O modelo também não representa bem a turbulência intermitente que desenvolve-se próxima à paredes, onde pequenos turbilhões podem não ser bem resolvidos. Com o intuito de tornar as simulações cada vez mais realísticas, diversas para- 
metrizações para acoplar ao LES implementação de nuvens, e.g. Sorbjan e Uliasz (1999); Brown et al. (2002), reações químicas, e.g. Sykes et al. (1994); Vilà-Guerau de Arellano et al. (2005) ou melhorar a representação do entranhamento e.g. Sorbjan (2005) são utilizadas. Essas parametrizações, apesar de muito úteis, demandam uma maior quantidade de cálculos e interações entre as diversas variáveis para cada passo de tempo. Esses processos aumentam expressivamente o custo computacional do modelo.

As simulações numéricas com LES para a CLP convectiva iniciaram-se na década de 70 com os trabalhos pioneiros de Deardorff, (Deardorff, 1972, 1974). Nos anos 80, o interesse em simulações numéricas da turbulência na CLP convectiva aumentou devido ao salto computacional observado neste período (Moeng, 1984; Nieuwstadt e de Valk, 1987; Moeng e Wyngaard, 1988; van Haren e Nieuwstadt, 1989). Considerando que as simulações para a CLE apresentam outras dificuldades, e.g. divergência do fluxo radiativo, cisalhamento associado ao JBN, intermitência e ondas de gravidade, (Vilà-Guerau de Arellano et al., 2005; Mahrt e Vickers, 2006; Meillier et al., 2008), o estudo numérico da CLE com modelos de alta resolução iniciou-se somente em meados dos anos 90, e.g. Cederwall (1994); Mahrt et al. (1998). Ainda hoje, a necessidade de maior tempo computacional e de altas resoluções espaciais e temporais faz com que a CLE seja menos estudada do ponto de vista numérico (Mahrt et al., 1998; Kosovic e Curry, 2000; Saiki et al., 2000; Jiménez e Cuxart, 2005; Beare et al., 2006; Basu e Porté-Angel, 2006; Cuxart e Jiménez, 2007).

Diversos outros estudos já foram realizados e demonstraram a habilidade do modelo LES em simular as características dos escoamentos turbulentos, principalmente os casos convectivos, (Moeng e Wyngaard, 1988; Dosio et al., 2003; Marques-Filho, 2004). Segundo Moeng (1984); Schmidt e Schumann (1989); Nieuwstadt et al. (1992); Mason (1994); Sullivan et al. (1994); Piomelli et al. (2001); Dosio et al. (2003); Kim et al. (2003); Fedorovich et al. (2004); Sorbjan (2004); Jiménez e Cuxart (2005); Patton et al. (2005), os modelos do tipo LES são os mais indicados para simular numericamente a CLP.

No modelo LES, as propriedades da CLP são simuladas com precisão suficiente para gerar um conjunto de dados das variáveis meteorológicas, que pode ser utilizado na validação dos modelos operacionais existentes (Marques-Filho, 2004). Mesmo a CLE apresentando dificuldades de simulação, devido ao tamanho dos vórtices e outros efeitos não-turbulentos competirem com a turbulência, novas parametrizações para a CLP noturna são fundamen- 
tais para a melhoria dos modelos de larga escala, ou previsão numérica de tempo, (Beljaars e Holtslag, 1991). Segundo Beare et al. (2006), algumas aplicações incluem as predições de temperatura sobre o continente no período noturno, nevoeiro, tempo de convecção e clima polar. O modelo LES também pode ser aplicado para o oceano, e.g. McWilliams et al. (1993); Moeng et al. (2009).

No Brasil, o modelo LES tem sido utilizado para simular as propriedades da CLP principalmente durante o período convectivo, (Marques-Filho, 2004; Codato, 2008; Puhales, 2008; Nunes, 2008). Com exceção do trabalho de Puhales (2008) que simula um ciclo diurno da CLP, todos os outros envolvem simulações somente da CLP convectiva. Portanto, torna-se necessário que grupos de pesquisa no Brasil passem a adquirir experiência de simulações da CLE.

\subsection{Motivação: São Paulo e problemas ambientais}

A cidade de São Paulo, com aproximadamente 11 milhões de habitantes e mais de 6,5 milhões de veículos automotores, caracteriza-se por um grau moderado de contaminação por material particulado, (Kretzchmar, 1994; CETESB, 2009). Contudo, as emissões veiculares contribuem consideravelmente para o aumento dos valores de material particulado, ozônio e monóxido de carbono (CO), tanto em escala local quanto regional, (Bogo et al., 2001; Sanchez Ccoyllo, 2002; Gomez-Perales et al., 2004; Sanchez-Ccoyllo et al., 2006). Segundo Bogo et al. (2001) e Sánchez-Ccoyllo et al. (2009), a emissão veicular é a principal fonte poluidora de ambientes urbanos. Sánchez-Ccoyllo et al. (2009) ainda constataram que a emissão de particulado por veículos nos túneis da cidade de São Paulo é maior do que o encontrado para outras cidades do mundo.

A cidade de São Paulo e 38 cidades vizinhas formam a região metropolitana de São Paulo, (RMSP, figura 1.2). Esta região, localizada a $60 \mathrm{~km}$ do oceano Atlântico é ocupada por 20,5 milhões de habitantes e possui aproximadamente 7,5 milhões de veículos (20\% da frota nacional). Sua área é de aproximadamente $8050 \mathrm{Km}^{2}$, sendo a maior área urbana da América do Sul e uma das 10 maiores do mundo.

O clima da RMSP - típico de regiões subtropicais - é caracterizado por um inverno seco durante junho-agosto e um verão úmido durante dezembro-março (Oliveira et al., 2003). 
Os valores mínimos da média mensal para temperatura do ar e umidade ocorrem em julho e agosto $\left(16^{\circ} \mathrm{C}\right.$ e $74 \%$, respectivamente). Os máximos por sua vez, ocorrem em em fevereiro $\left(22,5^{\circ} \mathrm{C}\right)$ e durante dezembro-janeiro e março-abril (80\%). A distribuição sazonal do vento em superfície indica que a região urbana de São Paulo é caracterizada por ventos fracos durante todo o ano, com intensidade de aproximadamente $1 \mathrm{~ms}^{-1}$, (Oliveira et al., 2003).
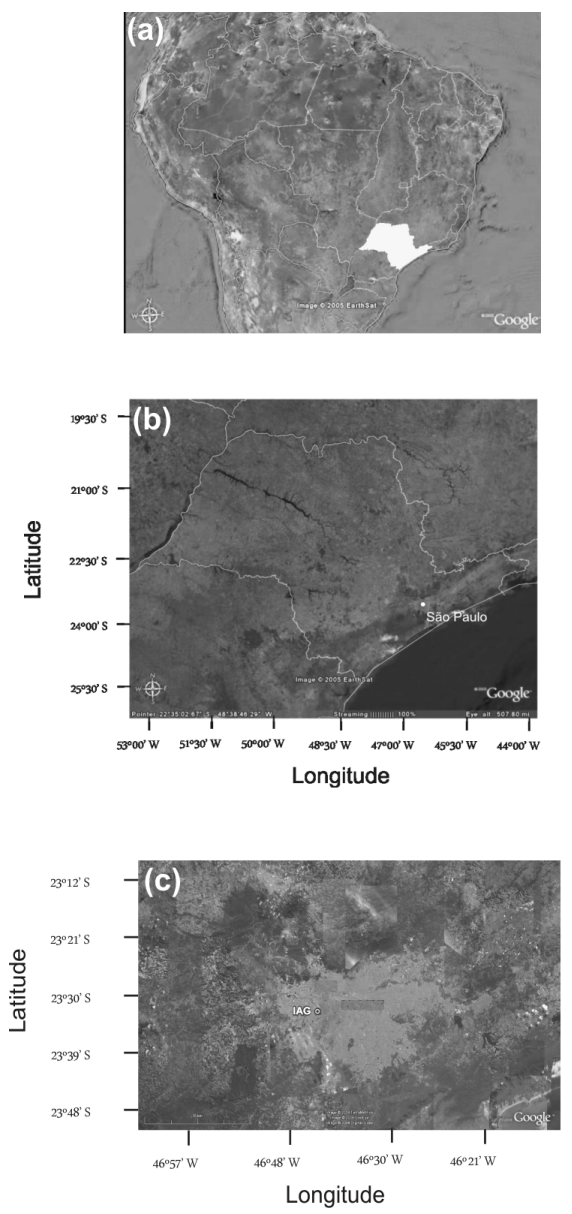

Figura 1.2: Posição geográfica do (a) estado de São Paulo, (b) cidade de São Paulo e (c) RMSP e localização do IAG-USP

A RMSP emite 1.460.000 toneladas de CO por ano, (CETESB, 2009). Aproximadamente $98 \%$ dessa emissão é produzida por 7 milhões de veículos automotores, e sob condições de vento fraco uma fração considerável de CO permanece na RMSP gerando altas concentrações nas regiões de trânsito intenso (Comrie e Diem, 1999). Mesmo a poluição sendo um problema crítico, seus efeitos no clima urbano continuam pouco es- 
tudados, (Baker et al., 2004; Gomez-Perales et al., 2004; Masson et al., 2008). Oliveira et al. (1996), Oliveira et al. (2002) e Codato et al. (2008) mostraram que a poluição em São Paulo altera o clima urbano afetando as evoluções de radiação difusa, direta e global, localmente e em escala regional.

Gomez-Perales et al. (2004) investigaram os efeitos do CO no transporte público da região metropolitana da cidade do México: ônibus, metrô e mini-ônibus para os períodos de trânsito mais intenso, início da manhã e final da tarde. Os resultados indicam que as concentrações em mini-ônibus alcançaram 14ppm na média, com picos de 18ppm no período da manhã. A melhor situação dá-se no metrô, com níveis da ordem de 4ppm. Segundo o autor, esses valores são quatro vezes menores do que estudos do início da década de 90. Algumas medidas governamentais impostas para a redução do CO foram: melhoria da qualidade do combustível, catalizadores obrigatórios em todos os veículos e programas de inspeção (Gomez-Perales et al., 2004). Esse tipo de medida vem sendo tomada também no Brasil, através de alguns programas de controle de fontes móveis. O mais importante deles é o PROCONVE (Programa de Controle da Poluição do Ar por Veículos Automotores) do início da década de 90.

Segundo CETESB (2009) as concentrações de CO vem diminuindo desde o final da década de 90 como resultado desses programas de controle. Entretanto, segundo Comrie e Diem (1999), ventos fracos podem impedir a melhoria da qualidade do ar, mesmo com uma substancial redução nas emissões de CO. Além disso, Novelli et al. (1998) e Boian e Kirchhoff (2006), mostraram que o CO gerado nas queimadas que ocorrem no centro oeste do Brasil pode ser advectado para a região sudeste, indicando que fontes remotas podem contribuir para aumentar a concentração de CO na RMSP. Os efeitos à saúde da exposição prolongada e sistemática ao CO ainda são pouco conhecidas, (Conceição et al., 2001).

O CO é um gás incolor, sem cheiro e venenoso. Em menor quantidade, o CO é também produzido em processos naturais, (Raub, 1999). A exposição a índices moderados de CO pode resultar em efeitos discretos, e.g. olhos secos e dores de cabeça. Entretanto, altas concentrações de CO podem ser letais. Os efeitos danosos do CO à saúde humana são resultados da formação nos glóbulos vermelhos de um complexo estável de carbono chamado carboxiemoglobina (COHb). O COHb não absorve e ainda impede a capacidade do sangue de transporte de oxigênio, (Raub, 1999). 
Com o avanço computacional, o estudo da dispersão de poluentes na CLP vem se tornando cada vez mais importante, (Raga et al., 1999; So et al., 2005; Marques-Filho et al., 2006; Boian e Kirchhoff, 2006). Ulke e Andrade (2001) aplicaram um modelo euleriano fotoquímico com o intuito de estudar a formação e o transporte de poluentes na RMSP. Os resultados indicaram a necessidade de um conjunto robusto de observações para a determinação das características principais do escoamento na região. Ainda, dados de qualidade podem ser utilizados como condição inicial em modelos numéricos.

Diversos estudos foram realizados para a RMSP visando caracterizar as fontes poluidoras (Sanchez Ccoyllo, 2002; Oyama, 2010) e ainda investigar o transporte de poluentes (Sanchez Ccoyllo, 1998; Silva Junior, 2009). Entretanto, a grande dificuldade encontrada nas simulações numéricas do transporte de poluentes na RMSP reside na representação da CLP durante o período noturno. Deve ser destacado que existe uma grande incerteza nas estimativas das fontes (intensidade e distribuições espacial e temporal dos poluentes) aumentando assim o grau de incerteza dos estudos de dispersão de poluentes na RMSP. Nesse sentido, o modelo LES permitirá investigar de forma precisa o papel dos processos turbulentos no comportamento da CLP em São Paulo, principalmente durante o período noturno. Tendo em vista que o CO é um gás inerte, é possível simular numericamente com o modelo LES o impacto que os processos turbulentos da CLP em São Paulo têm sobre o CO. Assim, o papel do CO poderá ser avaliado de maneira objetiva com uma estimativa confiável dos campos médios e do fluxo em superfície.

\subsection{Objetivos}

Verifica-se, conforme descrito acima, que várias propriedades da CLP na RMSP não são bem conhecidas; em parte porque não existe observação e não há uma boa representação destas propriedades em modelos numéricos. Destacando-se:

- Extensão vertical da CLE;

- Propriedades do JBN;

- Propriedades do CO;

- Fluxos turbulentos de calor sensível e de monóxido de carbono. 
Assim, o objetivo deste trabalho é utilizar o modelo LES para caracterizar as principais propriedades da CLP estável sobre a RMSP abordando de maneira objetiva estas questões. Pretende-se através de experimentos numéricos com o modelo LES contribuir para melhorar o conhecimento das propriedades físicas da CLE e investigar o papel do monóxido de carbono durante o período noturno. Serão realizadas simulações numéricas dos campos tridimensionais de vento, temperatura potencial e concentração de monóxido de carbono para um ciclo diurno completo. Para garantir a capacidade do modelo LES de representar os processos turbulentos da CLP foram realizadas 3 validações utilizando como referência resultados consagrados na literatura e representativos das condições convectiva, neutra e estável.

Serão apresentados quatro experimentos numéricos, dois com o intuito de simular uma condição média de atmosfera para meses de inverno e dois com o intuito de simular as condições médias para céu claro no mesmo período. Para estas simulações, os padrões climáticos locais foram determinados utilizando como condição de contorno inferior as evoluções temporais médias mensais da temperatura potencial e concentração de CO para o mês de junho na RMSP. Os fluxos turbulentos de calor sensível e monóxido de carbono em superfície serão estimados pelo modelo LES utilizando observações como parâmetros de entrada no modelo. O papel do JBN associado à oscilação inercial será investigado por meio da análise dos perfis verticais do balanço de ECT e do número de Richardson. O papel do JBN na dispersão de CO será analisado visto que o JBN pode gerar turbulência na CLE e na camada residual. Os resultados para altura da CLP obtidos através do modelo LES serão comparados com dados de LIDAR tomados no Instituto de Pesquisas Energéticas e Nucleares (IPEN-USP). A altura da CLE será também estimada utilizandose formulações empíricas com o intuito de verificar a acurácia destas para a latitude da cidade de São Paulo.

É importante ressaltar que este é o primeiro trabalho para a RMSP que investiga as características da CLE utilizando o modelo LES. Uma descrição do modelo, bem como a metodologia de implementação dos momentos estatísticos e os processos de validação são apresentados no capítulo 2. A caracterização dos experimentos numéricos e análise das simulações serão discutidas no capítulo 3. As principais conclusões são sumarizadas no capítulo 4. 
CAPÍtulo 2

\section{Descrição e validação do modelo LES}

\subsection{Descrição do modelo LES}

As simulações com o LES exigem computadores de alta capacidade de processamento além de uma estrutura computacional que possibilite a transmissão destes dados de maneira rápida. Todas as simulações desenvolvidas neste trabalho foram realizadas utilizando o modelo LES desenvolvido originalmente por Moeng (1984) e aprimorado por Sullivan et al. (1994). A versão atual do modelo conta ainda com as implementações descritas neste capítulo. O modelo LES utilizado inicialmente, foi cedido e modificado pelo Dr. Umberto Rizza do Istituto di Scienze dell'Atmosfera e del Clima (CNR-ISAC) de Lecce, Itália.

O modelo LES foi utilizado pelo Grupo de Micrometeorologia da USP pela primeira vez com o intuito de simular a evolução espacial da CLP convectiva sobre uma superfície plana e homogênea e simular a evolução diurna do monóxido de carbono na RMSP para uma CLP convectiva (Marques-Filho, 2004; Codato, 2008). Primeiramente, este foi implementado no $C R A Y$-J90 e no $C R A Y$-SV1 do Laboratório de computação científica avançada (LCCA) da USP em 2000 e 2003, respectivamente, (Marques-Filho, 2004). Entre 2000 e 2003, essa versão do modelo permitiu também simular a dispersão de fontes do tipo área, tipo pontual e para investigar a validade da hipótese de Taylor na CLP altamente convectiva, (Marques-Filho, 2004; Marques-Filho et al., 2003, 2005; Marques-Filho e Oliveira, 2005; Marques-Filho et al., 2006). Todas as simulações com a versão serial do modelo LES ficaram restritas a períodos de no máximo 1 hora.

A estrutura vertical da CLP sobre a região urbana de São Paulo foi simulada numericamente durante o período diurno (10 horas) utilizando o modelo LES por Codato (2008). Neste estudo foi utilizada uma grade numérica com $128^{3}$ pontos, distribuídos de 
forma igualmente espaçada sobre um domínio de 10x10 $\mathrm{km}^{2}$ no plano horizontal e $2 \mathrm{~km}$ na direção vertical. Nessa simulação, foram utilizadas como condição de contorno inferior os fluxos verticais turbulentos de calor sensível e CO representativos da cidade de São Paulo no mês de junho. Nesta versão do modelo a temperatura potencial e a concentração de CO são determinados em função dos respectivos fluxos e da teoria da similaridade de Monin-Obukhov (TSMO) a cada passo de tempo.

Em todas as simulações realizadas entre os anos de 2000 e 2008, os fluxos turbulentos de calor sensível e monóxido de carbono foram especificados como condição de fronteira infeiror. Entretanto, esse tipo de forçante não funciona adequadamente quando a temperatura diminui. Principalmente durante a noite, diversos autores, e.g. Basu et al. (2008), mostram que a velocidade característica $u_{*}$ não é adequadamente representada quando os valores de fluxo são utilizados como forçante.

No início de 2009 uma nova versão do modelo LES que permite forçar a evolução da CLP através da temperatura foi cedida pelo professor Umberto Rizza. Alguns resultados dessa versão do modelo LES podem ser encontrados em Rizza et al. (2007) e Puhales (2008). Esta nova versão foi implementada na servidora R900 Intel 2-quad (8 nós) $12 \mathrm{~Gb}$ de memória e 1.2 Tb de HD, adquirida através do projeto $\mathrm{CNPq}$ (Proc. No. $476807 / 2007$ - 7). Este computador permite executar o modelo LES utilizando 8 nós em processamento paralelo. Além da velocidade no processamento, esse novo computador é utilizado exclusivamente para as execuções do modelo LES, permitindo enfim efetuar-se modificações no código e ainda executar simulações para o período estável, (Barbaro et al., 2009).

Deve ser ressaltado que a implementação da versão paralelizada do modelo LES em uma máquina implica na instalação de um módulo MPI (message passing interface). O MPI é um padrão de comunicação entre os processos para sistemas com mais de um processador e com memória distribuída. É constituído de um conjunto de bibliotecas que foi projetado para trabalhar com processamento paralelo massivo em clusters, (Pacheco, 1997; Moreira et al., 2005).

Considerando que as simulações exigem alteração dos parâmetros de superfície, foi utilizada a técnica de restart para a simulação de um ciclo diurno completo. Este procedimento evita instabilidade numérica no modelo, e.g. erro de arredondamento, além de permitir que as condições forçantes de temperatura, $\mathrm{CO}$ ou ainda os fluxos sejam alteradas 
a cada hora (Chartier, 2005).

Depois da fase de instalação do modelo, um algoritmo de cálculo dos momentos estatísticos foi implementado, permitindo calcular em tempo real os perfis verticais médios no plano horizontal dos momentos estatísticos de primeira e segunda ordem para $u, v, w, \theta, \mathrm{CO}$, além de termos de terceira ordem, ver tabela 2.1. Esse algoritmo possibilitou também calcular as componentes do balanço de ECT para a escala resolvida e subgrade.

\subsubsection{Descrição da escala resolvida}

Para a escala resolvida, o modelo LES de Moeng (1984) e Sullivan et al. (1994) resolve numericamente as equações do movimento utilizando um método pseudoespectral nas direções horizontais i.e. utiliza uma transformada rápida de Fourier (FFT) para resolver as derivadas horizontais, (ao invés de inversão matricial). Um esquema de diferenças finitas de segunda ordem centrado no espaço é utilizado para a direção vertical, (Moeng, 1984; Luo e Kreiss, 1998). As derivadas temporais, para escala resolvida, são discretizadas através do esquema de $2^{a}$ ordem Adams-Bashforth, estável para pequenos passos de tempo (Mesinger e Arakawa, 1976; Fortuna, 2001; Boyce e DiPrima, 2005). A estabilidade do sistema numérico é determinada através do cálculo do número de Courant (CFL- equação 2.1), para cada passo de tempo, i.e. a condição é testada a cada $d t$ :

$$
d t=\alpha \frac{d x_{i}}{\max \left(u_{i}\right)}
$$

Onde $0<\alpha<1$.

As condições de fronteiras laterais são assumidas como sendo cíclicas. Esse tipo de fronteira é apropriado para representar escoamentos turbulentos da CLP sobre superfícies homogêneas, (Mesinger e Arakawa, 1976). A TSMO é empregada para estimar os fluxos turbulentos de momento em superfície, (Frisch, 1995; Foken, 2004). Essa fronteira é considerada rígida e com velocidade vertical nula. A condição de fronteira superior é radiativa, com gradientes verticais nulos para as componentes horizontais de velocidade do vento e fluxos turbulentos de subgrade. Por consistência, a velocidade vertical também é nula no topo da grade. A fronteira radiativa é a mais apropriada para propagar as ondas de gravidade para fora do domínio numérico sem reflexão, (Saiki et al., 2000). O domínio 
numérico na vertical deve estender-se acima do topo da CLP, visto que as condições de fronteira podem se propagar para a camada turbulenta.

O modelo LES possui seis variáveis prognósticas - 3 componentes do vento $(u, v, w)$, temperatura potencial $(\theta)$, ECT de subgrade $(e)$, e ainda um escalar passivo, no caso concentração de monóxido de carbono (CO). O modelo é constituído pelas equações de conservação de momento, energia, massa e equação de estado que representam adequadamente os movimentos turbulentos. Para tanto, as equações do modelo LES satisfazem as aproximações da convecção rasa (Stull, 1988).

Segundo Moeng (1984) e Moeng e Wyngaard (1988), a média de Reynolds não descreve completamente as flutuações do fluxo turbulento. O modelo LES utiliza outra metodologia de cálculo de média, conhecida como média de volume, definida pela equação 2.2:

$$
<u_{i}\left(x_{i}\right)>=\int_{V} u_{i}(x, y, z) d V
$$

Essa média é definida por $<>$ diferentemente da média de Reynolds $\left(^{-}\right)$. Para a subgrade a notação adotada é ('). Utilizando-se esse tipo de média, os operadores antes descartados na média de Reynolds, são calculados pelo modelo de subgrade. Por exemplo, para o termo de advecção (equações 2.3 e 2.4 ):

$$
\frac{\partial\left(<u_{i} u_{j}>\right)}{\partial x_{j}}=\frac{\partial\left(<u_{i}><u_{j}>+R_{i j}\right)}{\partial x_{j}}
$$

Onde o primeiro termo do lado direito da equação é diretamente calculado pelo modelo LES e $R_{i j}$ é o termo de subgrade dado pela equação 2.4 :

$$
R_{i j}=<u_{i}^{\prime}<u_{j}>>+<u_{j}^{\prime}<u_{i}>>+<u_{i}^{\prime} u_{j}^{\prime}>
$$

\subsubsection{Descrição da escala de subgrade}

Existem diversas parametrizações de subgrade para o modelo LES. Iizuka e Kondo (2004) fazem uma análise de quatro modelos SGS. As principais conclusões são referentes à necessidade do desenvolvimento de um modelo SGS híbrido, o qual combina modelos SGS dinâmicos, onde $z_{0}$ pode variar e modelos do tipo Smagorinsky clássicos, i.e. $z_{0}$ constante. 
Dubrulle et al. (2002) afirmam que a prescrição da velocidade de subgrade está confinada a escalas até duas vezes menores que a própria malha numérica. Em seu artigo eles propõe um novo modelo de subgrade que em princípio é válido para todas as escalas menores que a própria malha.

Esta versão do LES utiliza uma parametrização de subgrade originalmente proposta por Smagorinsky (Smagorinsky, 1963) e aprimorado por Sullivan (Sullivan et al., 1994). O modelo de Smagorinsky (1963) considera a existência de um equilíbrio local entre a produção e a dissipação molecular da ECT. Segundo Sullivan et al. (1994) e Iizuka e Kondo (2004), há uma forte necessidade de novas estimativas de parametrizações de subgrade visto que em determinados casos, e.g. próximo a paredes ou CLPs neutras e estáveis, a parte SGS é tão importante quanto a escala resolvida, (Baggett, 1998). O principal problema é que as parametrizações SGS demandam muito tempo computacional.

As parametrizações SGS determinam os fluxos de subgrade em termos da escala resolvida. Assim, o problema de fechamento do modelo fica restrito somente à escala de subgrade, ao contrário de modelo tipo média de Reynolds.

Segundo Moeng (1984), o termo $R_{i j}$ pode ser descrito pela equação 2.5:

$$
R_{i j}=\tau_{i j}+\frac{R_{k k} \delta_{i j}}{3}
$$

A parametrizacão utilizada no modelo LES assume que o tensor de Reynolds $\tau_{i j}$ pode ser expresso em termos do tensor taxa de deformação do escoamento médio (escala resolvida) e de um coeficiente turbulento de difusividade $\nu_{t}$, equação 2.6 .

$$
\tau_{i j}=-2 \nu_{t} \gamma S_{i j}-2 \nu_{T}\left[S_{i j}\right]
$$

Onde [ ] significa média no plano horizontal e $S_{i j}$ é o tensor taxa de deformação dado pela equação 2.7 .

$$
S_{i j}=\frac{1}{2}\left(\frac{\partial\left\langle u_{i}\right\rangle}{\partial x_{j}}+\frac{\partial\langle u\rangle_{j}}{\partial x_{i}}\right)
$$

A equação 2.8 apresenta a parametrização para os escalares: 


$$
\tau_{\theta i}=-2 \nu_{\theta} \frac{\partial\langle\theta\rangle}{\partial x_{i}}
$$

Onde:

- $\nu_{t}$ é o coeficiente de difusividade de momento isotrópico;

- $\nu_{T}$ é o coeficiente de difusividade de momento não-homogêneo;

- $\nu_{\theta}$ é o coeficiente de difusividade térmica;

- $\gamma$ é um fator associado à isotropia.

O fator de isotropia $(\gamma)$ é responsável pela transição entre escalas resolvida e subgrade. Segundo Sullivan et al. (1994), as parametrizações SGS foram primeiramente desenvolvidas assumindo que o escoamento está no sub-intervalo inercial, portanto os movimentos na subgrade poderiam ser considerados isotrópicos. Segundo Moeng e Wyngaard (1988), as constantes são determinadas através de um espectro isotrópico de energia. Entretanto, isso indica que o efeito do cisalhamento próximo à superfície, determinante para tornar o escoamento não-isotrópico, é desconsiderado. O modelo SGS modificado por Sullivan et al. (1994), utilizado neste trabalho, considera que a turbulência apresenta uma parte não-isotrópica, considerando os efeitos do cisalhamento próximo à superfície, além da homogeneidade.

Os termos de subgrade no modelo LES são determinados através da solução da equação da ECT (equação 1.1). Esta equação é integrada no tempo utilizando um método explícito de terceira ordem do tipo Runge-Kutta, (Boyce e DiPrima, 2005). Espacialmente, da mesma maneira que na escala resolvida, utiliza-se um método pseudoespectral com transformadas de Fourier homogêneas. Para a vertical, um método de diferenças finitas de segunda ordem é utilizado.

\subsection{Validação do modelo LES atual}

A tabela 2.1 apresenta os momentos estatísticos implementados no modelo LES para as escalas resolvida e subgrade descritas acima. 
Tabela 2.1: Estatísticas implementadas no modelo LES.

\begin{tabular}{|c|c|c|}
\hline \multicolumn{3}{|c|}{ Perfis verticais } \\
\hline & escala resolvida & subgrade \\
\hline Temperatura potencial média & $<\theta>$ & \\
\hline Concentração média de CO & $<C O>$ & \\
\hline Variância da velocidade & $\left\langle u^{\prime 2}\right\rangle,\left\langle v^{\prime 2}\right\rangle,\left\langle w^{\prime 2}\right\rangle$ & $\overline{u^{\prime \prime 2},}, \overline{v^{\prime \prime 2}}, \overline{w^{\prime \prime 2}}$ \\
\hline Mom. estat. de $3^{\circ}$ ordem de $w$ & $<w^{\prime 3}>$ & $\overline{w^{\prime \prime 3}}$ \\
\hline Variância de $\theta$ e CO & $<\theta^{\prime 2}>,<C O^{\prime 2}>$ & $\overline{\theta^{\prime \prime 2}}, \overline{C O^{\prime \prime 2}}$ \\
\hline Variância de $\theta$ com $\mathrm{CO}$ & $<\theta^{\prime} C O^{\prime}>$ & $\overline{\theta^{\prime \prime} C O^{\prime \prime}}$ \\
\hline Fluxo vertical de calor sensível & $\left\langle w^{\prime} \theta^{\prime}\right\rangle$ & $\overline{w^{\prime \prime} \theta^{\prime \prime}}$ \\
\hline Fluxo vertical de $\mathrm{CO}$ & $<w^{\prime} C O^{\prime}>$ & $\overline{w^{\prime \prime} C O^{\prime \prime}}$ \\
\hline Fluxo zonal de calor sensível & $<u^{\prime} \theta^{\prime}>$ & $\overline{u^{\prime \prime} \theta^{\prime \prime}}$ \\
\hline Fluxo zonal de $\mathrm{CO}$ & $<u^{\prime} C O^{\prime}>$ & $\overline{u^{\prime \prime} C O^{\prime \prime}}$ \\
\hline Fluxo meridional de calor sensível & $\left.<v^{\prime} \theta^{\prime}\right\rangle$ & $\overline{v^{\prime \prime} \theta^{\prime \prime}}$ \\
\hline Fluxo meridional de $\mathrm{CO}$ & $\left\langle v^{\prime} C O^{\prime}\right\rangle$ & $\overline{v^{\prime \prime} C O^{\prime \prime}}$ \\
\hline Energia cinética turbulenta & $<E C T>$ & $\bar{e}$ \\
\hline Velocidade zonal média & $<u>$ & \\
\hline Velocidade meridional média & $<v>$ & \\
\hline Fluxo de momento & $<u^{\prime} w^{\prime}>$ & $\overline{u^{\prime \prime} w^{\prime \prime}}$ \\
\hline Fluxo de momento & $\left\langle v^{\prime} w^{\prime}\right\rangle$ & $\overline{v^{\prime \prime} w^{\prime \prime}}$ \\
\hline Fluxo de momento & $\left.<u^{\prime} v^{\prime}\right\rangle$ & $\overline{u^{\prime \prime} v^{\prime \prime}}$ \\
\hline Divergência & $\nabla \cdot \vec{V}$ & \\
\hline Produção Mecânica & $-\left\langle u^{\prime} w^{\prime}\right\rangle \frac{\partial<u\rangle}{\partial z}-\left\langle v^{\prime} w^{\prime}\right\rangle \frac{\partial<v\rangle}{\partial z}$ & $-\overline{u^{\prime \prime} w^{\prime \prime}} \frac{\partial \bar{u}}{\partial z}-\overline{v^{\prime \prime} w^{\prime \prime}} \frac{\partial \bar{v}}{\partial z}$ \\
\hline Produção Térmica & $\frac{g}{\theta}<w^{\prime} \theta^{\prime}>$ & $\frac{g}{\theta} \overline{w^{\prime \prime} \theta^{\prime \prime}}$ \\
\hline Transporte & $-\frac{\partial}{\partial z}\left(\left\langle e^{\prime} w^{\prime}\right\rangle+\frac{\left\langle w^{\prime} p^{\prime}\right\rangle}{\rho_{0}}\right)$ & $-\frac{\partial}{\partial z}\left(\overline{e^{\prime \prime} w^{\prime \prime}}+\frac{\overline{w^{\prime \prime} p^{\prime \prime}}}{\rho_{0}}\right)$ \\
\hline Dissipação & & $-c_{k} \frac{e^{1.5}}{l}$ \\
\hline
\end{tabular}


Tendo em vista que novas estatísticas para escalas resolvida e subgrade foram introduzidas no modelo LES, foi desenvolvido um procedimento de validação para verificar se essas implementações introduziram algum tipo de perturbação no modelo. É importante ressaltar que as mudanças efetuadas no modelo LES não têm como objetivo alterar nenhuma parametrização ou ainda metodologia de cálculo; para as escalas resolvida e subgrade. As diversas modificações prévias efetuadas no código também exigem validação, e.g. adaptação do modelo serial para versão em paralelo. A metodologia empregada é a de comparação dos resultados do modelo LES atual com resultados já publicados. Foram realizados três validações: caso convectivo (caso I), transição convectivo-estável (caso II) e estável (caso III). O caso I está baseado na simulação da CLP convectiva de Moeng e Sullivan (1994). O caso II baseia-se na simulação da CLP estável de Saiki et al. (2000) e o caso III na simulação da CLP estável de Beare et al. (2006).

\subsubsection{Caso I: convectivo}

Os resultados apresentados por Moeng e Sullivan (1994) são referentes a uma simulação de 2,5 horas com fluxo de calor sensível em superfície de $\left(\overline{w^{\prime} \theta^{\prime}}\right)=0,24 m K s^{-1}$ constante durante todo o período. O vento geostrófico imposto ao modelo foi $u_{g}=10 \mathrm{~ms}^{-1}$ para uma CLP horizontalmente homogênea e com topografia plana. O domínio utilizado foi 3000x3000x2000 metros com $96^{3}$ pontos de grade. Algumas propriedades do escoamento no último passo de simulação são apresentados na tabela 2.2:

Tabela 2.2: Comparação das propriedades do escoamento para o caso convectivo

\begin{tabular}{||c||c|c|c|c|c||}
\hline \hline Simulação & $u_{*}\left(m s^{-1}\right)$ & $w_{*}\left(m s^{-1}\right)$ & $z_{i}(\mathbf{m})$ & $-z_{i} / L$ & $\left(\overline{w^{\prime} \theta^{\prime}}\right)_{i}\left(m s^{-1} K\right)$ \\
\hline Moeng (1988) & 0,56 & 2,02 & 1030 & 18 & $-0,04$ \\
\hline LES atual & 0,56 & 2,01 & 1038 & 18,1 & $-0,035$ \\
\hline \hline
\end{tabular}

Onde:

$u_{*}$ é a velocidade característica dada pela equação 2.9:

$$
u_{*}=\sqrt[4]{\frac{\tau_{x z}^{2}+\tau_{y z}^{2}}{\rho_{0}^{2}}}
$$

$w_{*}$ é velocidade característica para atmosfera convectiva, dada pela equação 2.10: 


$$
w_{*}=\left[\frac{g}{\theta_{0}}\left(\overline{\theta^{\prime} w^{\prime}}\right)_{0} z_{i}\right]^{\frac{1}{3}}
$$

As escalas características $u_{*}$ e $w_{*}$ apresentaram resultados compatíveis entre os modelos. No novo modelo, a altura da CLP é apenas 0,8\% maior do que no modelo LES de Moeng e Sullivan (1994). O mínimo do fluxo de calor sensível, definido como o topo da CLP, também apresenta compatibilidade com o modelo LES de Moeng e Sullivan (1994).

Os perfis verticais do vento médio, das variâncias de velocidade e o balanço de ECT são apresentados a seguir, figuras 2.1,2.2 e 2.3, respectivamente:

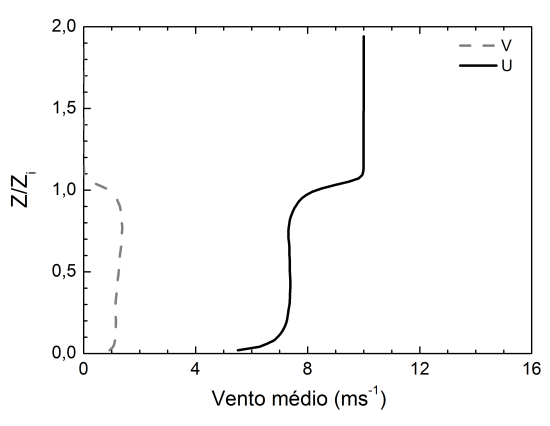

(a) LES atual

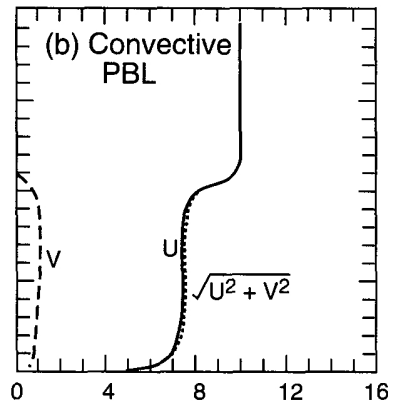

(b) LES (Moeng e Sullivan, 1994)

Figura 2.1: Perfis verticais das componentes zonal e meridional do vento médio.

A figura 2.1 compara o vento médio nas componentes zonal e meridional para ambas as simulações. Os resultados indicam uma camada de mistura bem desenvolvida. Este resultado comprova que a intensidade da mistura turbulenta está sendo reproduzida pelo modelo atual de forma similar ao caso de referência.

As variâncias de velocidade normalizadas pela escala característica de velocidade são apresentadas na figura 2.2. A variância normalizada apresentada é considerada como total, i.e. inclui os efeitos da subgrade. Observa-se que as variâncias verticais apresentam a mesma magnitude, aproximadamente 0,5 próximo à superfície decrescendo até 0,2 no meio da CLP e alcançando $\approx 0,3$ na camada de inversão. Segundo Moeng e Wyngaard (1988) e Moeng e Sullivan (1994) o perfil de $w_{*}$ parabólico e máximo em $0,4 Z / Z_{i}$ concorda com observações. O máximo sugerido pelos autores é 0,4 , muito próximo do valor simulado pelo modelo LES atual, 0,38 . 


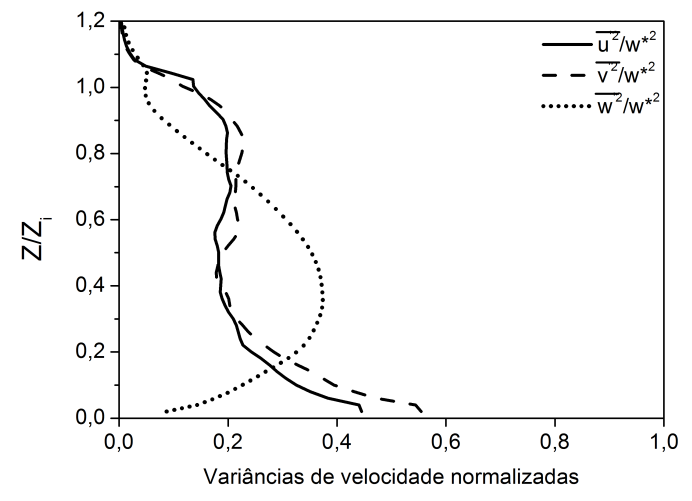

(a) LES atual

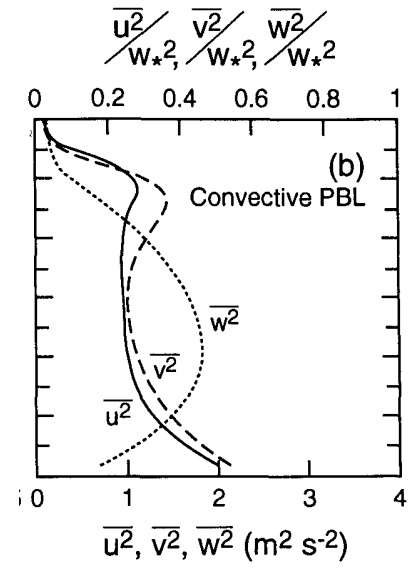

(b) LES (Moeng e Sullivan, 1994)

Figura 2.2: Perfis verticais das variâncias de velocidade normalizadas pela escala característica de velocidade, $w_{*}$.

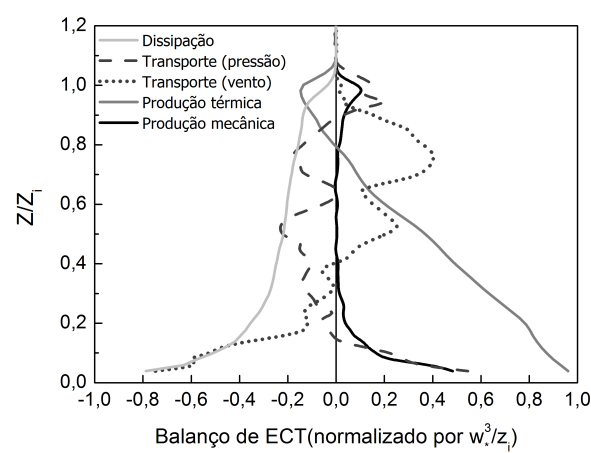

(a) LES atual

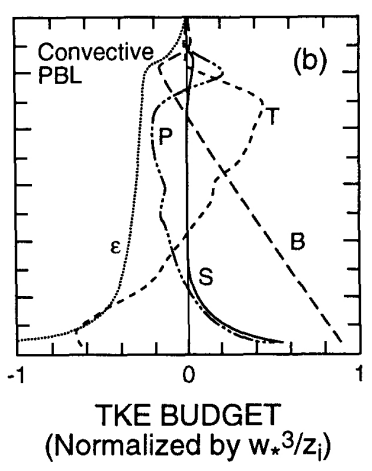

(b) LES (Moeng e Sullivan, 1994)

Figura 2.3: Perfil vertical do balanço de energia cinética turbulenta.

Observa-se pelo balanço de ECT, equação 1.1 e figura 2.3, que a produção térmica é a fonte principal de energia na CLP e a produção mecânica é importante somente nos primeiros metros. Através dessa comparação é possível ver que a subgrade também apresenta resultados esperados para este tipo de CLP. Segundo Moeng e Sullivan (1994) na camada de mistura, i.e. onde a produção mecânica é muito menor que a térmica (regime de convecção livre), a taxa de dissipação deve ser praticamente constante com a altura. O termo de transporte, devido às flutuações de pressão e vento, deve decair 
numa taxa praticamente constante, com o intuito de balancear a produção térmica. Essas características foram reproduzidas no modelo LES atual de forma similar ao caso de referência.

\subsubsection{Caso II: CLP na transição convectivo-estável}

Para o caso II, transição convectivo-estável, utilizou-se para validação do modelo LES atual, o artigo de Saiki et al. (2000). A simulação proposta é representativa de uma CLP continuamente turbulenta com forçante geostrófica intensa $\left(U_{g}=15 \mathrm{~ms}^{-1}\right)$. O domínio utilizado é de $1 \mathrm{~km}^{3}$ com $96^{3}$ pontos de grade resultando num espaçamento numérico uniforme da ordem de 10,4m. As condições iniciais do modelo são representativas de uma CLP convectiva, com fluxo de calor sensível de $0,05 m K s^{-1}$. A temperatura inicial da camada de mistura é $300 K$. O parâmetro de rugosidade é definido como constante e igual a 0,1 e a latitude simulada é $30^{\circ} N$. Inicialmente, a camada de inversão está localizada a 500 metros acima da superfície. A esta camada foi atribuído um gradiente vertical de temperatura de $0,06 \mathrm{Km}^{-1}$. Após 1 hora de simulação para a CLP convectiva, o fluxo de calor sensível em superfície é alterado para zero e mais 2 horas são simuladas. Após este período, durante 6 horas a CLP é submetida a uma variação no fluxo de calor sensível de condição neutra até $-0,05 m K s^{-1}$. Após esse período a CLP ainda é submetida a mais 5 horas de simulação com fluxo constante de $-0,05 m K^{-1}$, totalizando 14 horas de simulação (1 hora de CLP convectiva, 2 horas de CLP neutra e 11 horas de CLP estável).

Esta simulação avalia a capacidade do modelo LES de reproduzir as propriedades da CLP na transição convectivo/estável, além de apresentar resultados somente para o período estável. Essa camada convectiva inicial intensifica o papel do jato de baixos níveis que será explorado neste trabalho. Os perfis verticais apresentados referem-se sempre ao último passo da simulação numérica.

Observa-se pelo perfil vertical do vento médio na CLP que o modelo LES atual consegue reproduzir as principais características do JBN na camada limite noturna, i.e. a posição e a intensidade foram reproduzidas pelo modelo. Isso indica que a transição entre a CLP convectiva e estável é feita de maneira correta visto que tanto a posição quanto a intensidade do JBN dependem do período convectivo. O único mecanismo responsável pela geração do JBN no modelo LES é a oscilação inercial da camada imediatamente 


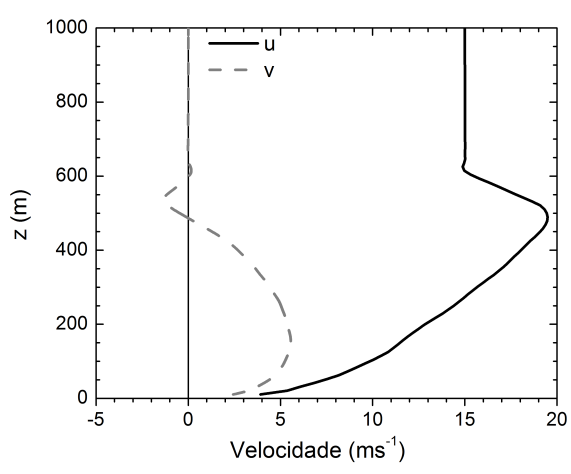

(a) LES atual

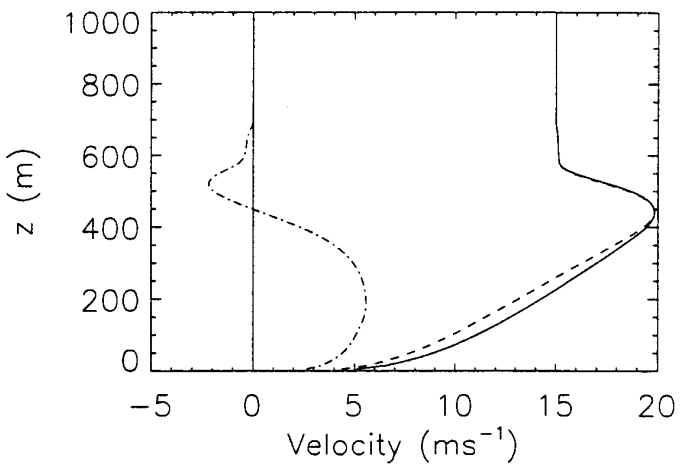

(b) LES (Saiki et al., 2000)

Figura 2.4: Perfil vertical da velocidade.

acima da CLE, a medida que esta camada desacopla da superfície. A amplitude e a fase inicial são dependentes da condição convectiva a qual a camada estava submetida.

A evolução do JBN é apresentada na figura 2.5. Os resultados do modelo LES são ainda comparados com a solução analítica proposta por Blackadar (1957):

$$
W=W_{0} e^{-i f t}
$$

Onde:

$W_{0}$ é a velocidade ageostrófica no instante onde o fluxo de calor sensível torna-se negativo;

$f$ é o parâmetro de Coriolis; $f=10^{-4} s^{-1}$ para esta simulação;

$W=\left(U-U_{g}\right)-i V$

$t=0$ representa início do resfriamento.

Observa-se na figura 2.5 que os valores da velocidade máxima do jato, $U_{j}=\sqrt{u^{2}+v^{2}}$, tornam-se supergeostróficos após duas horas de simulação estável atingindo um máximo de $19,6 m s^{-1} 7$ horas após o início do resfriamento. Considerando a diminuição do efeito da oscilação inercial, o jato desintensifica-se após 8 horas. Nota-se da comparação das figuras, que estas são compatíveis durante todo o período. Como o JBN apresentado por Saiki et al. (2000) desenvolve-se um pouco mais, 20,3ms $\mathrm{m}^{-1}$, o decaimento observado na 


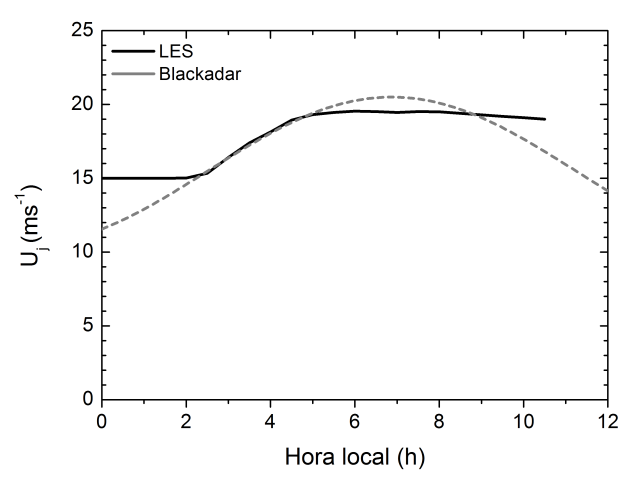

(a) LES atual

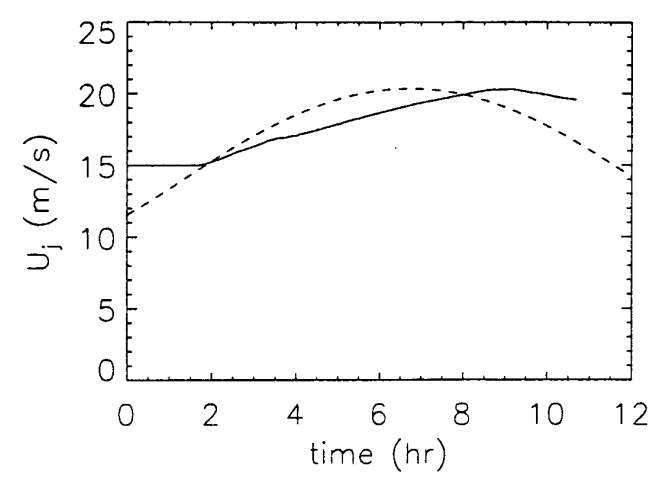

(b) LES (Saiki et al., 2000)

Figura 2.5: Variação temporal da intensidade máxima do JBN durante o período estável da simulação. A linha pontilhada representa a curva teórica proposta por Blackadar (1957).

nova simulação é um pouco menor, visto que ambas terminam com o valor de $\approx 19,0 \mathrm{~ms}^{-1}$.

A figura 2.6 apresenta a evolução temporal da altura do JBN. Nas duas primeiras horas, onde ainda não existem efeitos devido à oscilação inercial, observa-se que o modelo apresenta valores de altura que são referentes ao topo da camada de mistura. Com o início dos efeitos inerciais, a altura da CLE diminui rapidamente para $\approx 500 \mathrm{~m}$, onde permanece oscilando em um intervalo de 50 metros até o final da simulação.

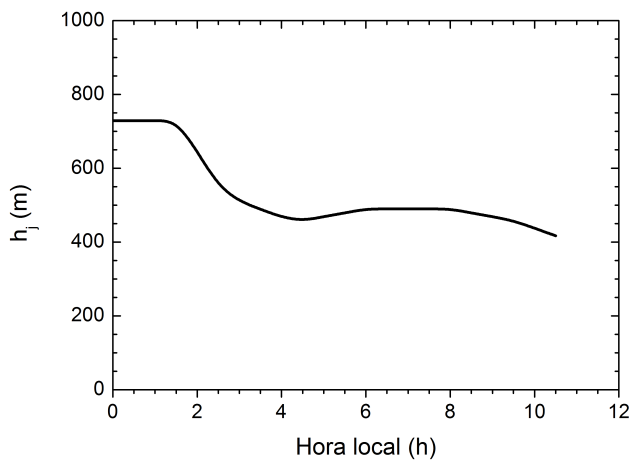

(a) LES atual

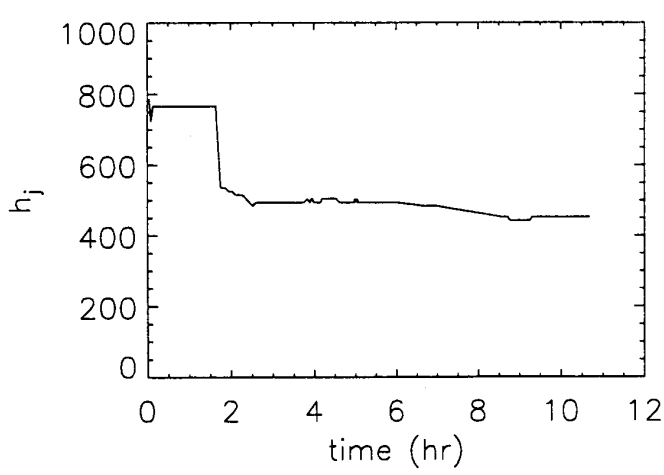

(b) LES (Saiki et al., 2000)

Figura 2.6: Variação temporal da altura máxima do JBN durante o período estável da simulação.

Segundo Mahrt et al. (1998), a altura do JBN é um parâmetro importante na descrição das propriedades da CLE, visto que o cisalhamento na região do jato é uma possível fonte 
de turbulência para a camada abaixo. Essa característica indica que a JBN pode modular, além da altura da camada e a produção de turbulência, a dispersão de poluentes na camada noturna.

O balanço de ECT é utilizado para analisar o impacto do JBN no caso estável, visto que a produção mecânica e a quantidade de turbulência na camada são apresentadas explicitamente:

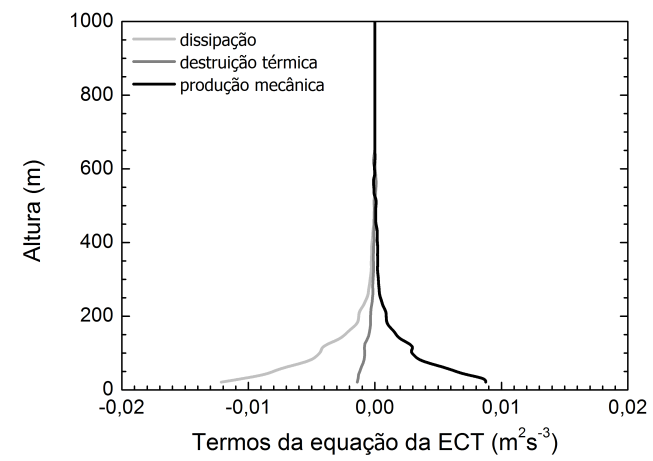

(a) LES atual

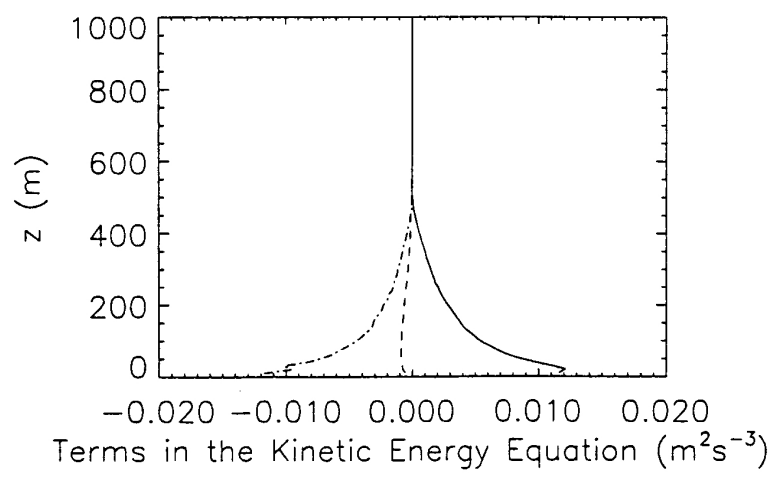

(b) LES (Saiki et al., 2000)

Figura 2.7: Balanço de energia cinética turbulenta para o final da simulação.

Observa-se pelo perfil do balanço de ECT que o jato não introduz nenhum tipo de perturbação no perfil vertical da produção mecânica. Segundo Saiki et al. (2000), o número de Richardson não indica produção de turbulência na altura do JBN, i.e. $R i>$ 0,25, assim, o cisalhamento associado ao jato não é uma fonte de turbulência na CLE. A comparação com o LES atual indica resultados novamente compatíveis para o balanço de ECT produzidos na simulação de referência.

\subsubsection{Caso III: CLP estável}

Para o caso III, estável, utilizou-se para validação a evolução da CLP estável descrita em Beare et al. (2006). Este artigo é indicado para o processo de validação, pois trata de comparações entre a capacidade de simulação da camada estável para onze diferentes modelos LES. O artigo faz parte de um abrangente estudo chamado GEWEX-GABLS ( "Global Energy and Water Cycle Experiment Atmospheric Boundary Layer Study"); para detalhes sobre o projeto GABLS ver Holtslag (2003). 
Os resultados de Beare et al. (2006) estão baseados em simulações para uma camada moderadamente estável; (mesmo a atmosfera sendo moderadamente estável, o tempo de máquina é extremamente elevado; aproximadamente 200 horas). Neste estudo foram utilizadas diversas resoluções para a simulação da CLE, desde 1 metro até 12.5 metros. A resolução escolhida para a validação do modelo LES atual foi 3 metros. Resoluções maiores tornam-se inviáveis, devido ao tempo de máquina. Entretanto, segundo Beare et al. (2006), essa resolução é suficiente para simular a camada estável, visto que as resoluções menores introduzem mudanças muito sutis nos campos finais.

O domínio numérico é de $400 \mathrm{~m}^{3}$ com $128^{3}$ pontos de grade, totalizando 3,125 metros de resolução nas três componentes. As condições iniciais da simulação são típicas da região ártica, $73^{\circ} \mathrm{N}$ de latitude, com uma camada de mistura de 100 metros de altura e uma camada de inversão de $0,01 \mathrm{Km}^{-1}$. O fluxo predito de calor sensível é constante e igual a $-0,25 K h^{-1}$. Esse fluxo é mantido por 9 horas até atingir a condição de quasiequilíbrio. O vento geostrófico é moderado, $8 \mathrm{~ms}^{-1}$ e zonal. Detalhes desta simulação podem ser encontrados em Kosovic e Curry (2000) e Beare et al. (2006). Todos os perfis verticais apresentados referem-se ao último passo da simulação numérica. Esta validação é importante, pois o intuito deste trabalho é simular a camada limite noturna.

As figuras 2.8, 2.9, 2.10, 2.11 indicam a comparação entre o LES atual e os 11 diferentes modelos LES discutidos no artigo.

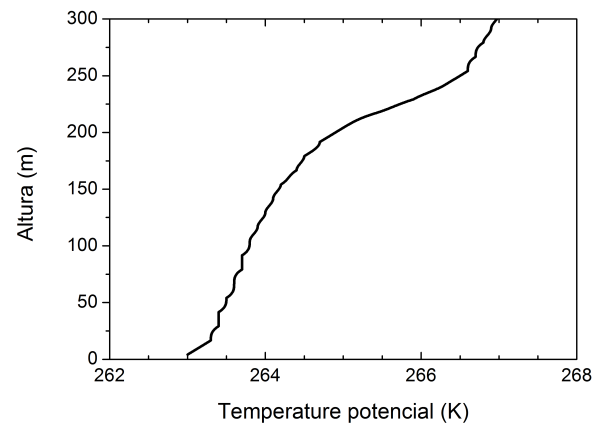

(a) LES atual

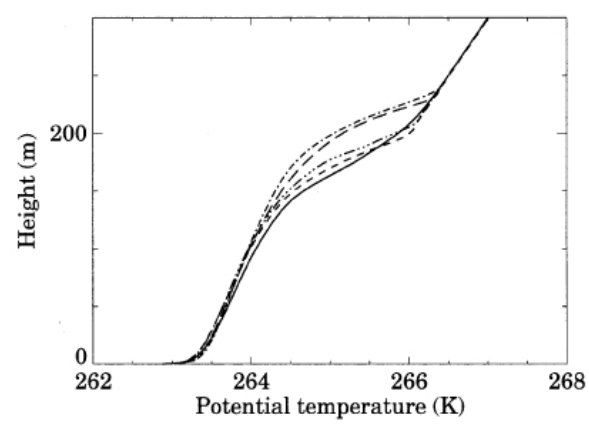

(b) LES Beare et al. (2006)

Figura 2.8: Perfil vertical de temperatura potencial.

Os resultados do modelo LES atual são compatíveis com os modelos LES apresentados no artigo. O modelo LES que mais se aproxima do atual é o NCAR-LES $(-\cdot-)$ visto 


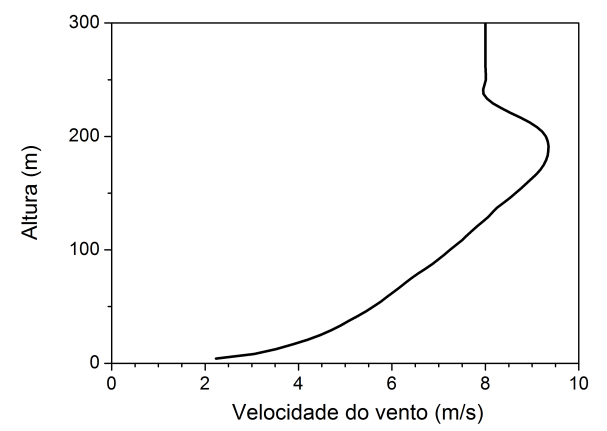

(a) LES atual

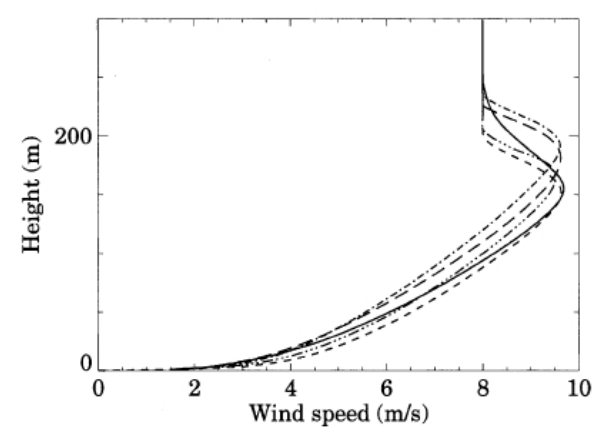

(b) LES Beare et al. (2006)

Figura 2.9: Perfil vertical de velocidade do vento.

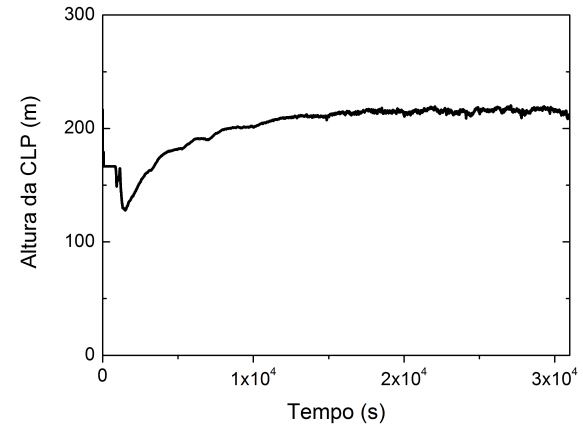

(a) LES atual

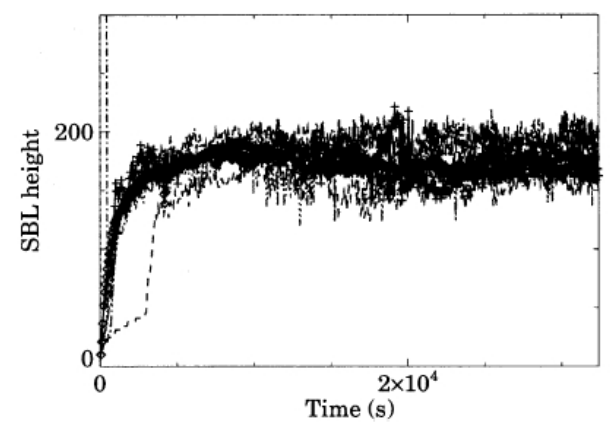

(b) LES Beare et al. (2006)

Figura 2.10: Variação temporal da altura da CLP

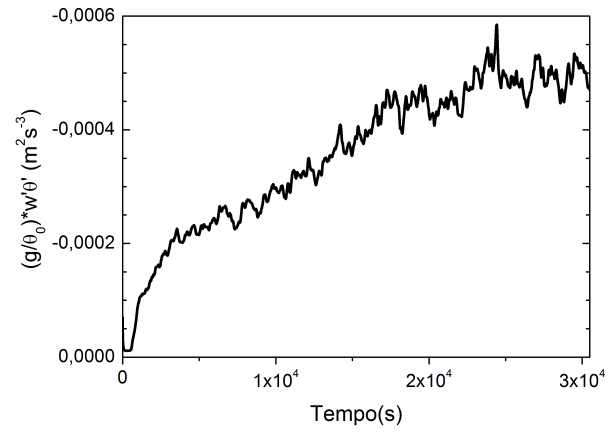

(a) LES atual

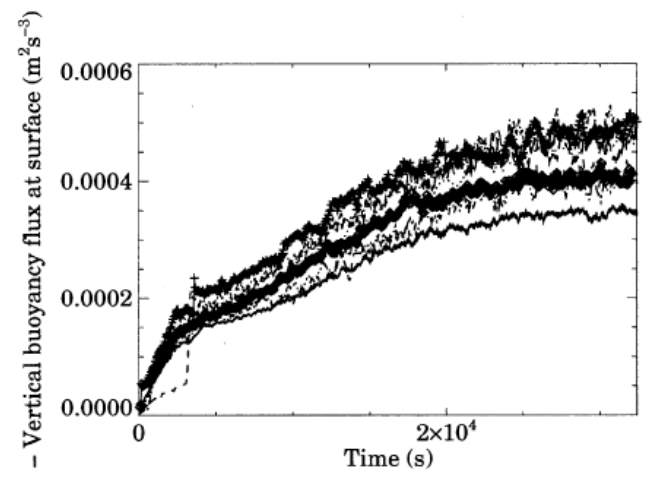

(b) LES Beare et al. (2006)

Figura 2.11: Evolução temporal do fluxo devido à produção térmica em superfície. 


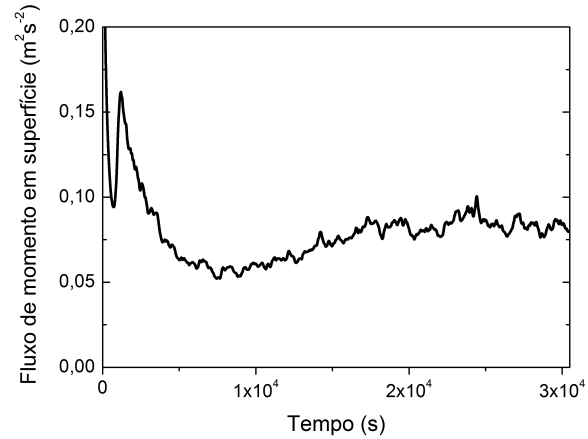

(a) LES atual

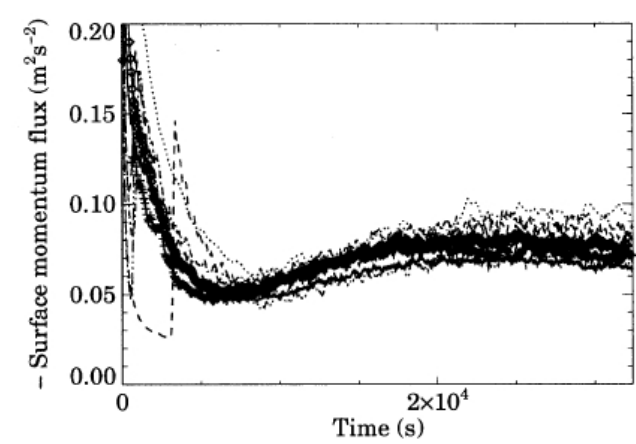

(b) LES Beare et al. (2006)

Figura 2.12: Evolução temporal do fluxo de momento em superfície.

que o modelo atual originalmente é o modelo do NCAR. Como já mencionado, as mudanças efetuadas no código foram somente de implementação, i.e. não alteraram esquemas numéricos ou ainda discretizações ou as parametrizações de subgrade, mas sim acrescentaram estatísticas, e.g. momentos estatísticos até a terceira ordem, além do balanço de ECT, para as escalas resolvida e subgrade.

A figura 2.8 indica a estabilidade da camada limite, visto que a temperatura potencial aumenta com a altura. O perfil vertical do vento é apresentado na figura 2.9. Analisando a altura do JBN, observa-se que existe dispersão entre os modelos; entretanto o modelo LES atual concorda com o NCAR-LES. Segundo Holtslag e Nieuwstadt (1986), as diferenças na intensidade e magnitude do jato devem-se basicamente à intermitência no topo da CLE. Outros fatores responsáveis podem ser as forçantes de superfície, ver figuras 2.11 e 2.12, visto que as diferenças são da ordem de $30 \%$ para o caso da produção térmica (Beare et al., 2006). Essas diferenças podem ser responsáveis por alterar a intensidade da turbulência no topo da camada limite, principalmente no caso estável, daí a necessidade da boa predição dos parâmetros de superfície. Os resultados encontrados pelo modelo atual também foram compatíveis para a altura da CLE, (figura 2.10). A boa representação da altura da CLE é um fator importante que será explorado nos resultados. 
Capítulo 3

\section{Resultados}

\subsection{Descrição dos experimentos numéricos}

Admitindo-se com base nos resultados do capítulo anterior que o modelo LES é capaz de reproduzir de maneira satisfatória os regimes turbulentos convectivo e estável, incluindo o período de transição, foram realizadas quatro simulações de um ciclo diurno completo. O objetivo destes experimentos numéricos é analisar os campos tridimensionais de velocidade, temperatura do ar e concentração de monóxido de carbono, bem como os momentos estatísticos e o balanço de energia cinética turbulenta para as diferentes condições do ciclo diurno. Para o período noturno, a altura da CLE e a importância do JBN serão investigados. Os experimentos numéricos utilizam dados de superfície de concentração de $\mathrm{CO}$ e temperatura do ar para a cidade de São Paulo como condição de contorno inferior. Os fluxos de calor sensível e CO são determinados em função dos respectivos valores de superfície e da TSMO a cada passo de tempo.

Não foram incorporadas simulações do vapor de água ao modelo LES neste estudo. Isso deve-se basicamente ao fato de o calor latente ser muito menor do que o sensível em regiões urbanas, (Ferreira, 2010). Como detalhado a seguir, os experimentos são referentes ao inverno, estação mais seca do ano, (Barbaro et al., 2010). Ainda, como não existe uma equação própria de conservação de um poluente, utilizaram-se as equações já implementadas referentes ao vapor de água.

\subsubsection{Conjunto de dados utilizado}

Os valores de temperatura do ar foram tomados à plataforma micrometeorológica localizada no topo do prédio do Instituto de Astronomia, Geofísica e Ciências Atmosféricas 
(IAG) da Universidade de São Paulo (USP), na porção oeste da cidade de São Paulo, a 744 metros do nível do mar, $\left(23^{\circ} 33^{\prime} 35^{\prime \prime} \mathrm{S} ; 46^{\circ} 43^{\prime} 55^{\prime \prime} \mathrm{W}\right)$. As observações foram amostradas com frequência de $0,2 \mathrm{~Hz}$ e armazenadas em médias de 5 minutos durante o período de 1997 a 2006. Simultaneamente e com a mesma frequência, foram medidos (i) radiação solar (componentes difusa, direta e global) e (ii) umidade relativa do ar. A seguir são apresentadas as médias mensais para temperatura do ar e umidade relativa (1997-2006):

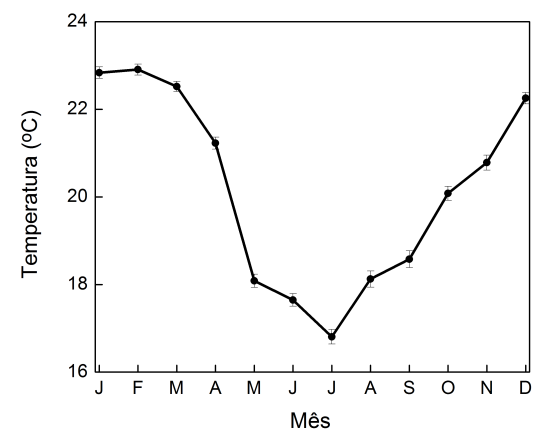

(a) Temperatura

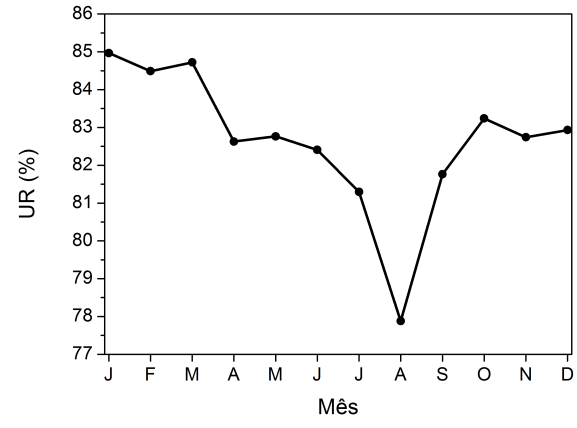

(b) Umidade relativa

Figura 3.1: Médias mensais para temperatura do ar e umidade relativa observadas na plataforma micrometeorológica do IAG-USP.

Os valores da temperatura média mensal variam entre $17^{\circ} \mathrm{C}$ em julho e $23^{\circ} \mathrm{C}$ em fevereiro. O valor da umidade relativa do ar média mensal atinge um mínimo de cerca de $78 \%$ em Agosto e um máximo de $85 \%$ em janeiro.

Os valores de concentração de $\mathrm{CO}$ e velocidade do vento utilizados neste trabalho são horários e correspondem a valores médios mensais observados na estação de monitoramento automático Lapa da Companhia de Tecnologia de Saneamento Ambiental (CETESB) também localizada na porção oeste da cidade de São Paulo a 720 metros do nível

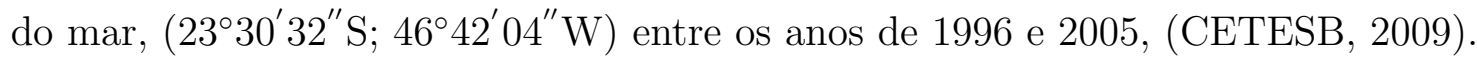

A RMSP é caracterizada por ventos fracos durante todo o ano, figura 3.2(b), principalmente nos meses de inverno. Observa-se pelas figuras 3.1(a) e 3.2(a) que os meses de inverno apresentam menores temperaturas e concentrações de CO mais elevadas. No mês de junho, a RMSP apresenta as maiores concentrações de CO, (2,45ppm na média). O mínimo mensal foi observado em fevereiro, $(1,56 \mathrm{ppm})$.

Este trabalho utilizará dados do mês de junho como referência para realizar os ex- 


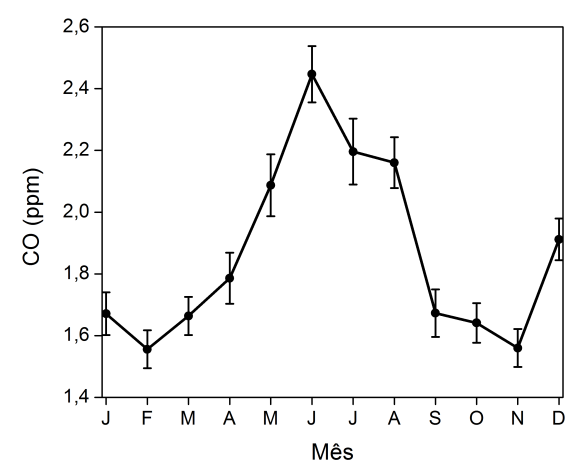

(a) Monóxido de carbono

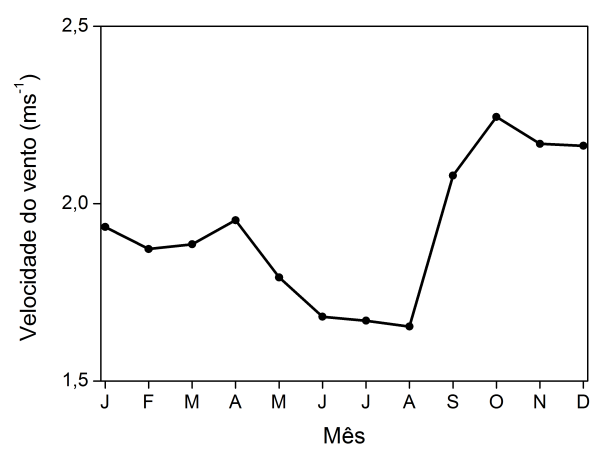

(b) Vento em 10 metros

Figura 3.2: Médias mensais para CO e vento observados na estação Lapa da CETESB entre 1996 e 2005.

perimentos com o LES. A escolha justifica-se no fato de este mês ser representativo das condições de inverno na RMSP.

Com o objetivo de investigar a influência dos dias de céu claro na altura da CLP bem como na estimativa dos fluxos turbulentos em superfície, os quatro experimentos numéricos foram divididos em dois grupos ${ }^{1}$ :

- 2 experimentos para o caso médio de junho $(\mathbf{A}$ e $\mathbf{B})$;

- 2 experimentos para os dias de céu claro de junho (C e D);

Os dias de céu claro para o período estudado foram escolhidos baseado na metodologia encontrada em Malek (1997); Long e Turner (2008); Barbaro et al. (2010). Deve ser enfatizado que quando comparam-se os dias de céu claro com o caso médio, o efeito das nuvens não é totalmente removido, visto que os dias parcialmente nublados e de céu claro estão inclusos na média para o caso médio. Infelizmente, não é possível remover completamente o efeito das nuvens, visto que não existe informação independente da cobertura de nuvens.

Seguindo a variação diurna das radiações global e difusa em superfície, é possível, por inspeção visual, identificar dias onde o céu não estava significativamente coberto por

\footnotetext{
${ }^{1}$ Ambos os grupos têm como base as médias horárias de temperatura do ar (1997-2006) e concentração de CO (1996-2005) para o mês de junho.
} 
nuvens. Aqui, dias são considerados de céu claro quando as curvas das variações diurnas de global e difusa são simultaneamente suaves, separam-se no início da manhã e juntam-se somente no final da tarde. Entre 1997 e 2006 foram identificados 138 dias de céu claro satisfazendo as condições descritas acima. Os meses de inverno são responsáveis por mais de $62 \%$ dos dias de céu claro para a RMSP, (Barbaro et al., 2010). Como esperado, os dias de céu claro são mais intensos no período mais seco do ano.

As evoluções diurnas, para o caso médio e somente dias claros, de temperatura do ar e concentração de CO durante o mês de junho são apresentadas na figura 3.3:

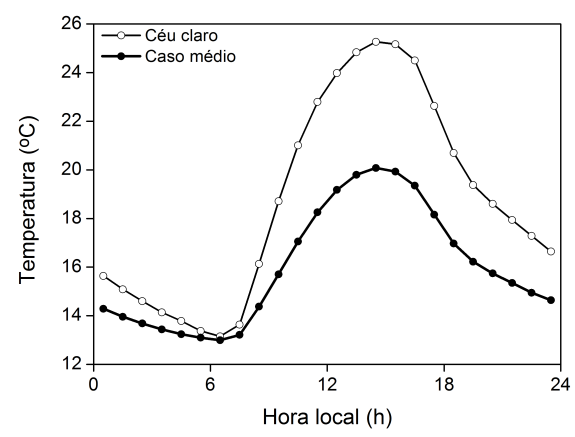

(a) Temperatura do ar

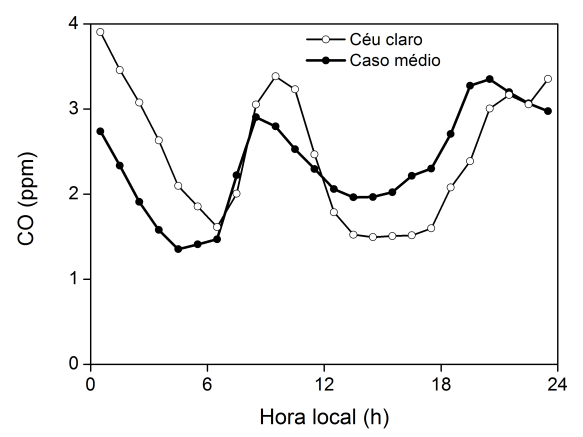

(b) Concentração de CO

Figura 3.3: Evoluções horárias para o mês de junho da temperatura do ar e CO para o caso médio e somente dias de céu claro.

Quando somente os dias de céu claro são considerados, observa-se uma maior amplitude nas evoluções temporais de temperatura do ar e CO, pois as nuvens diminuem a amplitude da radiação solar. Para a evolução de temperatura, as principais diferenças estão concentradas durante o período convectivo. Observam-se dois máximos na evolução diurna do CO. O pico da manhã ocorre às 08:30HL (2.90ppm) e 09:30HL (3.39ppm) (HL - hora local) para o caso médio e céu claro. O segundo pico, da mesma maneira, ocorre às 20:30HL (3.35ppm) e 00:30HL (3.90ppm). Os picos estão associados principalmente com a evolução diurna do tráfego de veículos na RMSP, visto que $98 \%$ de todo o CO emitido é devido à combustão incompleta, proveniente da frota veicular. As diferenças associadas ao ciclo diurno do CO devem-se basicamente a dois fatores. Durante o dia, a concentração de CO é predominantemente menor para as condições de céu claro. Isso deve-se ao fato de a CLP ser mais desenvolvida nesse caso, visto que há mais fluxo de calor sensível pois a variação de temperatura é mais intensa. A mistura turbulenta promovida pela CLP é 
responsável pela diminuição da concentração de CO em superfície. Já durante a noite, a concentração de CO é maior devido à inversão térmica de superfície, intensa nos dias de céu claro, suprimir o desenvolvimento da turbulência fazendo com que os níveis de concentração de CO se elevem.

As observações de CO para a RMSP são similares às discutidas em Bogo et al. (2001) para a cidade de Buenos Aires, considerando as variabilidades intrínsicas. Comrie e Diem (1999) fazem a análise do CO em superfície considerando a emissão para cada dia da semana. Como esperado, nos finais de semana não se observam os dois máximos diurnos, visto que o padrão de deslocamento dos carros casa-trabalho não existe. Os valores de CO observados em Comrie e Diem (1999), para Phoenix-Arizona, são maiores do que os da RMSP. Ambos os estudos mostram, comparando o ciclo de automóveis com o do monóxido de carbono, que praticamente todo o $\mathrm{CO}$ emitido é devido à combustão incompleta do carbono, efeito esse encontrado nos veículos automotores.

\subsubsection{Caracterização dos experimentos numéricos}

Os quatro experimentos numéricos de um ciclo diurno utilizaram como forçante externa as observações de temperatura e CO apresentadas na figura 3.3,(experimentos A e B - caso médio; C e D - dias de céu claro). Foram realizadas dois experimentos para cada condição, pois duas forçantes geostróficas foram simuladas $5 \mathrm{~ms}^{-1}$ e $10 \mathrm{~ms}^{-1}$ sempre na componente zonal, com o intuito de verificar qual se aproximava mais dos dados observados de vento. Com a alteração na forçante geostrófica, o papel do cisalhamento do vento e do JBN foi investigado. Uma descrição dos experimentos é apresentada na tabela 3.1:

Tabela 3.1: Caracterização dos quatro experimentos numéricos

\begin{tabular}{||c||c|c|c||}
\hline \hline Experimento & Condição atmosférica & Forçante zonal & Forçante meridional \\
\hline A & Caso médio & $U_{g}=5 m s^{-1}$ & $V_{g}=0 m s^{-1}$ \\
\hline B & Caso médio & $U_{g}=10 m s^{-1}$ & $V_{g}=0 m s^{-1}$ \\
\hline $\mathbf{C}$ & Céu claro & $U_{g}=5 m s^{-1}$ & $V_{g}=0 m s^{-1}$ \\
\hline D & Céu claro & $U_{g}=10 m s^{-1}$ & $V_{g}=0 m s^{-1}$ \\
\hline \hline
\end{tabular}

A tabela 3.2 descreve algumas das condições iniciais utilizadas nos experimentos numéricos do tipo "caso médio" e "céu claro". 
Tabela 3.2: Condições iniciais utilizadas para os experimentos numéricos

\begin{tabular}{||c||c|c||}
\hline \hline Experimentos Numéricos & Caso médio & Céu claro \\
\hline Domínio $(\mathbf{x}, \mathbf{y}, \mathbf{z}) \mathbf{( m )}$ & $2000 \times 2000 \times 2000$ & $4000 \times 4000 \times 2500$ \\
\hline Pontos de grade $\mathbf{( x , y , z )}$ & $96 \times 96 \times 96$ & $96 \times 96 \times 192$ \\
\hline Espaçamento $(\mathbf{x}, \mathbf{y}, \mathbf{z}) \mathbf{( m )}$ & $20,8 \times 20,8 \times 20,8$ & $41,6 \times 41,6 \times 13,0$ \\
\hline$\Delta \gamma$ atmosfera livre & $3 K_{k m^{-1}}$ & $3 K_{k m^{-1}}$ \\
\hline$\Delta \theta$ & $6 K$ & $7 K$ \\
\hline Latitude & $-23,34^{\circ}$ & $-23,34^{\circ}$ \\
\hline \hline
\end{tabular}

\section{Experimentos numéricos A e B}

Foram simuladas 24 horas de evolução da CLP, cobrindo as condições convectiva, neutra e estável. Os experimentos A e $\mathbf{B}$ (casos médios) foram realizados utilizando $96^{3}$ pontos de grade igualmente espaçados, distribuídos sobre um domínio de $2 \times 2 \times 2 \mathrm{~km}^{3}$. A superfície foi considerada plana e com ocupação do solo homogênea, caracterizada por um comprimento de rugosidade de $0,1 \mathrm{~m}$, correspondendo à área urbana localizada na cidade de São Paulo $\left(23.34^{\circ} S, 46.44^{\circ} \mathrm{W}\right)$. O parâmetro de Coriolis para essa latitude é $f=-0,57 \times 10^{-4} s^{-1}$. As condições iniciais, nos experimentos $\mathbf{A}$ e $\mathbf{B}$, consistem numa CLP fracamente convectiva, com uma variação de temperatura potencial entre a superfície $(286 K)$ e a camada de mistura $(285 K)$ igual a $1 K$. A camada de inversão está localizada em $500 \mathrm{~m}$, onde ocorre um aumento da temperatura de $6 K$ em oito níveis verticais do modelo. A diferença na concentração de $\mathrm{CO}$ da superfície e da camada de mistura é de 0,1ppm. Acima da camada de mistura, a concentração de $\mathrm{CO}$ diminui 1 ppm nos mesmos seis níveis verticais na camada de inversão. Acima da camada de inversão, o lapse-rate imposto é constante e igual a $3 \mathrm{Kkm}^{-1}$ e a concentração de $\mathrm{CO}$ é mantida constante com a altura, com um valor de 0,4ppm. O perfil inicial de vento foi definido constante para toda a CLP e igual aos valores geostróficos para os experimentos $\mathbf{A}$ e $\mathbf{B}$, figura 3.4.

Para satisfazer a condição de CFL, a qual controla o passo de tempo baseado no espaçamento de grade e velocidade do fluxo, cada experimento de 24 horas da evolução da CLP utiliza diferentes passos no tempo, figura 3.5. Todos os experimentos foram iniciados às 06:30 HL.

Ambos os experimentos foram realizados considerando as evoluções temporais da temperatura do ar e da concentração de CO observadas para o mês de junho na média. As 


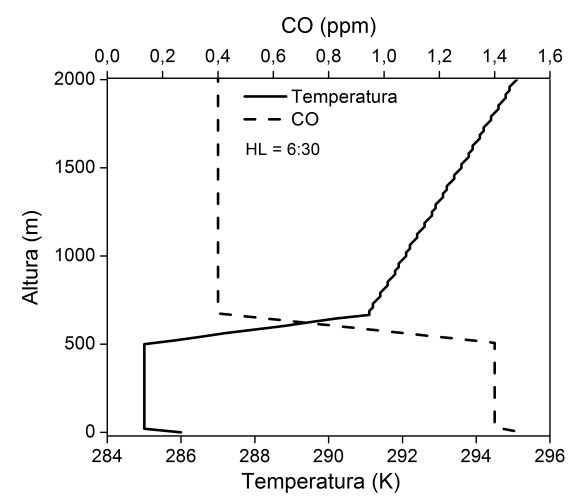

(a) Perfis iniciais de temperatura e CO.

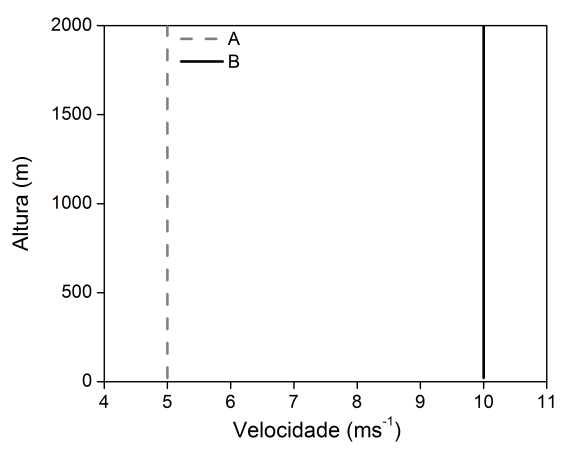

(b) Perfis iniciais de vento.

Figura 3.4: Perfis iniciais dos campos de temperatura, CO e vento para os experimentos $\boldsymbol{A}$ e $\boldsymbol{B}$.

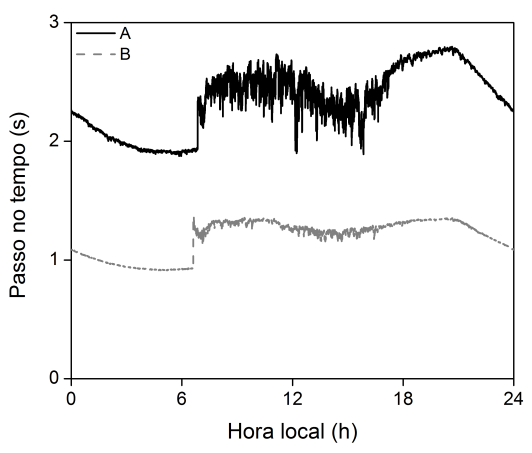

Figura 3.5: Variação do passo de tempo observado para os experimentos $\boldsymbol{A}$ e $\boldsymbol{B}$.

concentrações foram utilizadas como condição de fronteira para o modelo LES. O procedimento de restart foi empregado para que o modelo pudesse acompanhar os ciclos diurnos de temperatura do ar e CO.

Na figura 3.6, a curva contínua (LES) corresponde a valores interpolados linearmente a cada passo de tempo (figura 3.5), entre dois valores horários consecutivos (observações) para as simulações $\mathbf{A}$ e $\mathbf{B}$.

\section{Experimentos numéricos C e D}

Da mesma maneira que para os experimentos $\mathbf{A}$ e $\mathbf{B}$, foram simuladas 24 horas de evolução da CLP, cobrindo as condições convectiva, neutra e estável. Para os experimentos $\mathbf{C}$ e $\mathbf{D}$ (dias de céu claro) utilizou-se 96×96x192 pontos de grade, também igualmente espaçados. 


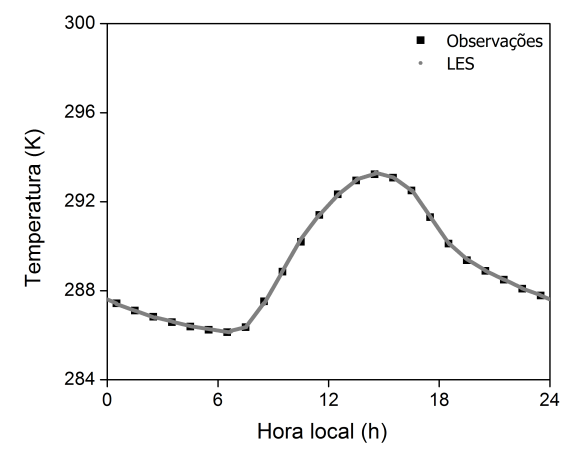

(a) Temperatura.

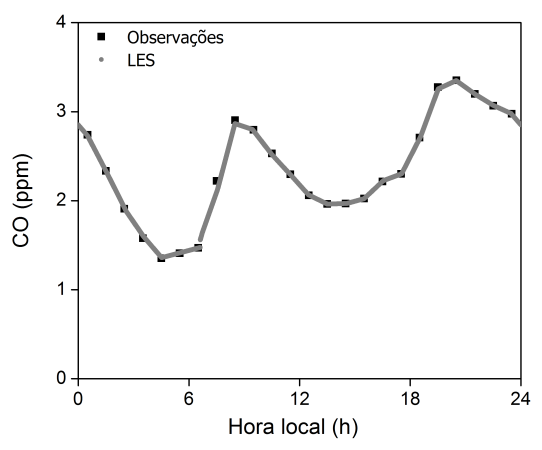

(b) $\mathrm{CO}$

Figura 3.6: Evoluções temporais da temperatura e da concentração de CO usadas como condições de fronteira no modelo LES. As linhas indicam os valores interpolados utilizados a cada passo de tempo. Os pontos são os valores medidos.

Os pontos são distribuídos sobre um domínio de $4 \times 4 \times 2,5 \mathrm{~km}^{3}$. A alteração do domínio deve-se ao fato de a temperatura em superfície ser maior do que o valor de temperatura no último nível do modelo no final do período convectivo. Este efeito gera perturbação numérica no modelo, visto que o LES entende que existe uma camada instável entre a superfície e o final do modelo, gerando assim instabilidades por todo o domínio. Outro fator importante é a altura da CLP que se aproximava da fronteira antiga. Por isso o domínio horizontal também foi ampliado. A superfície foi considerada com as mesmas características dos experimentos $\mathbf{A}$ e $\mathbf{B}$ (comprimento de rugosidade $0,1 \mathrm{~m}$ ). O parâmetro de Coriolis também foi mantido o mesmo. As condições iniciais, nos experimentos $\mathbf{C}$ e $\mathbf{D}$, consistem numa CLP fracamente convectiva, com uma variação de temperatura potencial entre a superfície $(286,3 K)$ e a camada de mistura $(286 K)$ igual a $0,3 K$. A camada de inversão está localizada em $200 \mathrm{~m}$, onde ocorre um aumento da temperatura de $7 \mathrm{~K}$ em oito níveis verticais do modelo. A diferença na concentração de CO da superfície e da camada de mistura é de 0,2ppm. Acima da camada de mistura, a concentração de CO diminui 1ppm nos mesmos seis níveis verticais na camada de inversão. Acima da camada de inversão, o lapse-rate imposto é constante e igual a $3 \mathrm{Kkm}^{-1}$ e a concentração de CO é mantida constante com a altura, com um valor de 0,4ppm. O perfil inicial de vento foi definido constante para toda a CLP e igual aos valores geostróficos para os experimentos C e D, figura 3.7. 


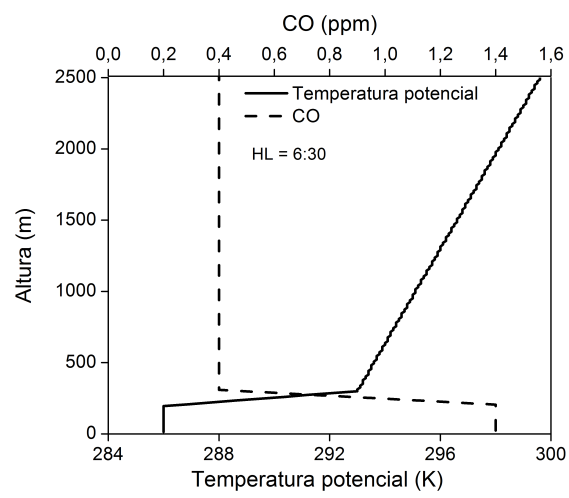

(a) Perfis iniciais de temperatura e CO.

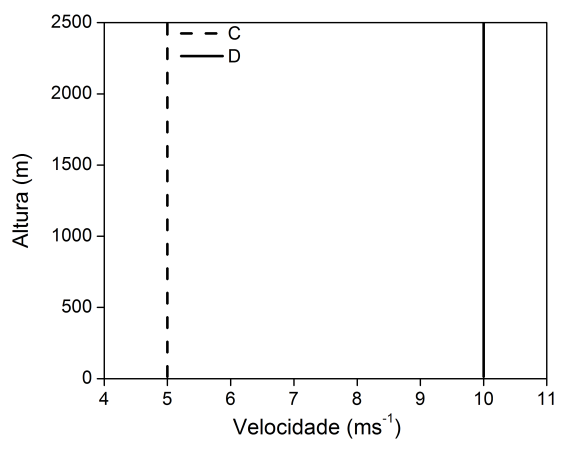

(b) Perfis de vento para experimentos $\mathrm{C}$ e D.

Figura 3.7: Perfis iniciais dos campos de temperatura, $C O$ e vento para experimentos $\boldsymbol{C}$ e D.

O passo de tempo para os experimentos C e D é apresentado na figura 3.8.

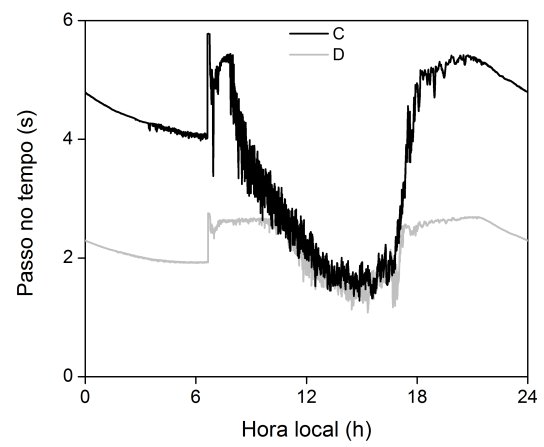

Figura 3.8: Variação do passo de tempo observado para os experimentos $C$ e D.

Ambos os experimentos foram realizadas considerando as evoluções temporais da temperatura potencial e da concentração de CO observadas para os dias claros em junho, figura 3.9. As concentrações foram utilizadas como condição de fronteira para o modelo LES.

\section{Evolução temporal da velocidade do vento}

O intuito de efetuar experimentos com diferentes condições de fronteira, i.e. céu claro e/ou vento mais intenso é tentar modelar as principais características da CLP para o mês de junho e identificar o impacto que a condição de céu claro e a intensidade do vento têm 


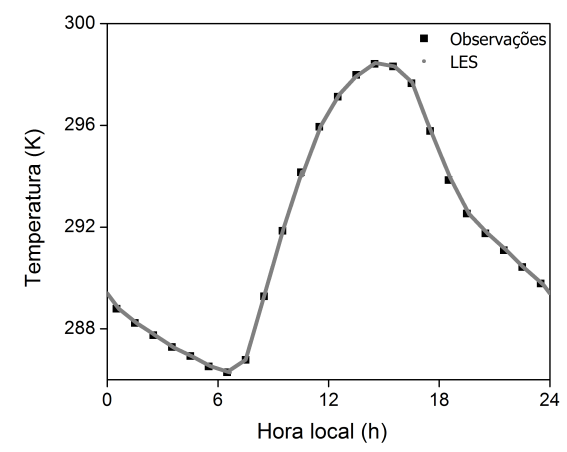

(a) Temperatura.

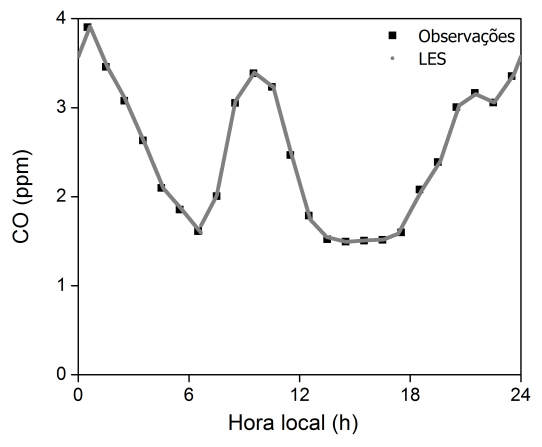

(b) $\mathrm{CO}$

Figura 3.9: Evoluções temporais da temperatura e da concentração de CO usadas como condições de fronteira no modelo LES. As linhas indicam os valores interpolados utilizados a cada passo de tempo. Os pontos são os valores medidos para os dias claros.

nas propriedades da CLP. Essa alteração, modelada no LES, pode ser uma informação importante na estimativa de fluxos turbulentos em superfície, na predição da altura da CLP ou na intensidade da inversão térmica ou ainda na contribuição do JBN.

Os perfis de vento observados são apresentados a seguir, figura 3.10. Esses perfis serão comparados com os resultados dos experimentos do modelo LES.

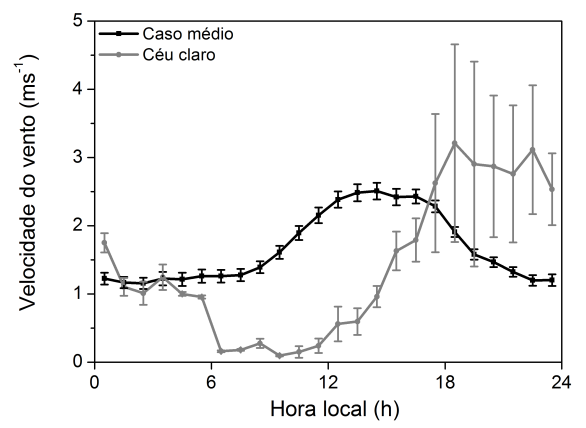

Figura 3.10: Evolução temporal da velocidade do vento para todos os experimentos.

Os resultados apresentados nas próximas seções são baseadas nas estatísticas dos campos tridimensionais gerados pelo modelo LES (a cada 100 passos de tempo). Cada conjunto de saídas é separado por 1-5 minutos (na média). As propriedades estatísticas são estimadas após a CLP ter atingido o estado de quasi-equilíbrio. De acordo com a figura 3.18 todos os experimentos atingem o estado de quasi-equilíbrio após aproximadamente 
1 hora. Devido à quantidade de informação, os experimentos $\mathbf{A}$ e $\mathbf{B}$ serão tomadas como base, e serão mais bem explorados. Os experimentos $\mathbf{C}$ e $\mathbf{D}$ serão utilizados para o estudo do efeito das condições de céu claro nos fluxos turbulentos de superfície, na altura da CLP e no balanço de ECT.

\subsection{Fluxos turbulentos em superfície}

A figura 3.11 apresenta a evolução diurna da velocidade do vento, para o caso médio e dias de céu claro. O intuido é o de verificar qual dos experimentos apresenta valores de velocidade de vento mais realísticos durante o inverno na cidade de São Paulo. Para a figura 3.11(a), o experimento A apresentou os resultados mais próximos aos observados. Isso indica que a forçante externa de $5 \mathrm{~ms}^{-1}$ é mais realística e representa melhor as condições médias de vento durante o mês de junho. Para o experimento $\mathbf{B}$, o vento predito é o dobro das observações para aproximadamente todo o período. No caso de dias de céu claro, observa-se que o vento é praticamente zero entre o início da manhã e o meio do dia, porém o modelo LES não reproduz esse comportamento. $\mathrm{O}$ experimento $\mathbf{C}$ apresenta os melhores resultados para as estimativas do período diurno. O experimento D é o que mais bem representa o padrão esperado para a primeira metade do período estável. Entretanto, para o restante do período, o experimento $\mathbf{C}$ apresenta novamente os melhores resultados.

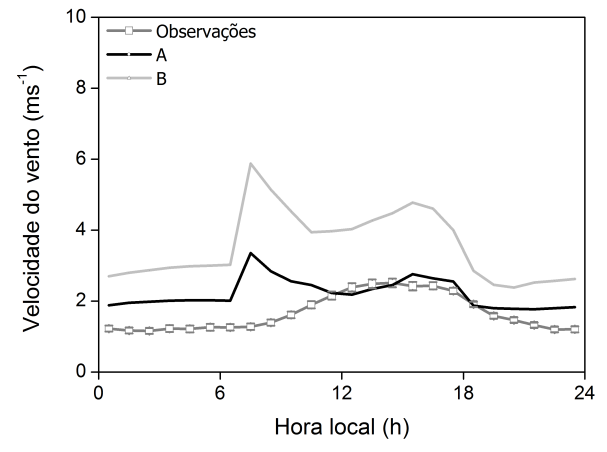

(a) Todos os dias

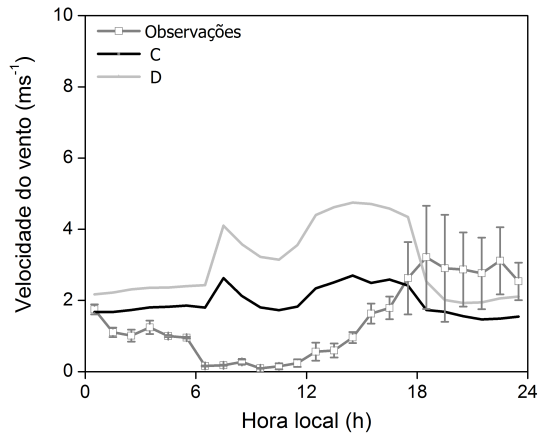

(b) Céu claro

Figura 3.11: Evoluções temporais da velocidade do vento para o caso médio (a) e somente céu claro (b). 
Curiosamente, existe um máximo local no final do período convectivo, em torno do meio da tarde, para todos os experimentos. Esse máximo local pode estar associado ao início da oscilação inercial, quando a turbulência nas porções superiores da camada de mistura desaparece.

O modelo LES estima os fluxos turbulentos em superfície utilizando a TSMO com as informações de vento, temperatura do ar e concentração de CO. A TSMO é válida para toda a CLS.

A figura 3.12 descreve o fluxo de calor sensível em superfície. Os valores modelados pelo LES foram comparados com observações referentes ao mês de junho de 2009 tomadas à plataforma micrometeorológica do IAG-USP utilizando um anemômetro sônico. Obviamente espera-se encontrar um padrão e não uma reprodução idêntica das observações. $\mathrm{O}$ resultado indica que o experimento $\mathbf{A}$ foi o que melhor representou as observações. Esse resultado explica-se porque as observações são representativas de condições médias para o mês de junho de 2009. Da figura 3.12 observa-se também que as maiores disparidades entre os experimentos ocorrem no período noturno.

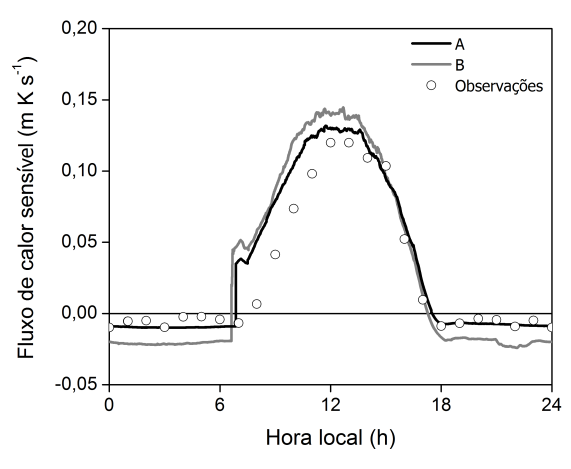

(a) Todos os dias

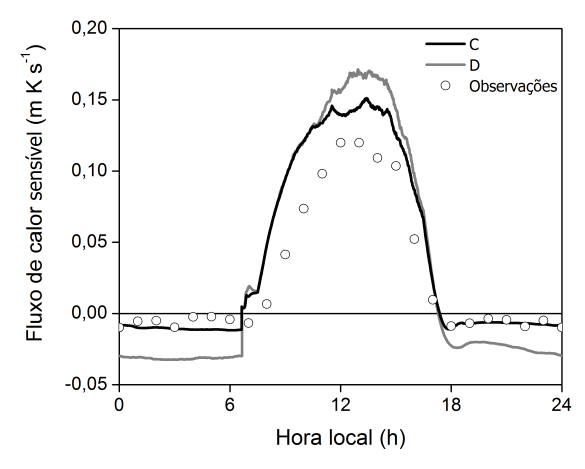

(b) Céu claro

Figura 3.12: Evolução temporal do fluxo de calor sensivel em superfície.

Comparando as figuras 3.12(a) e 3.12(b) observa-se que a condição de céu claro induz a fluxos de calor sensível mais intensos no período noturno. Essa condição pode suprimir a turbulência, visto que a estratificação térmica trabalha em direção oposta a produção mecânica. Essa característica pode representar uma diminuição na altura da CLE. Os fluxos no período convectivo também são maiores na condição de céu claro com intensificação conforme a forçante geostrófica aplicada. 
As evoluções diurnas do fluxo de CO simulado pelo LES em superfície apresentam o caráter bimodal esperado, figura 3.13. Para comparação, a evolução diurna hipotética do fluxo de CO estimado para a cidade de São Paulo do inventário de emissões veiculares é também apresentado (Codato, 2008).

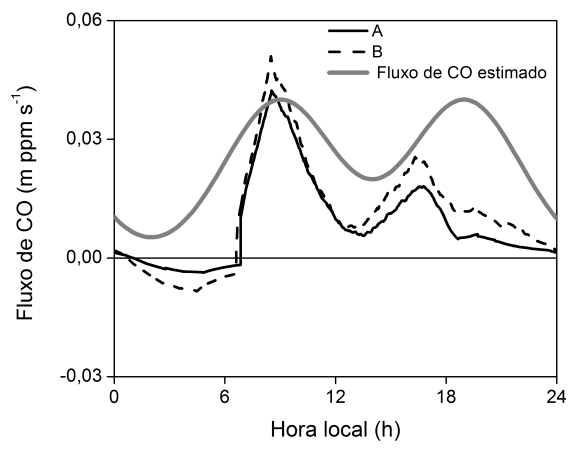

(a) Todos os dias

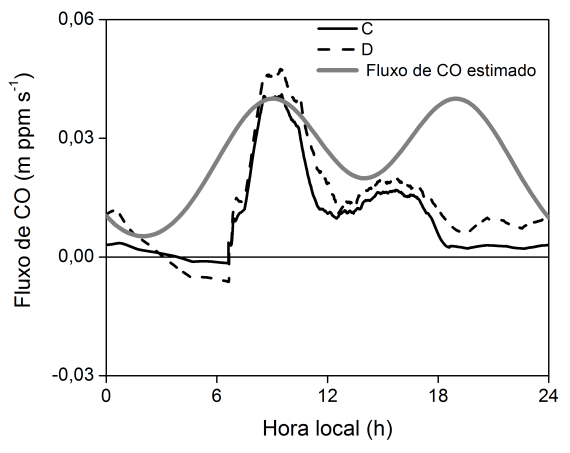

(b) Céu claro

Figura 3.13: Evolução temporal do fluxo de monóxido de carbono em superfície.

Durante o dia, os fluxos simulados de $\mathrm{CO}$ em ambos os casos apresentam valores compatíveis com o inventário. Observa-se que o fluxo de CO torna-se negativo para o caso médio (em torno de meia-noite) e para o caso de céu claro (em torno de três horas da manhã). Como um fluxo negativo de CO não é fisicamente possível, o padrão encontrado justifica-se pelo fato de no modelo LES o CO ser tratado com a TSMO como sendo vapor de água, i.e. as funções universais para o gradiente de CO são as mesmas que para o vapor de água. Essa hipótese não funciona para o período noturno, quando o gradiente de $\mathrm{CO}$ torna-se positivo, gerando fluxos negativos. É importante observar que, desconsiderando o horário do máximo, o modelo é capaz de simular a amplitude dos fluxos de superfície.

Durante a manhã, o fluxo de CO é comparável ao estimado baseado no inventário de carros em São Paulo. Entretanto, o segundo pico de CO está deslocado. Essa característica está presente em todos os experimentos e pode estar relacionada ao fato de que a convecção torna-se menos intensa que outros efeitos não-locais, e.g. advecção horizontal de ar limpo associada à penetração da brisa marítima em São Paulo. Observa-se porém que o inventário apresenta dois máximos idênticos de CO. Considerando o fato de que segundo Comrie e Diem (1999) o pico de CO da manhã é mais rápido, se comparado ao da tarde, o fluxo de CO deve ser mais intenso no período da manhã e menos intenso, 
porém mais espalhado, no período vespertino. Observa-se ainda que durante a madrugada a concentração de CO tende a diminuir muito devido à frota automotiva. Daí, o pico matutino deve ser mais intenso devido à grande variabilidade de CO num curto espaço de tempo. Para o último pico, a concentração do início da tarde é mais intensa, fazendo com que a variabilidade do $\mathrm{CO}$ seja menor.

\subsection{Evolução diurna da CLP}

A figura 3.14 descreve a evolução diurna da altura da CLP para as 24 horas de cada experimento. A altura foi estimada como sendo o nível do máximo gradiente vertical de temperatura potencial, ver figura 3.16.

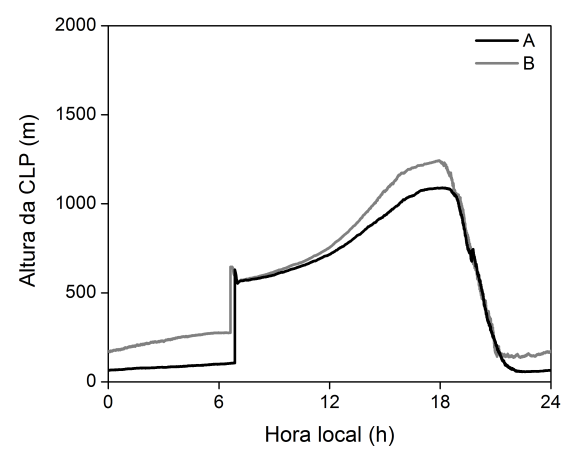

(a) Todos os dias

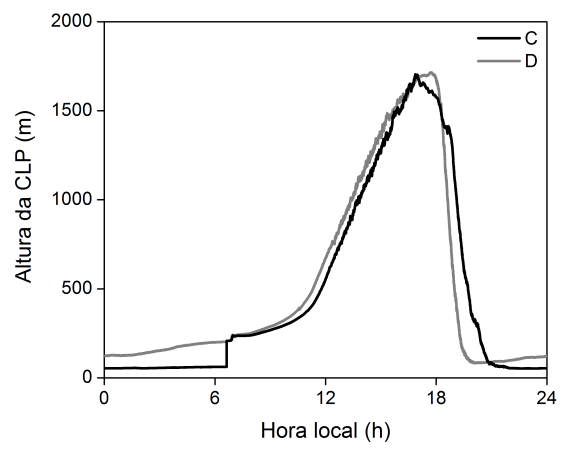

(b) Céu claro

Figura 3.14: Evolução diurna da altura da CLP.

A altura da camada é maior para os experimentos com vento mais intenso, $\mathbf{B}$ e $\mathbf{D}$. Para o experimento B, a CLP atinge $1240 \mathrm{~m}$ para o período convectivo e $275 \mathrm{~m}$ para o período estável. Para A, observa-se que a CLP atinge $1088 m$ no fim do período convectivo e $100 m$ no final do regime estável. Para os casos $\mathbf{C}$ e $\mathbf{D}$, observa-se que praticamente não há diferença no máximo da altura da CLP no regime convectivo, pois a produção térmica supera em muito a produção mecânica anulando a forçante mais intensa do caso D. No regime estável também observam-se grandes variabilidades, $203 m$ e $62 m$ para casos $\mathbf{C}$ e D respectivamente. Para os casos de céu claro, devido ao fluxo de calor sensível ser mais importante, o colapso da camada dá-se mais rapidamente, visto que a destruição térmica para o experimento $\mathbf{D}$ é mais intensa. 
Tendo em vista que não existem estimativas diretas da altura da CLP para a RMSP, optou-se por utilizar como referência a evolução diurna da profundidade da camada de aerossol determinada por meio do sitema LIDAR do IPEN, localizado no campus da USP. A análise dos perfis verticais do coeficiente de retroespalhamento do aerossol pode ser utilizado para estimar a altura da CLP (Landulfo et al., 2007, 2010).

A figura 3.15 é um exemplo de evolução da CLP para o dia 01/07/2010. Os máximos e mínimos são compatíveis com os experimentos realizados neste trabalho. As medições da altura da camada de aerossóis foram das 9:51 às 21:49 horas. A evolução diurna da CLP estimada pelo LIDAR indica valores de altura iguais a $1200 \mathrm{~m}$ (durante o dia) e $250 \mathrm{~m}$ (durante a noite), que concordam com a evolução diurna simulada pelo modelo LES para São Paulo.

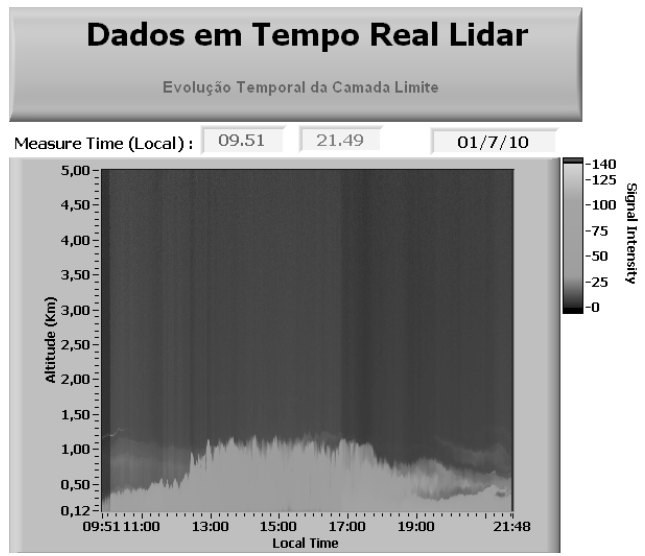

Figura 3.15: Evolução temporal da CLP estimada pelo LIDAR. Imagem cedida pelo Dr. Eduardo Landulfo, (comunicação pessoal).

Estimativas realizadas por Landulfo et al. (2010) para a RMSP no período de junhojulho indicam que a altura da CLP apresenta máximos da ordem de 1000 - 2300 metros e mínimos da ordem de 50 - 300 metros. Todos os resultados indicam que o modelo LES é capaz de reproduzir o comportamento médio e fornecer estimativas confiáveis da altura da CLP para os períodos convectivo e estável.

A figura 3.16 exibe a variação da temperatura potencial com a altura para três períodos do dia, convectivo, neutro e estável. O modelo LES conseguiu reproduzir os padrões esperados em todas as situações. Isso é um indicativo de que a altura da CLP está bem estimada, visto que esta é determinada baseada nestes perfis. Observa-se para o período convectivo a camada limite superficial até aproximadamente 80 metros e uma camada 
de mistura bem desenvolvida, própria desta situação. Para o instante que a CLP está neutra, observa-se o crescimento da camada, em comparação à situação convectiva. Após o colapso da CLP no final do dia e o resfriamento da superfície, a CLE desenvolve-se como esperado. A temperatura potencial aumenta com a altura em toda a CLE.

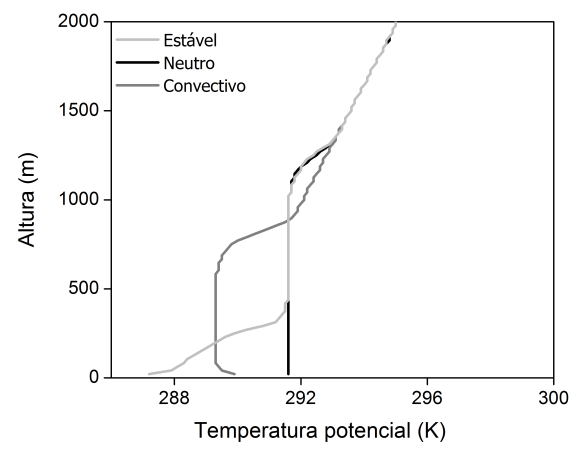

Figura 3.16: Evolução diurna da temperatura potencial para o experimento $\boldsymbol{B}$.

O comprimento de Obukhov (L) é uma grandeza importante na determinação da natureza da turbulência. Ele pode ser avaliado principalmente nos períodos convectivo e estável e é um indicativo da importância da produção mecânica no balanço de ECT, visto que é proporcional à fração das produções mecânica e térmica.

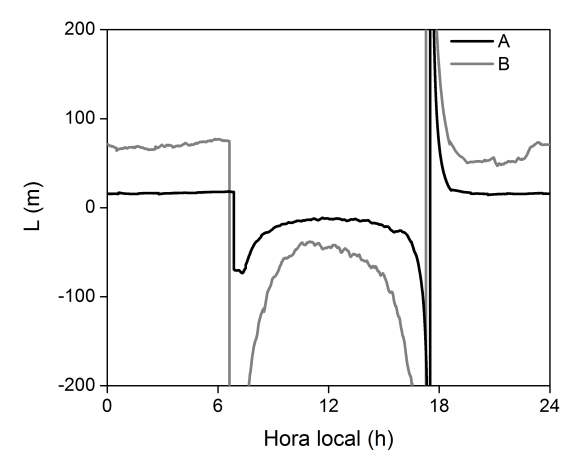

(a) Todos os dias

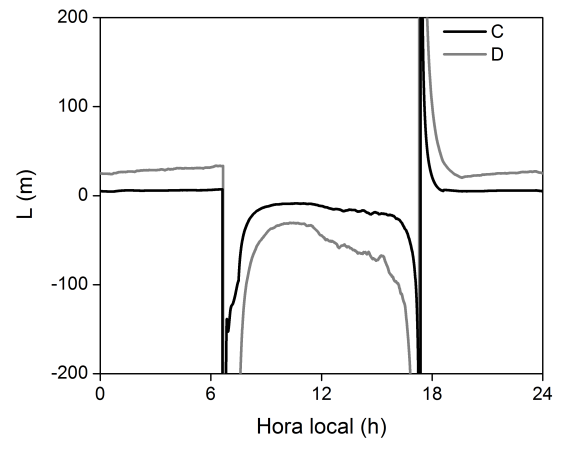

(b) Céu claro

Figura 3.17: Evolução temporal do comprimento de Obukhov.

Durante o período noturno, uma diferença relativa mais pronunciada pode ser observada. Por exemplo, o experimento $\mathbf{B}$ apresenta valores 2 ou 3 vezes maiores que o experimento A. Esse padrão pode estar relacionado ao fato de a produção mecânica ser 
mais intensa no caso da forçante geostrófica maior. Para os casos de céu claro o padrão se repete mais moderadamente.

Observa-se que durante os períodos de transição convectivo/estável/convectivo $L$ tende rapidamente a infinito. Nos experimentos com vento mais fracos, $\mathbf{A}$ e $\mathbf{C}$, o comprimento de Obukhov é, em módulo, menos intenso se comparado com os experimentos para forçante geostrófica intensa. Como nos experimentos $\mathbf{A}$ e $\mathbf{C}$ a forçante mecânica é mais fraca, o parâmetro é importante somente nos primeiros metros. Na transição, camada neutra, não há produção nem destruição térmica, portanto, toda a turbulência é gerada pela forçante mecânica, daí $L$ tende, em módulo, para infinito. Para o período noturno, observa-se a importância da produção mecânica, visto que a contribuição térmica é agora no sentido de destruir a turbulência. O sinal negativo indica uma CLP convectiva, se $L$ for positivo, a CLP é considerada estável.

A evolução diurna da ECT média na CLP (figura 3.18) mostra o padrão esperado com um máximo no final do período convectivo e um mínimo durante o período noturno (estável). Observa-se um máximo local por volta das 22 horas para o caso B, onde o vento geostrófico é mais intenso. Esse máximo pode estar associado ao início da formação de um jato de baixos níveis significativo para esse experimento. O mesmo máximo não é observado para o caso de céu claro. A CLP menos desenvolvida apresentada nos casos $\mathbf{C}$ e $\mathbf{D}$ pode indicar uma supressão térmica mais forte que nos casos $\mathbf{A}$ e $\mathbf{B}$. Observa-se pela figura 3.12 que o padrão de nuvens reduz essa contribuição. Considerando essas propriedades, a CLE não se desenvolve de maneira muito significativa principalmente no caso $\mathbf{C}$, visto que o a queda muito acentuada de temperatura induz um fluxo de calor sensível intenso, suprimindo a turbulência gerada mecanicamente.

\subsection{Balanço de ECT na CLP}

Nesta seção, o balanço de ECT na CLP será investigado durante os períodos convectivo, neutro e estável. Os balanços foram analisados para todas as componentes da equação 1.1. Essas componentes foram implementadas no modelo LES para as escalas resolvida e subgrade. Os horários escolhidos para representar essas condições são baseados no máximo do fluxo de calor sensível em superfície (convectivo), produção térmica tendendo a zero (neutro) além do início e final do regime estável para verificar os impactos que a 


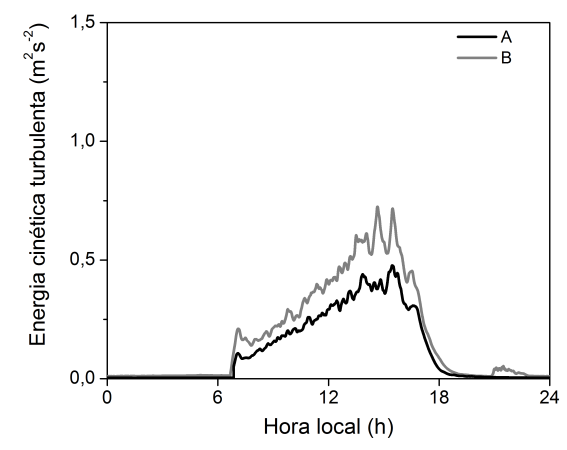

(a) Todos os dias

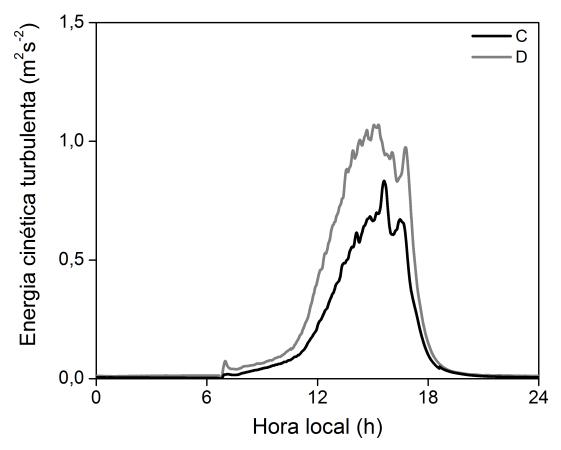

(b) Céu claro

Figura 3.18: Evolução temporal da ECT média na CLP.

estratificação térmica e a intensificação do perfil de velocidade apresentam.

A escala de subgrade é particularmente importante na determinação das componentes do balanço de ECT, basicamente na interação superfície-atmosfera como observa-se na figura 3.19 .

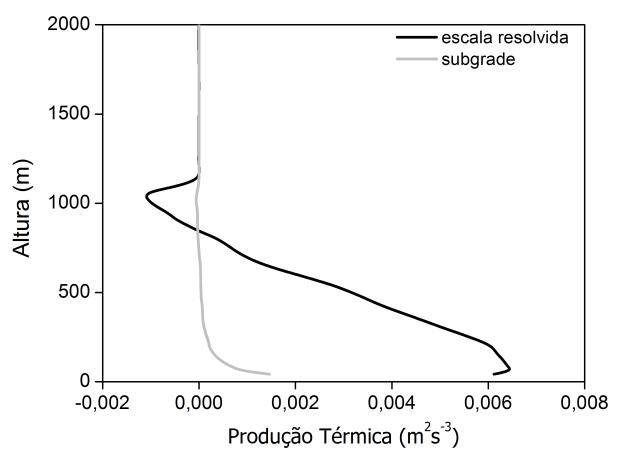

Figura 3.19: Produção térmica - Escalas resolvida e subgrade. Simulação convectiva de Moeng e Sullivan (1994)

A figura 3.19 exemplifica a importância da subgrade nos modelos do tipo LES. Daí a necessidade do desenvolvimento de novas parametrizações para a melhoria destas estimativas e por conseguinte uma melhor explicação dos fenômenos de superfície, (Sullivan et al., 1994; Ding et al., 2001; Iizuka e Kondo, 2004).

As distribuições verticais das componentes da equação da ECT representativas do período convectivo estão indicadas na figura 3.20. Estas figuras correspondem a evolução 
da CLP no horário de fluxo de calor sensível em superfície mais intenso, 13:30HL, na condição de céu claro, onde o fluxo de calor sensível é mais intenso se comparado à condição para o caso médio.

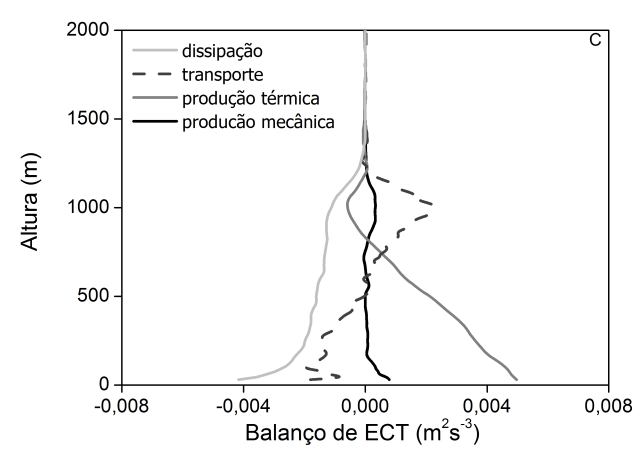

(a) Experimento $\mathrm{C}$

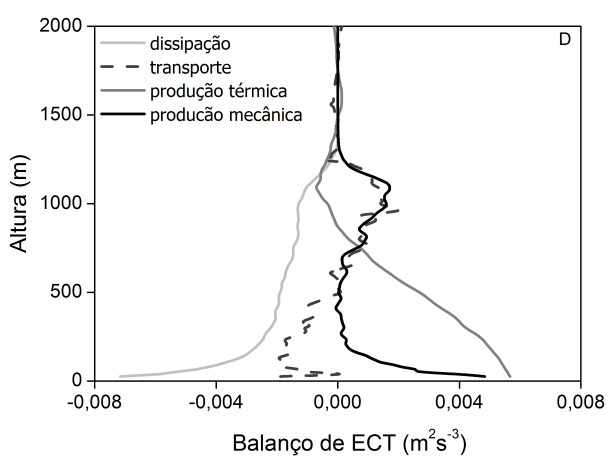

(b) Experimento D

Figura 3.20: Distribuição vertical das componentes do balanço de ECT para CLP convectiva (13:30HL)- céu claro

De acordo com os resultados, a produção térmica varia de maneira praticamente linear com a altura alcançando seu mínimo no topo da CLP. Observa-se que a produção mecânica varia em função da intensidade da forçante geostrófica. As principais variações estão na CLS e ainda no topo da camada. O aumento da produção mecânica a partir do meio da CLP, caso $\mathbf{D}$, indica que há cisalhamento vertical da velocidade no topo da camada. O cisalhamento no topo da CLP aumenta em função da intensidade da forçante geostrófica aplicada. O padrão do transporte, negativo em superfície e positivo no topo da camada, indica que está havendo remoção de energia da superfície para o topo. O termo de dissipação é da mesma ordem de grandeza que as produções térmica e mecânica. Isso indica que a CLP está evoluindo no tempo em um estado de quasi-equilíbrio entre os termos de produção e dissipação.

A figura 3.21 indica o balanço de ECT para a condição de CLP neutra, i.e. quando a produção térmica tende a zero. Esse perfil é observado no final da tarde, (18:30HL) instantes antes do colapso da CLP.

Observa-se que pela figura 3.21 que a forçante geostrófica intensifica a produção mecânica de maneira significativa. A dissipação também aumenta visto que mais turbulência é gerada. Seguindo o crescimento da CLP observa-se produção e dissipação até 


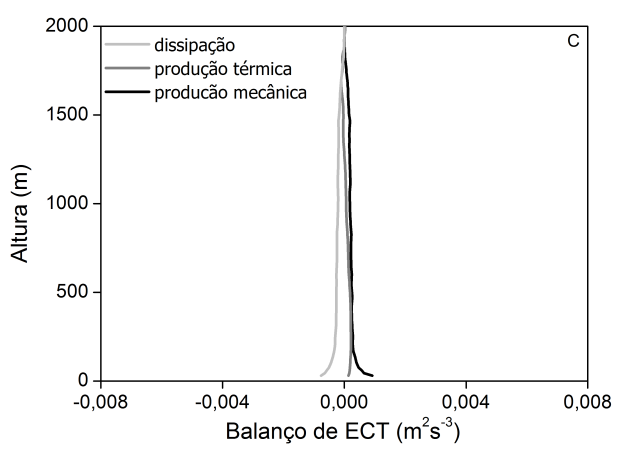

(a) Experimento $\mathrm{C}$

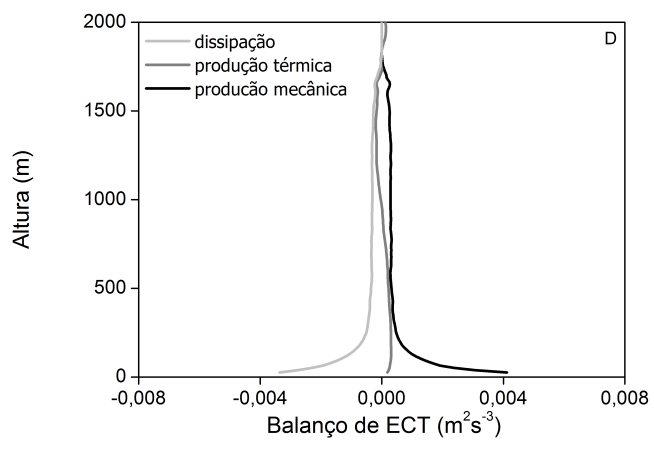

(b) Experimento D

Figura 3.21: Distribuição vertical das componentes do balanço de ECT para CLP neutra - céu claro

aproximadamente 1700 metros para ambos os casos. Em condições neutras a CLP ainda preserva algumas informações da CLP convectiva (a dissipação estende-se até o topo da camada residual).

Os perfis verticais das componentes do balanço de ECT representativos das condições estáveis estão indicados nas figuras 3.22 e 3.23. Os perfis correspondem à evolução da CLP à 01:00HL e às 05:00HL, i.e. estabilidade moderada e intensa respectivamente.

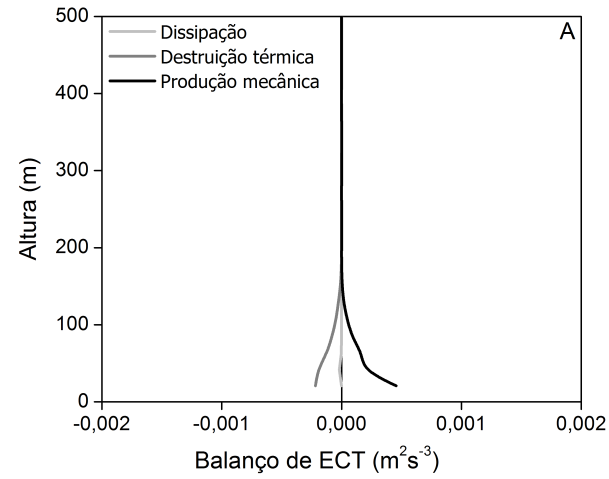

(a) Experimento A

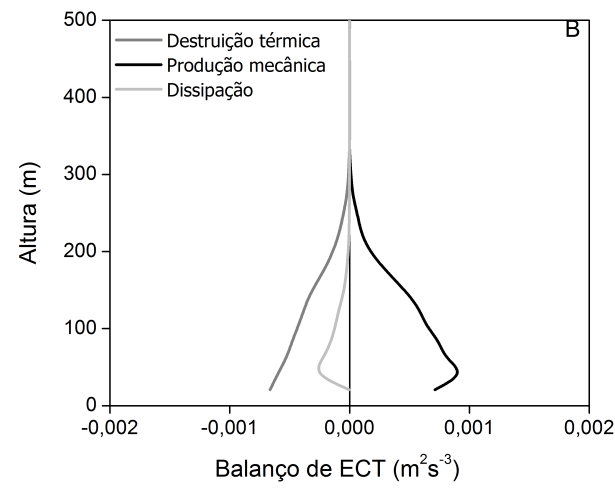

(b) Experimento B

Figura 3.22: Distribuição vertical das componentes do balanço de ECT para CLP moderadamente estável - caso médio.

A escala do eixo horizontal do balanço de ECT foi alterada para $25 \%$ da usada no 
caso convectivo para acomodar a diminuição da intensidade da turbulência. Neste caso, a destruição térmica é o principal mecanismo para remoção da turbulência. A dissipação molecular de ECT não contribui de maneira significativa para o balanço de ECT nas condições estáveis com pouco vento. Com a forçante geostrófica mais intensa sua contribuição torna-se mais importante. O termo de transporte é pequeno em toda a extensão da CLE. O transporte turbulento é realizado pelos turbilhões mais energéticos. No caso da CLE os turbilhões mais energéticos são pequenos. O balanço de energia indica que a CLE está em condição de equilíbrio pois o resíduo (não exibido) é pequeno em toda a camada.

Os próximos resultados, figura 3.23, são representativos do final do experimento, i.e. para uma condição fortemente estável com forçante geostrófica intensa. Na figura 3.23(a) são apresentadas as alturas do máximo do perfil de vento $\left(h_{\text {jato }}\right)$, e ainda o topo da camada limite $(h)$. O papel do JBN associado à intensificação do cisalhamento será mais bem investigado nas próximas seções.

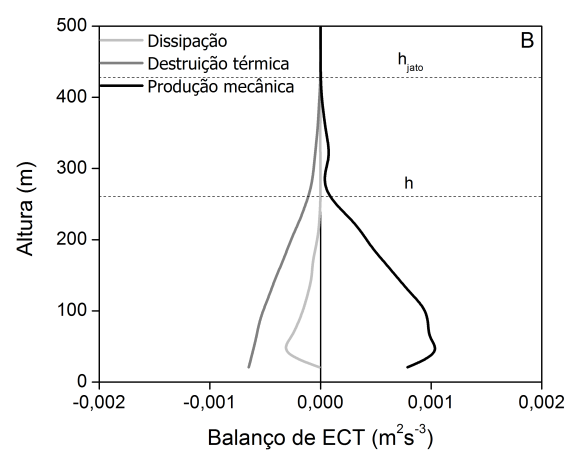

(a) Experimento B

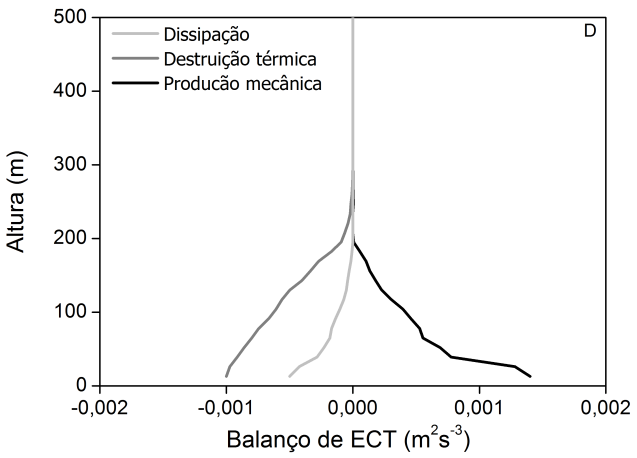

(b) Experimento D

Figura 3.23: Distribuição vertical das componentes do balanço de ECT para CLP fortemente estável.

Observa-se pela comparação das figuras 3.23(a) e 3.23(b) que a destruição térmica remove a maioria da ECT durante o regime estável. Comparando as figuras $3.23 \mathrm{com}$ 3.22 é possível perceber que há um aumento de todos os termos, principalmente do termo mecânico. A destruição térmica apresenta intensificação moderada. A dissipação permanece praticamente com a mesma importância. 


\subsection{Evolução temporal dos perfis verticais na CLE}

As figuras 3.24, 3.25, 3.30 e 3.31 mostram a evolução da componente zonal do vento, temperatura potencial e concentração de CO simulados pelo modelo LES durante o período noturno. Não serão exibidas todas as evoluções para os experimentos C e D para evitaremse repetições.

\subsubsection{Importância do JBN na evolução da CLE}

Conforme discutido na Introdução, os JBNs dependem do ajuste inercial, topografia e ocupação do solo, (Oliveira e Fitzjarrald, 1994; Karam, 2002; Oliveira, 2003). Neste trabalho, será avaliado apenas o efeito associado ao ajuste inercial, pois o modelo LES atual admite topografia plana e ocupação do solo homogênea.

A evolução noturna do perfil vertical de velocidade apresentada nas figuras 3.24 e 3.25 é limitada até $1200 m$ e $1300 m$ para o caso médio. Para o caso de céu claro, o JBN alcança aproximadamente $1800 \mathrm{~m}$ para ambos os experimentos. Essa altura é representativa do topo da camada de mistura residual, i.e. resultante da evolução vertical da CLP durante o período convectivo. O máximo do JBN acontece em torno das 5:30HL para todos os experimentos, porém com intensidades diferentes mesmo sob as mesmas condições geostróficas.

Observa-se que o JBN é mais desenvolvido para o caso médio em ambas as situações. A intensidade do máximo do JBN, quando comparada com a forçante geostrófica, indica que há um aumento na intensidade da velocidade do vento de $42 \%$ e $46 \%$ para o caso médio, A e B respectivamente, contra somente $32 \%$ e $38 \%$ para o caso de céu claro, C e D respectivamente. Considerando que a intensidade do JBN depende do déficit de momento no final do período convectivo e este déficit é maior nos casos $\mathbf{B}$ e $\mathbf{D}$, a amplitude do vento na oscilação inercial é mais intensa nesses casos.

O vento torna-se supergeostrófico aproximadamente às 22:00HL para as quatro condições. É interessante observar que o máximo do JBN está sempre acima do topo da CLE. A figura 3.26 descreve a posição e a intensidade do máximo do JBN para todo o período noturno.

A altura máxima da CLE para o caso A é aproximadamente $110 \mathrm{~m}$ e o máximo do jato 


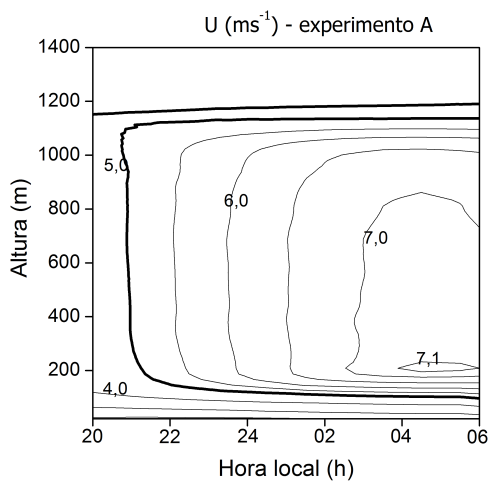

(a) Experimento A

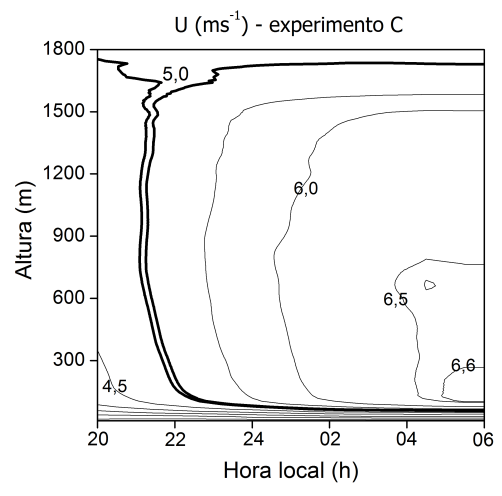

(b) Experimento $\mathrm{C}$

Figura 3.24: Variação temporal do perfil vertical de velocidade para os experimentos com forçante geostrófica fraca.

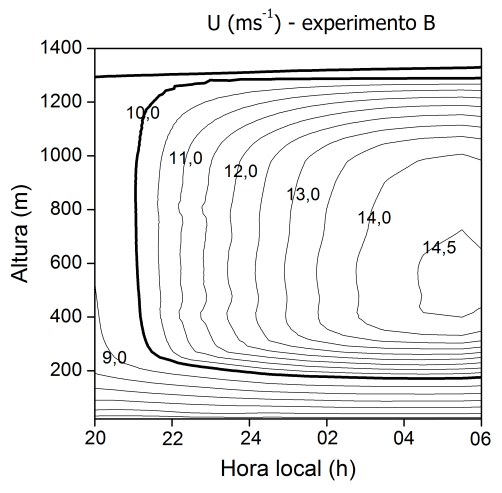

(a) Experimento B

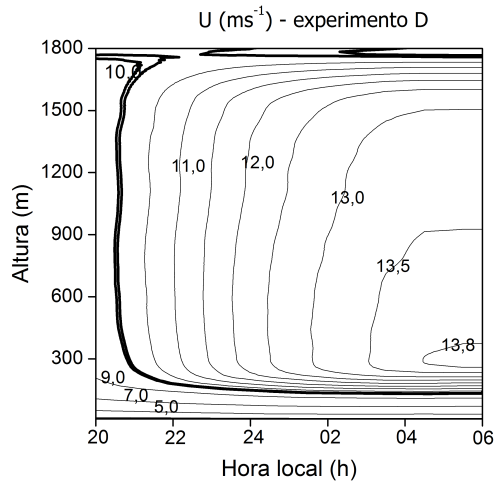

(b) Experimento D

Figura 3.25: Variação temporal do perfil vertical de velocidade para os experimentos com forçante geostrófica forte.

é $210 m$. Para o experimento $\mathbf{B}$ a altura máxima no período estável é $280 m$ e o máximo do jato está em 420m. A figura 3.26(a) indica que a posição vertical do máximo do JBN decresce suavemente após a intensificação da estratificação térmica para o experimento A e permanece aproximadamente constante para o experimento B. A velocidade máxima do JBN foi comparada com a equação proposta por Blackadar (1957), equação 2.11. Observase aumento da velocidade até 05:30HL quando a velocidade decresce de acordo com os efeitos da oscilação inercial.

Espera-se que camadas mais turbulentas durante o período diurno estejam associadas 


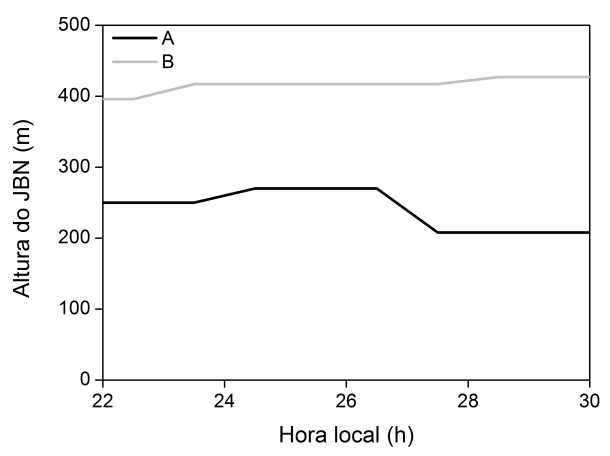

(a) Altura do máximo do JBN

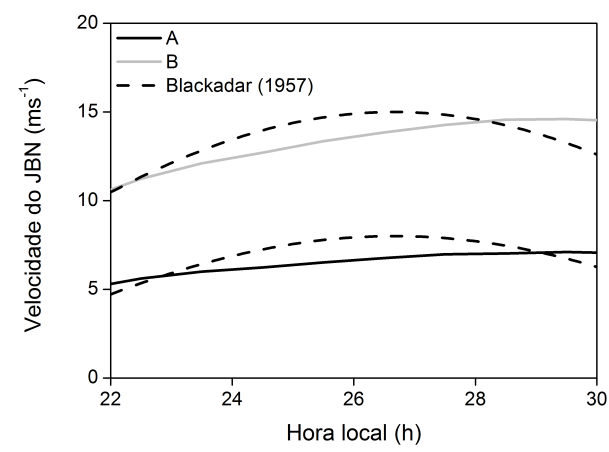

(b) Velocidade no máximo do JBN

Figura 3.26: Altura e velocidade do máximo do JBN.

a JBNs mais intensos (B e $\mathbf{D}$ ), figura 3.27. A altura da CLP durante a noite é aproximadamente $180 \%$ maior quando o JBN é mais intenso. Para as condições convectivas, as diferenças relativas entre as alturas não ultrapassam 20\%. Nos casos de céu claro, essa diferença é menos significativa ainda, figura 3.14. Esse padrão é controlado pelo JBN que intensifica a produção mecânica e a energia cinética turbulenta, (figuras 3.27 e 3.18) no período noturno. Portanto, a forçante geostrófica aumenta a produção mecânica, favorecendo o crescimento diferenciado da CLP, principalmente no caso estável, figuras 3.22 e 3.23. A figura 3.27 exibe o perfil vertical do JBN quando sua intensidade é máxima para todos os experimentos.

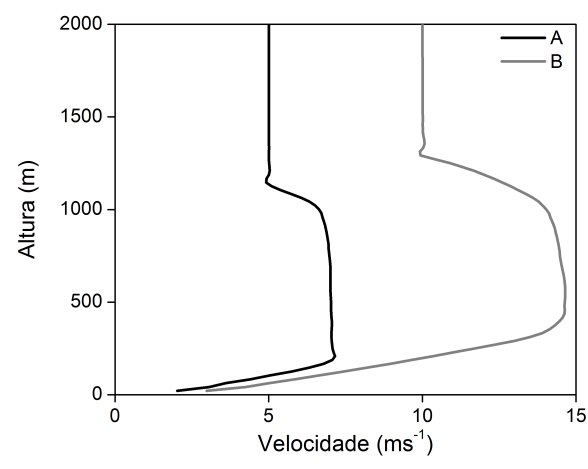

(a) Todos os dias

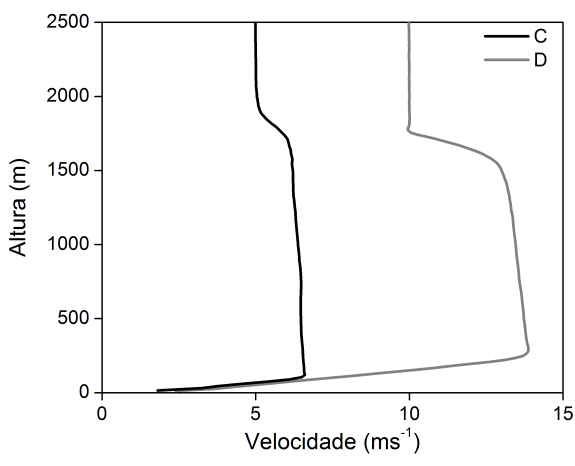

(b) Céu claro

Figura 3.27: Perfis verticais da velocidade do vento zonal.

A figura 3.23 indica que mesmo após o topo da CLE determinado pelo máximo do 
gradiente de temperatura potencial observa-se turbulência gerada pelo termo mecânico. Esse padrão foi mais bem analisado por meio dos momentos estatísticos de segunda ordem para velocidade, figura 3.28 .

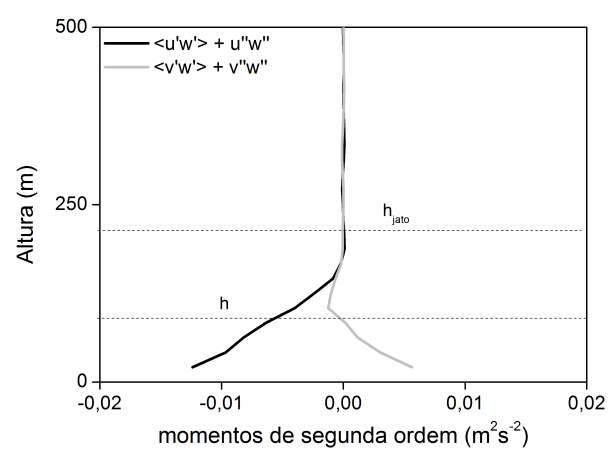

(a) Experimento A

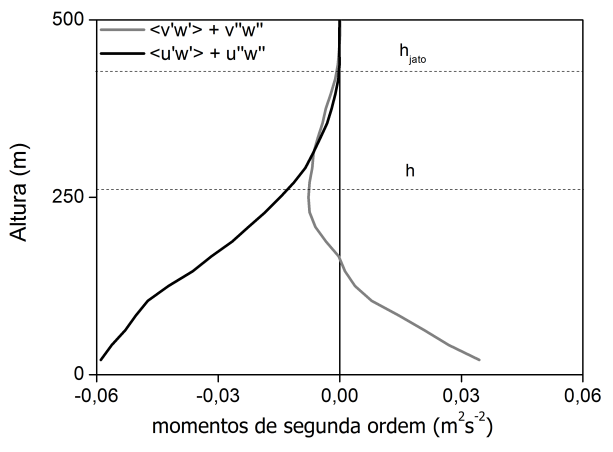

(b) Experimento B

Figura 3.28: Perfil vertical dos momentos estatísticos de segunda ordem para velocidade.

Seguindo o mesmo padrão encontrado na produção mecânica, os momentos estatísticos de segunda ordem não tendem a zero no topo da CLE. Ainda há geração de turbulência até o máximo do JBN, $\left(h_{\text {jato }}\right)$.

O número de Richardson, figura 3.29, indica que a CLE é, como esperado, estável durante toda sua extensão vertical, com alguns pontos intermitentes $R i>R i_{c}$, indicando que há uma forte estratificação térmica associada.

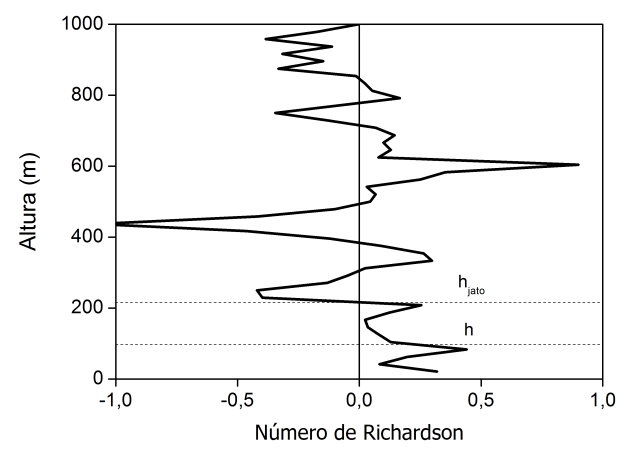

(a) Experimento A

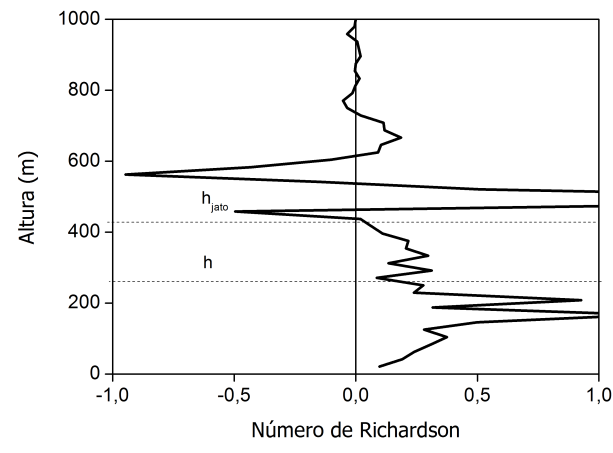

(b) Experimento B

Figura 3.29: Perfil vertical do número de Richardson.

Para ambos os experimentos, entre o topo da CLE e o máximo do JBN, o número 
de Richardson apresenta valores entre zero e o crítico, i.e. $0 \leq R i \leq 0,25$. No nível do máximo do JBN tem-se $R i=0$. Durante toda a camada de mistura residual, para ambos os experimentos, o número de Richardson apresenta oscilações indicando intermitência na turbulência. Segundo Mahrt et al. (1998) o JBN pode ser uma fonte de turbulência acima da CLE. Para Saiki et al. (2000) a metodologia para análise da importância do JBN é a verificação dos perfis verticais de $\left\langle u^{\prime} w^{\prime}\right\rangle$ e $\left\langle v^{\prime} w^{\prime}>\right.$ e do número de Richardson.

Da análise dos perfis verticais sugeridos em Saiki et al. (2000), pode-se concluir que o cisalhamento associado ao jato é uma fonte de turbulência na CLE. Pela análise do número de Richardson, o jato pode ainda induzir turbulência acima do seu máximo pois a camada residual é altamente intermitente.

\subsubsection{Perfis de temperatura potencial e concentração de CO}

A figura 3.30 apresenta os campos para temperatura potencial para o caso médio:

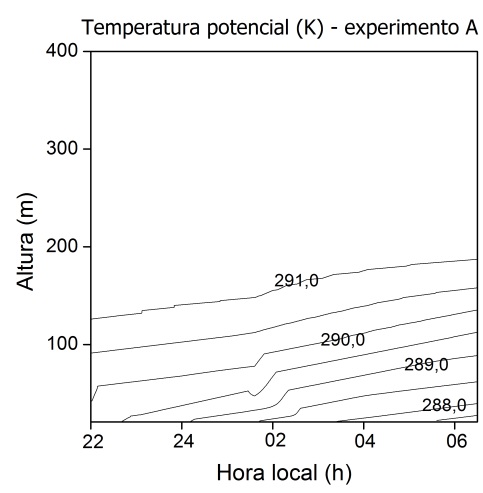

(a) Experimento A

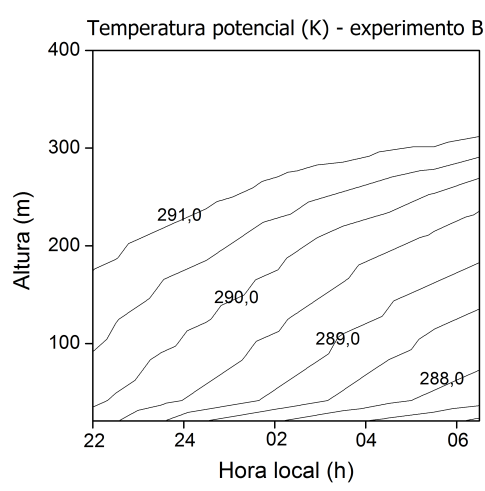

(b) Experimento B

Figura 3.30: Variação temporal do perfil vertical de temperatura potencial para os experimentos do caso médio.

Em ambos os casos a camada de inversão de superfície torna-se mais alta durante o período noturno. A espessura desta camada varia de $120 \mathrm{~m}$ para até $180 \mathrm{~m}$ para o experimento $\mathbf{A}$ e de $130 \mathrm{~m}$ até $310 \mathrm{~m}$ para o experimento $\mathbf{B}$. Isso é um indicativo que ocorre diminuição do gradiente vertical de temperatura em ambos os experimentos.

Um padrão semelhante é observado durante a evolução da concentração de CO na camada de inversão, figura 3.31. JBNs mais intensos geram CLEs mais altas e camadas 
de inversão de superfície mais suaves. Essa combinação gera concentrações de CO mais distribuídas na atmosfera e por um período mais longo.

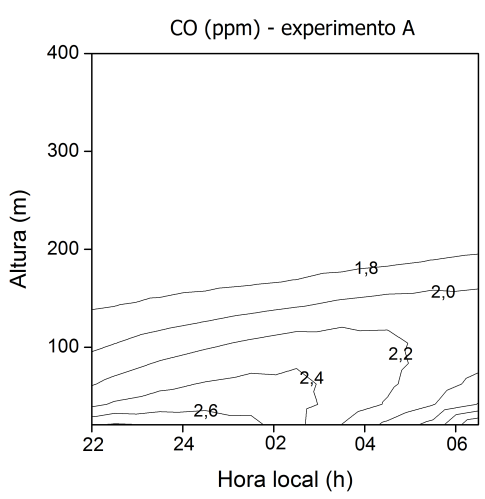

(a) Experimento A

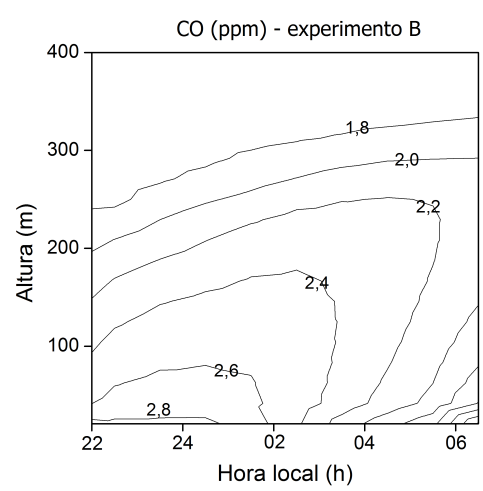

(b) Experimento B

Figura 3.31: Variação temporal do perfil vertical de concentração de CO para os experimentos do caso médio.

Para o caso da concentração de CO a camada de inversão intensifica-se até praticamente as mesmas alturas da camada de inversão de temperatura para ambos os casos. Daí, a concentração de CO em superfície é modulada principalmente pela intensidade da camada de inversão, a qual depende da intensidade e posição do JBN.

\subsubsection{Estimativa de altura da CLE}

Existem várias maneiras de estimar a altura da CLE. Entretanto, somente as expressões que estimam a altura da CLE a partir de parâmetros de superfície serão analisadas neste trabalho. Além de simples, este tipo de estimativa pode ser facilmente utilizada em modelos de dispersão de poluentes.

Quatro formulações empíricas foram escolhidas (Koracin e Berkowicz, 1988; Oliveira et al., 1998; Zilitinkevich e Baklanov, 2002; Steeneveld et al., 2007) com base nos critérios descritos acima.

$$
h_{1}=700 u_{*}
$$




$$
\begin{gathered}
h_{2}=0,5 \sqrt{\frac{u_{*} L}{|f|}} \\
\left(\frac{f h_{3}}{C_{n} u_{*}}\right)^{2}+\frac{h_{3}}{C_{s} L^{*}}+\frac{N h_{3}}{C_{i} u_{*}}=1 \\
h_{4}=L\left(\frac{\left|\frac{g}{\theta_{s}} \overline{w \theta_{s}}\right|}{\alpha u_{*} f N L}\right)^{\frac{1}{\left(C_{1}-0,001 \frac{N}{f}\right)}}
\end{gathered}
$$

Onde:

$h_{1}$ - altura estimada segundo Koracin e Berkowicz (1988);

$h_{2}$ - altura estimada segundo Oliveira et al. (1998).

$h_{3}$ - altura estimada segundo Zilitinkevich e Baklanov (2002);

$h_{4}$ - altura estimada segundo Steeneveld et al. (2007);

$C_{n}=0,5 ; C_{s}=10 ; C_{i}=20 ; C_{1}=1,8 ; \alpha=3$ são constantes empíricas;

$f$ - parâmetro de Coriolis;

$N$ - frequência de Brunt-Väisälä;

$L$ - Comprimento de Obukhov;

$L_{*}$ - Comprimento de Obukhov modificado; $\left(L_{*}=\frac{L}{\kappa}\right)$ onde $\kappa$ é a constante de von Karman igual a 0,4 .

Comparando-se a evolução temporal da altura da CLE estimada pelas formulações empíricas e simulada pelo modelo LES (figura 3.32) verifica-se que:

Todas as fórmulas foram capazes de reproduzir a ordem de grandeza da altura da CLE. Entretanto, os resultados indicam que a formulação proposta por Steeneveld et al. (2007) superestima os resultados, enquanto que a fórmula de Zilitinkevich e Baklanov (2002) subestima os valores de altura simulados pelo modelo LES.

Nenhuma das formulações analisadas foi capaz de acompanhar o crescimento da CLE. Uma possível explicação é o fato das fórmulas serem fortemente dependentes de $u_{*}$. Esse 


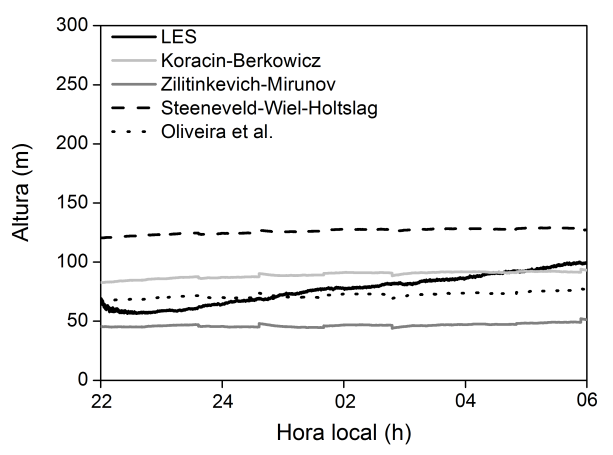

Figura 3.32: Performance das formulações empíricas comparadas ao resultado do modelo LES.

parâmetro no modelo LES é praticamente constante durante todo o período noturno. As fórmulas de Koracin e Berkowicz (1988) e extraída de Oliveira et al. (1998) são as mais indicadas para a simulação da altura da CLE, pois foram as que mais se aproximaram dos valores simulados pelo modelo LES. 
Capítulo 4

\section{Conclusão}

A modelagem numérica da atmosfera consiste em uma importante ferramenta de previsão de tempo e clima. Os modelos numéricos são também intensivamente utilizados para avaliar a dispersão de poluentes atmosféricos. Apesar de todo avanço obtido no desenvolvimento de modelos, os processos turbulentos associados à CLP ainda não são bem representados. A melhor forma de representar os processos turbulentos na CLP é a simulação numérica da turbulência de grande escala com modelos LES. Neste tipo de modelo, os movimentos turbulentos de grande escala são resolvidos diretamente e a turbulência de pequena escala é resolvida indiretamente através de parametrizações.

O presente trabalho tem como objetivo investigar a evolução temporal e espacial da camada limite planetária (CLP) na cidade de São Paulo durante o período noturno, utilizando um modelo LES. Foram simulados os campos tridimensionais das três componentes da velocidade do vento, temperatura potencial e concentração de monóxido de carbono (CO). Três propriedades da CLP noturna em São Paulo foram analisadas: a) altura da CLP estável (CLE); b) jatos de baixos níveis (JBN); c) dispersão turbulenta de CO. Foi analisado também o ciclo diurno dos fluxos turbulentos de calor sensível e de CO em superfície.

Foi realizado um procedimento de validação do modelo LES com o intuito de verificar se a atual versão do modelo é capaz de reproduzir o comportamento da CLP em condições convectiva, neutra e estável. A validação foi realizada comparando os perfis verticais médios de velocidade horizontal, temperatura potencial, variância das componentes da velocidade e as componentes da equação do balanço de energia cinética turbulenta (ECT). Os resultados dessas comparações indicam que o modelo LES em questão é capaz de reproduzir todas as características dos processos turbulentos destes escoamentos. Esse resultado indica que o modelo LES reproduz de maneira satisfatória os regimes turbulentos convectivo e estável, incluindo o período de transição, quando a CLP é neutra. 
Uma vez validado, o modelo LES foi utilizado para simular um ciclo diurno completo da CLP sobre uma superfície com topografia plana e ocupação do solo horizontalmente homogênea com coeficiente de rugosidade aerodinâmico representativo de uma área urbana típica de São Paulo. Quatro experimentos numéricos de um ciclo diurno completo foram realizados utilizando o modelo LES atual com o objetivo de descrever os campos tridimensionais das três componentes da velocidade, temperatura potencial e da concentração do monóxido de carbono.

Para caracterizar a situação de inverno na RMSP foram utilizados como condição de contorno inferior nestas simulações os valores horários médios mensais da temperatura do ar e concentração de CO observados cidade de São Paulo durante o mês de junho, de 1997 até 2006. Os experimentos foram divididos em dois grupos, e para cada grupo, duas condições de forçante geostrófica foram analisadas, $5 \mathrm{~ms}^{-1}$ e $10 \mathrm{~ms}^{-1}$ na componente zonal. Os grupos foram chamados de "caso médio" (simulações A e B) e "caso médio para céu claro" (simulações $\mathbf{C}$ e $\mathbf{D}$ ). Os dias de céu claro foram separados para o mês de junho.

O objetivo de efetuar simulações considerando condições de céu claro ou geostróficas diferentes foi tentar modelar as principais características da CLP para o mês de junho e identificar o papel que as nuvens e a intensidade do vento têm nas propriedades da CLP. Assim, a condição de céu claro e o padrão de nuvens foram simulados de maneira indireta, i.e. utilizando dados em superfície de temperatura do ar e concentração de CO, que possuem informações indiretas sobre a cobertura de nuvens. A evolução diurna da velocidade do vento medida na cidade de São Paulo, para todos os dias e dias de céu claro, foi comparada com as saídas do LES para as quatro condições simuladas.

Os resultados indicaram que a simulação A é a mais realística para todos os dias e que o modelo não consegue reproduzir a intensidade, mas somente a ordem de grandeza da velocidade do vento para as condições de céu claro. Todas as simulações apresentam um máximo local no final do período convectivo. Esse máximo deve estar associado ao início da oscilação inercial.

Os resultados para o fluxo de calor sensível estimado pelo modelo LES foram comparados à medidas de fluxo turbulento realizadas na plataforma micrometeorológica do IAG-USP. A comparação indicou que o modelo LES é capaz de reproduzir as principais características do fluxo, bem como os máximos e mínimos. A ordem de grandeza do fluxo de calor sensível durante o período noturno foi mais bem simulada pelo caso $\mathbf{A}$. 
As evoluções diurnas do fluxo vertical de CO simulado pelo LES em superfície apresentaram o caráter bimodal esperado. Os resultados também foram comparados com a evolução diurna hipotética do fluxo de CO para a cidade de São Paulo baseada no inventário de emissões veiculares da CETESB. É importante observar que o modelo é capaz de simular a amplitude dos fluxos de superfície, mas não a posição do pico vespertino. A intensidade do fluxo de $\mathrm{CO}$ deve ser diferente para a manhã e a tarde, visto que durante a madrugada, a concentração de CO tende a diminuir muito devido à diminuição do tráfego de veículos. Consequentemente, o pico matutino deve ser mais intenso devido à grande variabilidade de $\mathrm{CO}$ num curto espaço de tempo. Para o período da tarde, a concentração de CO não apresenta a mesma variabilidade, fazendo com que a intensidade do fluxo seja menor. Esse padrão é reproduzido pelo modelo em todas as simulações.

Para o caso todos os dias, a altura da CLP foi maior para a simulação $\mathbf{B}$, com forçante geostrófica mais intensa, tanto no período convectivo quanto na parte estável, $1240 \mathrm{~m}$ e $275 m$ respectivamente. Para a simulação A, a CLP atingiu $1088 m$ para o período convectivo e $100 \mathrm{~m}$ para o caso estável. Considerando somente os dias de "céu claro" observou-se que a altura da CLP para a condição convectiva não apresenta variação significativa quando alteradas as forçantes geostróficas, simulações $\mathbf{C}$ e $\mathbf{D}$. Isso deve-se ao fato de a produção térmica ser muito mais importante do que a variação na forçante geostrófica no caso de dias de céu claro, pois a amplitude térmica encontrada no período convectivo é mais significativa. Para os experimentos $\mathbf{A}$ e $\mathbf{B}$ as diferenças relativas na altura da CLP durante o período convectivo não ultrapassaram 20\%. Entretanto, durante o período noturno as diferenças são da ordem de $180 \%$. Para as simulações $\mathbf{C}$ e $\mathbf{D}$ o padrão também é observado, com variações da ordem de $230 \%$. Os resultados foram comparados ainda, de maneira qualitativa, com dados de LIDAR e os resultados indicam que o modelo LES é capaz de reproduzir o comportamento médio e fornecer estimativas confiáveis da altura da CLP para o período convectivo e estável.

O balanço de ECT foi calculado para os casos em questão para quatro períodos do dia, máximo do fluxo de calor sensível em superfície, produção térmica tendendo a zero além do início e final do regime estável. As distribuições das componentes da equação de ECT simuladas pelo LES apresentaram as características esperadas para todos os horários do dia avaliados. Sob condições estáveis a dissipação mostrou-se menos importante se comparada aos outros termos do balanço. A destruição térmica mostrou-se como o principal 
sistema para remoção da turbulência gerada pela componente mecânica.

O papel do JBN foi investigado através da comparação dos perfis verticais de velocidade do vento nas diferentes condições geostróficas propostas. O vento torna-se supergeostrófico aproximadamente às 22:00HL para todas as condições estudadas. A análise da intensidade do máximo do JBN, quando comparada com a forçante geostrófica, indicou um aumento na intensidade da velocidade do vento de $42 \%$ e $46 \%$ para o caso com nuvens e $32 \%$ e $38 \%$ para o caso sem nuvens. Esse padrão é esperado, visto que a intensidade do JBN depende do déficit de momento no final do período convectivo.

As simulações indicam que o máximo do JBN está sempre acima do topo da CLE. Para o caso A a diferença entre o nível do JBN e a altura da CLE é de aproximadamente $100 \mathrm{~m}$. Para o caso B observou-se que a altura máxima da CLE é $280 \mathrm{~m}$ e o máximo do jato $420 \mathrm{~m}$. A análise dos momentos estatísticos de segunda ordem para velocidade indicou que ainda há turbulência acima da CLE, resultado esse que indica que o cisalhamento associado ao jato é uma fonte de turbulência na CLE e acima dela, visto que a produção mecânica é intensificada também em superfície. O número de Richardson também indicou que há intermitência durante todo o JBN. Observou-se que com o aumento da forçante geostrófica a camada de inversão torna-se mais alta, variando de $120 \mathrm{~m}$ até $180 \mathrm{~m}$ para a simulação $\mathbf{A}$ e de $130 m$ até $310 m$ para a simulação $\mathbf{B}$.

Os resultados da utilização de formulações empíricas indicaram que todas as fórmulas foram capazes reproduzir a ordem de grandeza da altura da CLE simulado pelo modelo LES. As fórmulas $h=700 u_{*}$ e $h=0,5 \sqrt{\frac{u_{*} L}{|f|}}$ foram as que mais se aproximaram da altura da CLE simulada pelo modelo LES para São Paulo.

Com sugestão para futuros trabalhos, do ponto de vista de modelagem seria importante incluir no modelo LES um algoritmo que pudesse efetuar o acoplamento direto entre o dossel urbano e a atmosfera. Do ponto de vista observacional seria extremamente importante realizar estimativas diretas da extensão vertical da CLP na RMSP. Seria importante também, efetuar medidas do perfil de concentração de monóxido de carbono e dos fluxos verticais turbulentos de calor sensível e de CO na superfície. 


\section{Referências Bibliográficas}

Acevedo, O. e Mahrt, L. (2010). Systematic vertical variation of mesoscale fluxes in the nocturnal boundary layer. Boundary-Layer Meteorology, 135:19-30.

Andrén, A. (1995). The structure of stably stratified atmospheric boundary layers: A large-eddy simulation study. Quarterly Journal of the Royal Meteorological Society, 121:961-985.

Arya, S. P. (2001). Introduction to Micrometeorology, volume 79. Academic Press.

Baas, P., Bosveld, F., Baltink, H., e Holtslag, A. (2009). A climatology of nocturnal lowlevel jets at Cabauw. Journal of Applied Meteorology and Climatology, 48:1627-1642.

Baggett, J. S. (1998). On the feasibility of merging LES with RANS for the near-wall region of attached turbulent flows. Annual Research Briefs, pages 267-277.

Baik, J. J., Kim, J. J., e Fernando, H. J. S. (2003). A CFD model for simulation urban flow and dispersion. Journal of Applied Meteorology, 42:1636-1648.

Baker, J., Walker, H. L., e Cai, X. (2004). A study of the dispersion and transport of reactive pollutants in and above street canyons. a large eddy simulation. Atmospheric Environment, 38:6883-6892.

Banta, R. M., Newsom, R., Lundquist, J. K., Pichugina, Y. L., Coulter, R. L., e Mahrt, L. (2002). Nocturnal low-level jet characteristics over Kansas during CASES-99. Boundary-Layer Meteorology, 105:221-252.

Barbaro, E., Oliveira, A. P., e Soares, J. (2009). Validation of a statistic algorithm applied to LES model - part i: First and second order statistics. Revista Ciência e Natura Micrometeorologia, Especial:233-236.

Barbaro, E., Oliveira, A. P., Soares, J., Codato, G., Ferreira, M. J., Mlakar, P., Boznar, M. Z., e Escobedo, J. F. (2010). Observational characterization of the downward at- 
mospheric longwave radiation at the surface in the city of São Paulo. Journal of Applied Meteorology and Climatology (e-View).

Basu, S., Holtslag, A. M., van de Wiel, J. H., Moene, A. F., e Steeneveld, G.-J. (2008). An inconvenient "truth" about using sensible heat flux as a surface boundary condition in models under stably stratified regimes. Acta Geophysica, pages DOI: 10.2478/s11600007-0038-y.

Basu, S. e Porté-Angel, F. (2006). Large-eddy simulation of stable stratified atmospheric boundary layer turbulence: A scale-dependent dynamic modeling approach. Journal of the Atmospheric Sciences, 63(8):2074-2091.

Beare, R., Macvean, M., Holtslag, A., Cuxart, J., Esau, I., Golaz, J.-C., Jimenez, M., Khairoutdinov, M., Kosovic, B., Lewellen, D., Lund, T., Lundquist, J., Mccabe, A., Moene, A., Noh, Y., Raasch, S., e Sullivan, P. (2006). An intercomparison of large-eddy simulations of the stable boundary layer. Boundary-Layer Meteorology, 118(2):247-272.

Beljaars, A. C. M. e Holtslag, A. A. M. (1991). Flux parameterization over land surfaces for atmospheric models. Journal of Applied Meteorology, 30:327-341.

Blackadar, A. K. (1957). Boundary layer wind maxima and their significance for the growth of nocturnal inversions. Bulletin of American Meteorological Society, 38:283290.

Bogo, H., Gómez, D. R., Reich, S. L., Negri, R. M., e San Román, E. (2001). Traffic pollution in a downtown site of Buenos Aires city. Atmospheric Environment, 35:17171727.

Boian, C. e Kirchhoff, V. W. J. H. (2006). High carbon monoxide concentrations during the rainy season in Campo Grande, in central Brazil. Environment Pollution., 143:536544 .

Boyce, W. E. e DiPrima, R. C. (2005). Elementary Differential Equations and Boundary Value Problems. John Wiley and Sons.

Brown, A. R., Cederwall, R. T., Chlond, A., Duynkerke, P., Golaz, J.-C., Khairoutdinov, M., Lewellen, D. C., Lock, A. P., MacVean, M. K., Moeng, C.-H., Neggers, R. A. J., 
Siebesma, A. P., e Stevens, B. (2002). Large-eddy simulation of the diurnal cycle of shallow cumulus convection over land. Quarterly Journal of the Royal Meteorological Society, 128:1075-1093.

Caughey, S. J., Wyngaard, J. C., e Kaimal, J. C. (1979). Turbulence in the evolving stable boundary layer. Journal of the Atmospheric Sciences, 36:1041-1052.

Cederwall, R. (1994). Large-eddy simulation of the development of stably-stratified atmospheric boundary layers over cool flat surfaces. In 11th Symposium on Boundary Layers and Turbulence.

CETESB (2009). Relatório de qualidade do ar no estado de São Paulo. ISSN 0103-4103.

Chartier, T. (2005). Devastating roundoff error. Math. Horizons, 11(4).

Codato, G. (2008). Simulação numérica da evolução diurna do co na CLP sobre a RMSP com o modelo LES. Dissertação de Mestrado, IAG-USP.

Codato, G., Oliveira, A. P., Soares, J., Escobedo, J. F., Gomes, E. N., e Pai, D. A. (2008). Global and diffuse solar irradiances in urban and rural areas in southeast of Brazil. Theoretical and Applied Climatology, 93(1-2):57-73.

Comrie, A. C. e Diem, J. E. (1999). Climatology and forecast modeling of ambient carbon monoxide in Phoenix, Arizona. Atmospheric Environment, 33:5023-5036.

Conceição, G. M. S., Miraglia, S. G. E. K., Kishi, H. S., Saldiva, P. H. N., e Singe, J. M. (2001). Air pollution and child mortality: A time-series study in São Paulo, Brazil. Environmental Health Perspectives Supplements, 109(S3).

Cuxart, J. e Jiménez, M. A. (2007). Mixing processes in a nocturnal low-level jet: A LES study. Journal of the Atmospheric Sciences, 64:1666-1679.

Deardoff, J. W. (1972). Numerical investigation of neutral and unstable planetary boundary layers. Journal of the Atmospheric Sciences, 29:91-115.

Deardorff, J. (1972). Numerical investigation of neutral and unstable planetary boundary layers. Journal of the Atmospheric Sciences, 29:91-115. 
Deardorff, J. (1974). Three-dimensional numerical study of turbulence in an entraining mixed layer. Boundary-Layer Meteorology, 7:199-226.

Ding, F., Arya, S. P., e Lin, Y.-L. (2001). Large-eddy simulations of the atmospheric boundary layer using a new subgrid-scale model i. slightly unstable and neutral cases. Environmental Fluid Mechanics., 1:20-47.

Dosio, A., Arellano, J. V. G., Holtslag, A. A. M., e Builtjes, P. J. H. (2003). Dispersion of a passive tracer in buoyancy- and shear-driven boundary layers. Journal of Applied Meteorology, 42:1116-1130.

Dubrulle, B., sur Yvette, G., Laval, J.-P., Sullivan, P., e Werne, J. (2002). A new dynamical subgrid model for the planetary surface layer. part i: The model and a priori tests. Journal of the Atmospheric Sciences, 59:861-876.

Fedorovich, E., Conzemius, R. E., e Mironov, D. (2004). Convective entrainment into a shear-free, linearly stratified atmosphere: Bulk models reevaluated through large eddy simulations. Journal of Applied Meteorology, 61:281-295.

Ferreira, M. J. (2010). Estudo do Balanço de Energia na Superfície Aplicado à Cidade de São Paulo. Tese de Doutorado, IAG-USP.

Foken, T. (2004). 50 years of the Monin-Obukhov Similarity Theory. In Proceedings of 16th Symposium on Boundary Layers and Turbulence.

Fortuna, A. O. (2001). Técnicas Computacionais Para a Dinâmica dos Fluidos. EDUSP.

Frisch, U. (1995). Turbulence: The legacy of A.N. Kolmogorov. Cambrigde University Press.

Garrat, J. (1993). Sensitivity of climate simulations to land-surface and atmospheric boundary-layer treatments - a review. Journal of Climate, 6:419-448.

Garrat, J. R. (1994). The atmospheric boundary layer. Cambrigde University Press.

Glowinski, R., Pan, T. W., Hesla, T. I., Joseph, D. D., e Périaux, J. (2001). Numerical simulation of incompressible viscous flow past moving rigid bodies: Application to particulate flow. Journal of Computational Physics, 169:363-426. 
Gomez-Perales, J. E., Colvile, R. N., Nieuwenhuijsena, M. J., Fernández-Bremauntz, A., Gutiérrez-Avedoy, V. J., Páramo-Figueroa, V. H., Blanco-Jiménez, S., Bueno-López, E., Mandujano, F., Bernabé-Cabanillas, R., e Ortiz-Segovia, E. (2004). Commuters exposure to $\mathrm{pm}_{2.5} \mathrm{c} 0$ and benzene in public transport in the metropolitan area of Mexico City. Atmospheric Environment, 38:1219-1229.

Guo, H., Golaz, J.-C., Donner, L., Larson, V., Schanen, D., e Griffin, B. (2010). A dynamic probability density function treatment of cloud mass and number concentrations for low level clouds in GFDL SCM/GCM. Geosci. Model Dev. Discuss., 3:541-568.

Holton, J. (2004). An Introduction to Dynamic Meteorology. Elsevier Academic Press.

Holtslag, A. A. M. (2003). GABLS initiates intercomparison for stable boundary layer case. GEWEX News, 13:7-8.

Holtslag, A. A. M. e Nieuwstadt, F. T. M. (1986). Scaling the atmospheric boundary layer. Boundary-Layer Meteorology, 36:201-209.

Howell, J. F. e Sun, J. (1999). Surface-layer fluxes in stable conditions. Boundary-Layer Meteorology, 90:495-520.

Iizuka, S. e Kondo, H. (2004). Performance of various sub-grid scale models in largeeddy simulations of turbulent flow over complex terrain. Atmospheric Environment, 38:7083-7091.

Jiménez, M. A. e Cuxart, J. (2005). Large-eddy simulations of the stable boundary layer using the standard Kolmogorov theory: range of applicability. Boundary-Layer Meteorology, 115:241-261.

Karam, H. A. (2002). Estudo de Jatos de Baixos Niveis e das Implicações no Transporte de Poluentes no Estado de São Paulo. Tese de Doutorado, IAG-USP.

Karipot, A., Leclerc, M. Y., Zhang, G., Lewin, K. F., Nagy, J., Hendrey, G. R., e Starr, G. (2008). Influence of nocturnal low-level jet on turbulence structure and $\mathrm{CO}_{2}$ flux measurements over a forest canopy. Journal of Geophysical Research, 113:doi:10.1029/2007JD009149. 
Kim, S., Park, S., e Moeng, C.-H. (2003). Entrainment processes in the convective boundary layer with varying wind shear. Boundary-Layer Meteorology, 108:221-245.

Koracin, D. e Berkowicz, R. (1988). Nocturnal boundary-layer height: Observations by acoustic sounders and prediction in terms of surface-layer parameters. Boundary-Layer Meteorology, 43:65-83.

Kosovic, B. e Curry, J. (2000). A large eddy simulation study of a quasi-steady, stably stratified atmospheric boundary layer. Journal of the Atmospheric Sciences, 57:10521068.

Kretzchmar, J. G. (1994). Particulate matter levels and trends in Mexico city, São Paulo, Buenos aires and Rio de Janeiro. Atmospheric Environment, 28:3181-3191.

Landulfo, E., Lopes, F. J. S., Mariano, G. L., Torres, A. S., Jesus, W. C., Nakaema, W. M., Jorge, M. P. P. M., e Mariani, R. (2010). Study of the properties of aerosols and the air quality index using a backscatter lidar system and aeronet sunphotometer in the city of São Paulo, Brazil. Journal of Air and Waste Manage Assoc., 60:386-392.

Landulfo, E., Matos, C. A., Torres, A. S., Sawamura, P., e Uehara, S. (2007). Air quality assessment using a multi-instrument approach and air quality indexing in an urban area. Atmospheric Research, 85:98-111.

Lenschow, D. H., Li, X. S., Zhu, C. J., e Stankov, B. B. (1988). The stably stratified boundary layer over the Great Plains, i. mean and turbulent structure. BoundaryLayer Meteorology, 42:95-121.

Lesieur, M. e Métais, O. (1996). Trends in large-eddy simulation of turbulence. Annual Review Fluids Mechanics, 28:45-82.

Long, C. e Turner, D. D. (2008). A method for continuous estimation of clear sky downwelling longwave radiative flux developed using ARM surface measurements. Journal of Geophysical Research, 113:D18206.

Luo, E. e Kreiss, H.-O. (1998). Pseudospectral vs finite difference methods for initial value problems with discontinuous coeficients. Journal on Scientific Computing, 20:148-163. 
Mahrt, L., Sun, J., Blumen, W., Delany, T., e Oncley, S. (1998). Nocturnal boundary-layer regimes. Boundary-Layer Meteorology, 88:255-278.

Mahrt, L. e Vickers, D. (2006). Extremely weak mixing in stable conditions. BoundaryLayer Meteorology, 119:19-39.

Malek, E. (1997). Evaluation of effective atmospheric emissivity and parameterization of cloud at local scale. Atmospheric Research, 45:41-54.

Mansour, N. N. e Wray, A. A. (1994). Decay of isotropic turbulence at low Reynolds number. Phys. Fluids, 6(2):808-814.

Marques-Filho, E. P. (2004). Investigação da Camada Limite Planetária Convectiva com Modelo LES Aplicado à Dispersão de Poluentes. Tese de Doutorado, IAG-USP.

Marques-Filho, E. P. e Oliveira, A. P. (2005). Simulação numérica do transporte de poluentes na camada limite atmosférica. Observar e pensar, antes de modelar. SBMA, São Carlos, São Paulo, 19:15-44.

Marques-Filho, E. P., Oliveira, A. P., Karam, H. A., e Rizza, U. (2003). Simulação numérica do transporte de um poluente inerte e passivo na CLP convectiva através de um modelo LES. Revista Ciência e Natura, 1:83-96.

Marques-Filho, E. P., Oliveira, A. P., Karam, H. A., e Rizza, U. (2006). Pollutant transport in a convective boundary layer with LES. Revista Brasileira de Geofísica, $24(4): 547-557$.

Marques-Filho, E. P., Oliveira, A. P., Rizza, U., e Pereira, M. (2005). Verificação da aplicação da hipótese de Taylor em uma CLP em condições altamente convectivas. Revista Ciência e Natura, pages 339-342.

Mason, P. J. (1994). Large-eddy simulation: A critical review of the technique. Quarterly Journal of the Royal Meteorological Society, 120:1-26.

Masson, V., Gomes, L., Pigeon, G., Liousse, C., Pont, V., Lagouarde, J.-P., Voogt, J., Salmond, J., Oke, T. R., Hidalgo, J., Legain, S., Garrouste, O., Lac, C., Connan, O., Briottet, X., Lach, S., e Tulet, P. (2008). The canopy and aerosol particles interactions in TOulouse Urban Layer (CAPITOUL) experiment. Meteorology and Atmospheric Physics, 102:135-157. 
McWilliams, J. C., Gallacher, P., Moeng, C.-H., e Wyngaard, J. C. (1993). Modeling the oceanic planetary boundary layer. Large-Eddy Simulations of Complex Engineering and Geophysical Flows, 1:441-454.

Meillier, Y., Frehlich, R., Jones, R., e Balsley, B. (2008). Modulation of small-scale turbulence by ducted gravity waves in the nocturnal boundary layer. Journal of the Atmospheric Sciences, 65:1414-1427.

Melgarejo, J. W. e Deardorff, J. W. (1974). Stability functions for the boundary-layer resistance laws based upon observed boundary-layer heights. Journal of the Atmospheric Sciences, 31:1324-1333.

Mesinger, F. e Arakawa, A. (1976). Numerical Methods use in Atmospheric Models. Garp Publications Series 17.

Moeng, C.-H. (1984). A large eddy simulation model for the study of planetary boundary layer turbulence. Journal of the Atmospheric Sciences, 41(13):2052-2062.

Moeng, C.-H., LeMone, M., Khairoutdinov, M., Krueger, S., Bogenschutz, P., e Randall, D. (2009). The tropical marine boundary layer under a deep convection system: a large-eddy simulation study. Journal of Advances in Modeling Earth Systems, 1(16):art \#16.

Moeng, C.-H. e Sullivan, P. (1994). A comparison of shear- and buoyancy-driven planetary boundary layer flows. Journal of the Atmospheric Sciences, 51-7:999-1022.

Moeng, C.-H. e Wyngaard, J. C. (1988). Spectral analysis of large-eddy-simulations of the convective boundary layer. Journal of the Atmospheric Sciences, 45-23:3573-3587.

Moreira, D. M., Carvalho, J. C., e Vilhena, M. T. (2005). Tópicos em turbulência e modelagem da dispersão de poluentes na camada limite planetária. Editora da UFRGS.

Nair, K. N., Freitas, E. D., Sánchez-Ccoyllo, O. R., Silva Dias, M. A. F., Silva Dias, P. L., Andrade, M. F., e Massambani, O. (2004). Dynamics of urban boundary layer over São Paulo associated with mesoscale processes. Meteorology and Atmospheric Physics, 86:87-98. 
Nieuwstadt, F. (1984). The turbulent structure of the stable nocturnal boundary layer. Journal of the Atmospheric Sciences, 41:2202-2216.

Nieuwstadt, F. e de Valk, J. (1987). A large eddy simulation of buoyant and nonbouyant plume dispersion in the atmospheric boundary layer. Atmospheric Environment, 21(12):2573-2587.

Nieuwstadt, F. T. M.and Mason, P. J., Moeng, C.-H., e Schumann, U. (1992). Largeeddy simulation of the convective boundary layer: A comparison of four computer codes. Turbulent Shear Flows, 8:343-367.

Novelli, P. C., Masarie, K. A., e Lang, P. M. (1998). Distributions andrecent changes of carbon monoxide in the lower troposphere. Journal of Geophysical Research, 103(D15):19015-19033.

Nunes, A. B. (2008). Crescimento da camada limite convectiva: estudo analítico e numérico. Tese de Doutorado, INPE.

Oberkampf, W. L. e Truncano, T. G. (2002). Verification and validation in computacional fluid dinamics. Progress in Aerospace Sciences, 38:209-272.

Oliveira, A. P. (2003). Investigação da camada limite planetária na região de iperó. Tese de Livre docência - IAG-USP.

Oliveira, A. P., Bornstein, R., e Soares, J. (2003). Annual and diurnal wind patterns in the city of São Paulo. Water, Air and Soil Pollution - FOCUS, 3:3-15.

Oliveira, A. P., Escobedo, J. F., Machado, A. J., e Soares, J. (2002). Diurnal evolution of solar radiation at the surface in the city of São Paulo: seasonal variation and modeling. Theoretical and Applied Climatology, 71(3-4):231-249.

Oliveira, A. P., Escobedo, J. F., Plana-Fattori, A., Soares, J., e Santos, P. M. (1996). Measures of solar radiation in the city of São Paulo: Pyranometers calibration and meteorological applications. Brazilian Journal of Geophysics, 14(2):203-216.

Oliveira, A. P. e Fitzjarrald, D. (1994). The Amazon river breeze and local boundary layer: Ii. linear analysis and modelling. Boundary-Layer Meteorology, 67:75-96. 
Oliveira, A. P., Soares, J., Tirabassi, T., e Rizza, U. (1998). A surface energy-budget model coupled with a skewed puff model for investigating the dispersion of radionuclides in a sub-tropical area of Brazil. Il nuovo Cimento, $21 \mathrm{C}(6)$.

Orellano, A. e Wengle, H. (2000). Numerical simulation (DNS and LES) of manipulated turbulent boundary layer flow over a surface-mounted fence. Eur. J. Mech. B - Fluids, 19:765-788.

Oyama, B. (2010). Identificação de fontes de partículas finas na atmosfera urbana de São Paulo. Dissertação de Mestrado, IAG-USP.

Pacheco, P. S. (1997). Parallel Programming with MPI. Morgan Kaufmann.

Patton, E., Sullivan, P., e Moeng, C.-H. (2005). The influence of idealized heterogeneity on wet and dry planetary boundary layers coupled to the land surface. Journal of Applied Meteorology, 62:2078-2097.

Pichugina, Y. L. e Banta, R. M. (2010). Stable boundary layer depth from high-resolution measurements of the mean wind profile. Journal of Applied Meteorology and Climatology, 49:20-35.

Piomelli, U., Scotti, A., e Balaras, E. (2001). Large-eddy simulations of turbulent flows, from desktop to supercomputer. In VECPAR '00: Selected Papers and Invited Talks from the 4th International Conference on Vector and Parallel Processing, pages 551-578. Springer-Verlag.

Poulos, G. S., Blumen, W., Fritts, D. C., Lundquist, J. K., Sun, J., Burns, S. P., Nappo, C., Banta, R., Newsom, R., Cuxart, J., Terradellas, E., Balsley, B., e Jensen, M. (2002). CASES-99: A comprehensive investigation of the stable nocturnal boundary layer. Bulletin of American Meteorological Society, pages 555-581.

Puhales, F. (2008). Estudo do ciclo diário da camada limite planetária através da simulação dos grandes turbilhões. Dissertação de Mestrado, UFSM.

Raga, G. B., Baumgardner, D., Kok, G., e Rosas, I. (1999). Some aspects of boundary layer evolution in Mexico City. Atmospheric Environment, 33:5013-5021.

Raub, J. (1999). Carbon Monoxide. World Healt Organization. 
Rizza, U., Mangia, C. Miglietta, M., Moscatello, A., Carvalho, J., Degrazia, G., Puhales, F., e Marques-Filho, E. (2007). LES modeling of a diurnal cycle. In Proceedings of $V$ Workshop Brasileiro de Micrometeorologia, pages 337-340.

Saiki, E. M., Moeng, C.-H., e Sullivan, P. P. (2000). Large-eddy simulation of the stably stratified planetary boundary layer. Boundary-Layer Meteorology, 95:1-30.

Sanchez Ccoyllo, O. R. (1998). Interação entre os poluentes atmosféricos e a circulação local na cidade de São Paulo. Dissertação de Mestrado, IAG-USP.

Sanchez Ccoyllo, O. R. (2002). Identificação da Contribuição das fontes locais e remotas de poluentes na Região Metropolitana de São Paulo. Tese de Doutorado, IAG-USP.

Sanchez-Ccoyllo, O. R., Dias, P. L. S., Andrade, M. F., e Freitas, S. (2006). Determination of $o_{3}$, co and $p m_{10}$ transport in the metropolitan area of São Paulo, Brazil through synoptic-scale analysis of back trajectories. Meteorology and Atmospheric Physics, 92:83-93.

Schmidt, H. e Schumann, U. (1989). Coherent structure of the convective boundary layer derived from large-eddy simulations. Journal of Fluid Mechanics, 200:511-562.

Schumman, U. e Moeng, C.-H. (1991). Plume fluxes in clear and cloudy convective boundary layers. Journal of the Atmospheric Sciences, 48:1746-1757.

Silva Junior, R. S. (2009). Sensibilidade na estimativa da concentração de poluentes fotoquímicos com a aplicação de diferentes parametrizações da Camada limite planetária utilizando o modelo qualidade do ar WRF/CHEM. Tese de Doutorado, IAG-USP.

Smagorinsky, J. (1963). General circulation experiments with the primitive equations. I. The Basic Experiment, Monthly, 91:99-164.

Sánchez-Ccoyllo, O. R., Ynoue, R. Y., Martins, L. D., Astolfo, R., Miranda, R. M., Freitas, E. D., Borges, A. S., Fornaro, A., Freitas, H., Moreira, A., e Andrade, M. F. (2009). Vehicular particulate matter emissions in road tunnels in São Paulo, Brazil. Environmental Monitoring and Assessment, 149:241-249.

So, E. S. P., Chan, A. T. Y., e Won, A. Y. T. (2005). Large-eddy simulations of wind flow and pollutant dispersion in a street canyon. Atmospheric Environment, 39:3573-3582. 
Song, J., Liao, K., Coulter, R., e Lesht, B. (2005). Climatology of the low-level jet at the southern great plains atmospheric boundary layer experiments site. Journal of Applied Meteorology, 44:1593-1606.

Sorbjan, Z. (2004). The Large-Eddy Simulations of the Atmospheric Boundary Layer Chapter 5B - Theories, Methodologies, Computational Techniques and Available Databases and Software. The EnviroComp Institute and the Air and Waste Management Association.

Sorbjan, Z. (2005). Statistics of scalar fields in the atmospheric boundary layer based on large-eddy simulations. part i: Free convection. Boundary-Layer Meteorology, 116(3):467-486.

Sorbjan, Z. e Uliasz, M. (1999). Large-eddy simulation of air pollution dispersion in the nocturnal cloud-topped atmospheric boundary layer. Boundary-Layer Meteorology, 91:145-157.

Sørensen, N., Bechmann, A., Johansen, J., Myllerup, L., Botha, P., Vinther, S., e Nielsen, B. S. (2007). Identification of severe wind conditions using a Reynolds Averaged NavierStokes solver. Journal of Physics: Conference Series, 75:1-13.

Steeneveld, G. J., van de Wiel, B. J. H., e Holtslag, A. A. M. (2007). Diagnostic equations for the stable boundary layer height: Evaluation and dimensional analysis. Journal of Applied Meteorology and Climatology, 46:221-225.

Stull, R. B. (1988). An introduction to boundary layer meteorology, volume 79. Springer Press.

Su, H., Shaw, R. H., Paw, U. K. T., Moeng, C. H., e Sullivan, P. P. (1998). Turbulent statistics of neutrally stratified flow within and above a sparse forest from large-eddy simulation and field observations. Boundary-Layer Meteorology, 88:363-397.

Sullivan, P., McWilliams, J. C., e Moeng, C.-H. (1994). A subgrid-scale model for large-eddy simulation of planetary boundary-layer flows. Boundary-Layer Meteorology, $71: 247-276$. 
Sykes, R. I., Parker, S., Henn, D. S., e Lewellen, W. S. (1994). Turbulent mixing with chemical reaction in the planetary boundary layer. Journal of Applied Meteorology, $33: 825-834$.

Ulke, A. G. e Andrade, M. F. (2001). Modeling urban air pollution in São Paulo, Bazil: sensitivity of model predicted concentrations to diferent turbulence parameterizations. Atmospheric Environmental, 35:1747-1763.

van Dop, H. e Axelsen, S. (2007). LES of the stable boundary layer: A retrospect to Nieuwstadt early work. Flow Turbulence Combustion, 79:235-249.

van Haren, L. e Nieuwstadt, F. (1989). The behavior of passive and buoyant plumes in a convective boundary layer, as simulated with a large-eddy model. Journal of Applied Meteorology, 28:818-832.

Vickers, D. e Mahrt, L. (2004). Evaluating formulations of stable boundary layer height. Journal of Applied Meteorology, 43:1736-1749.

Vilà-Guerau de Arellano, J., Kim, S.-W., Barth, M., e Patton, E. (2005). Transport and chemical transformations influenced by shallow cumulus over land. Atmospheric Chemistry and Physics, 5:3219-3231.

Wang, L. e Pitsch, H. (2007). Large-eddy simulation of an industrial furnace with a cross-flow-jet combustion system. Annual Research Briefs, 1:231-240.

Wyngaard, J. e Peltier, L. (1996). Experimental micrometeorology in an era of turbulence simulations. Boundary-Layer Meteorology, 78:71-86.

Yamada, T. (1979). Prediction of the nocturnal surface inversion height. Journal of Applied Meteorology, 18:526-531.

Zilitinkevich, S. e Baklanov, A. (2002). Calculation of the height of the stable boundary layer in practical applications. Boundary-Layer Meteorology, 105:389-409. 